\title{
PANOPLIAS PINTADAS: ESTUDIO ANTICUARIO DE LAS ARMAS PINTADAS EN UNA TUMBA DE PAESTUM RECUPERADA EN 1854
}

\author{
PAINTED PANOPLIES: ANTIQUARIAN STUDY OF THE WEAPONS PAINTED IN A TOMB IN PAESTUM, \\ FOUND IN 1854
}

RAIMON GRAELLS I FABREGAT

Römisch-Germanisches-Zentralmuseum, Mainz

\section{INTRODUCCIÓN}

En junio de 1856 G. Minervini publicaba las pinturas de una espectacular tumba recuperada en la necrópolis Spinazzo, en el área conocida como Fondo Fusillo ${ }^{1}$, de Paestum (Minervini, 1856, 177-181, Tav. IV-VII). La tumba había sido sumariamente descrita dos años antes por G. Forchhammer, que comentaba que había sido excavada durante los últimos días de marzo de 1854 (Forchhammer, 1854, 63).

Fue dibujada primero por Braun para el trabajo de Forchhammer (1854) que publicó sólo el tímpano
(Fig. 1). Posteriormente Minervini (1856) publicó integralmente los dibujos realizados por G. Abbate (Figs. 2, 3, 4, 5 y 6). La tumba destacó rápidamente entre la comunidad científica, a causa de su importante decoración con escenas de guerreros armados con panoplias metálicas y por un tímpano representando una comitiva que resultó sugerente para interpretarla como la llegada de los lucanos a Poseidonia.

Esas primeras interpretaciones evidenciaban la excepcionalidad de la tumba, capaz de transmitir a través de su iconografía unos contactos complejos en

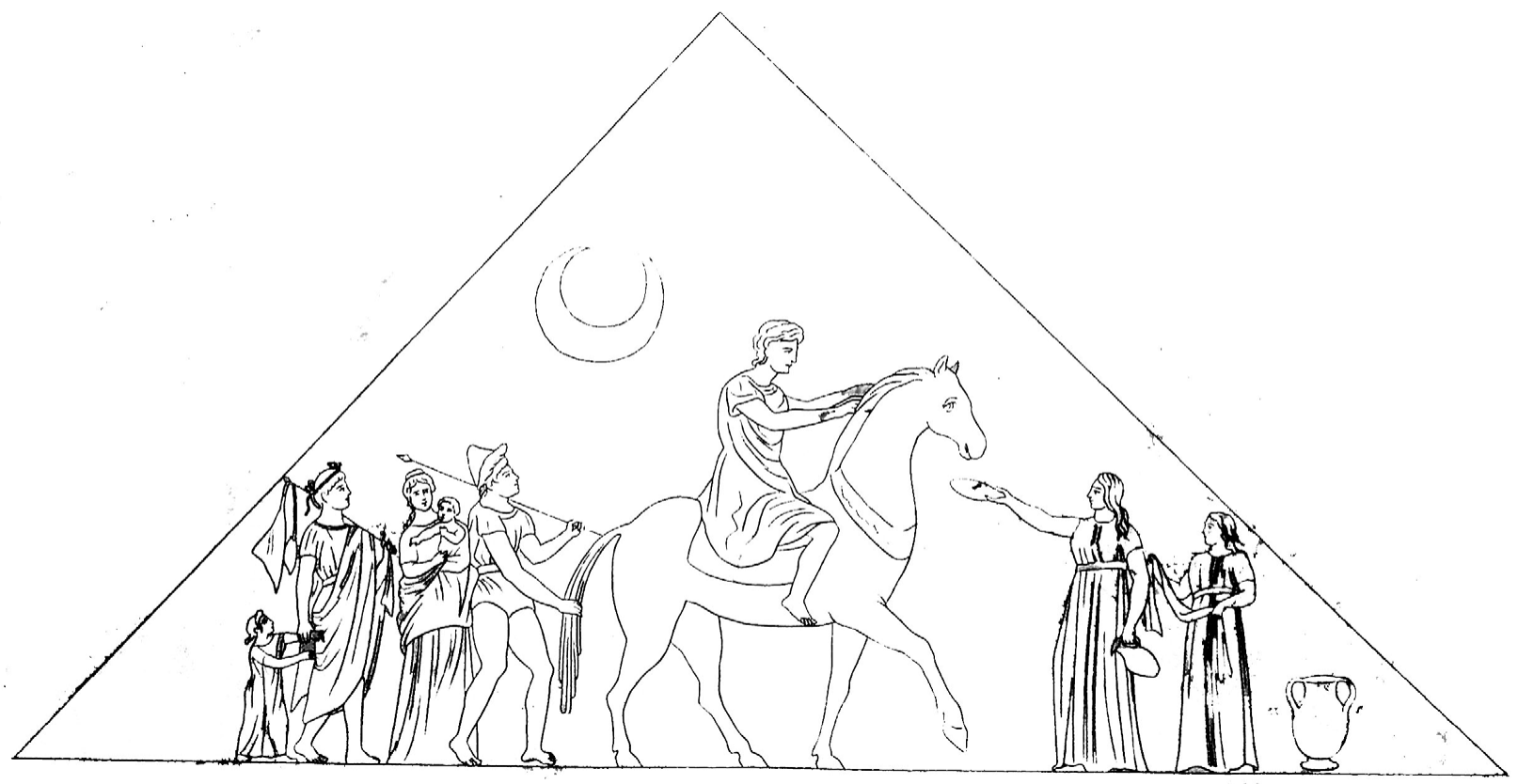

Figura 1: Dibujo del frontón publicado por Braun que a su vez era la primera representación gráfica de una parte de la tumba. A partir de Braun, 1854.

1. Este Fondo fue objeto de otras intervenciones durante la década de 1950, llamándolo Fuscillo. 


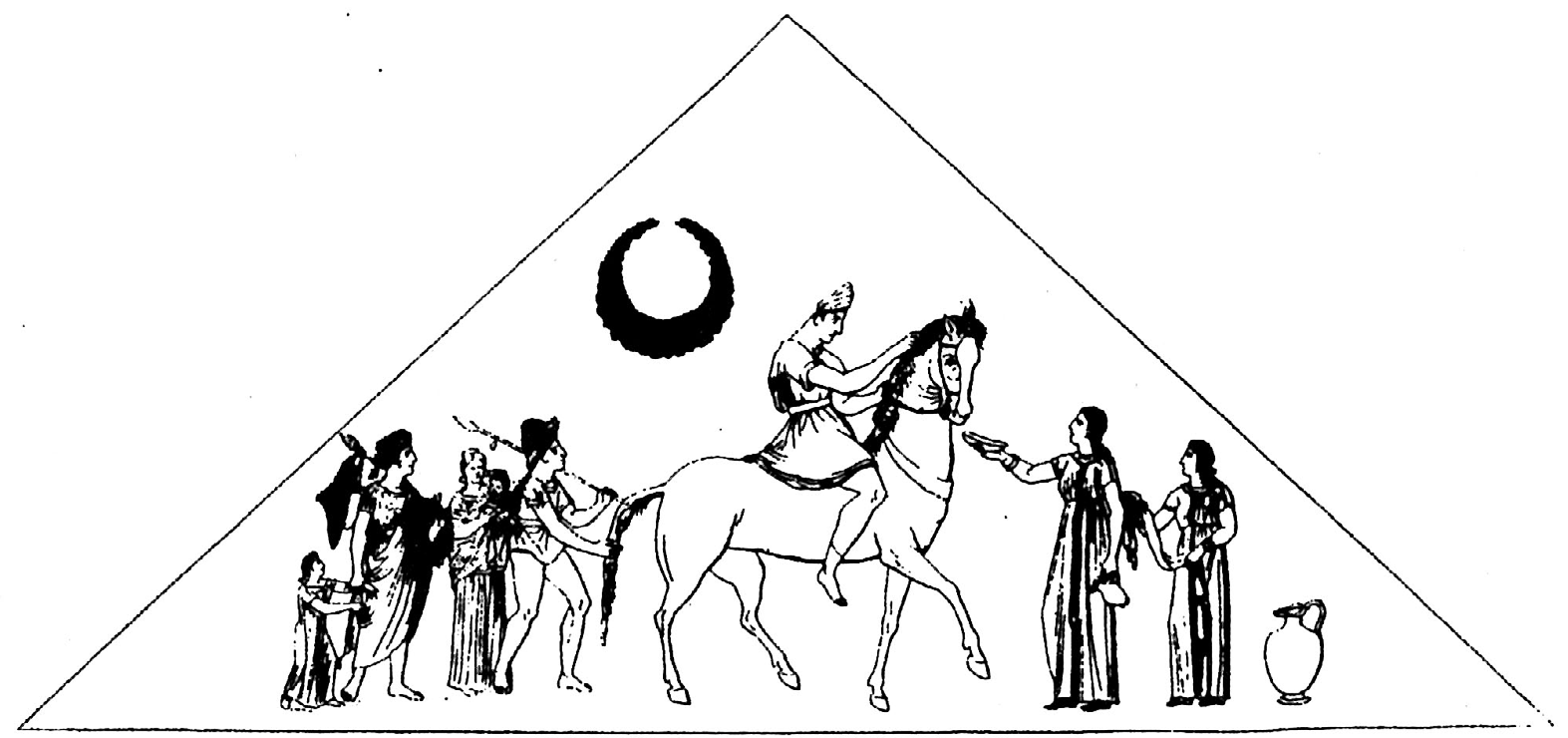

Figura 2: Dibujo del frontón publicado por Minervini. A partir de Minervini, 1856, Tav. VII.

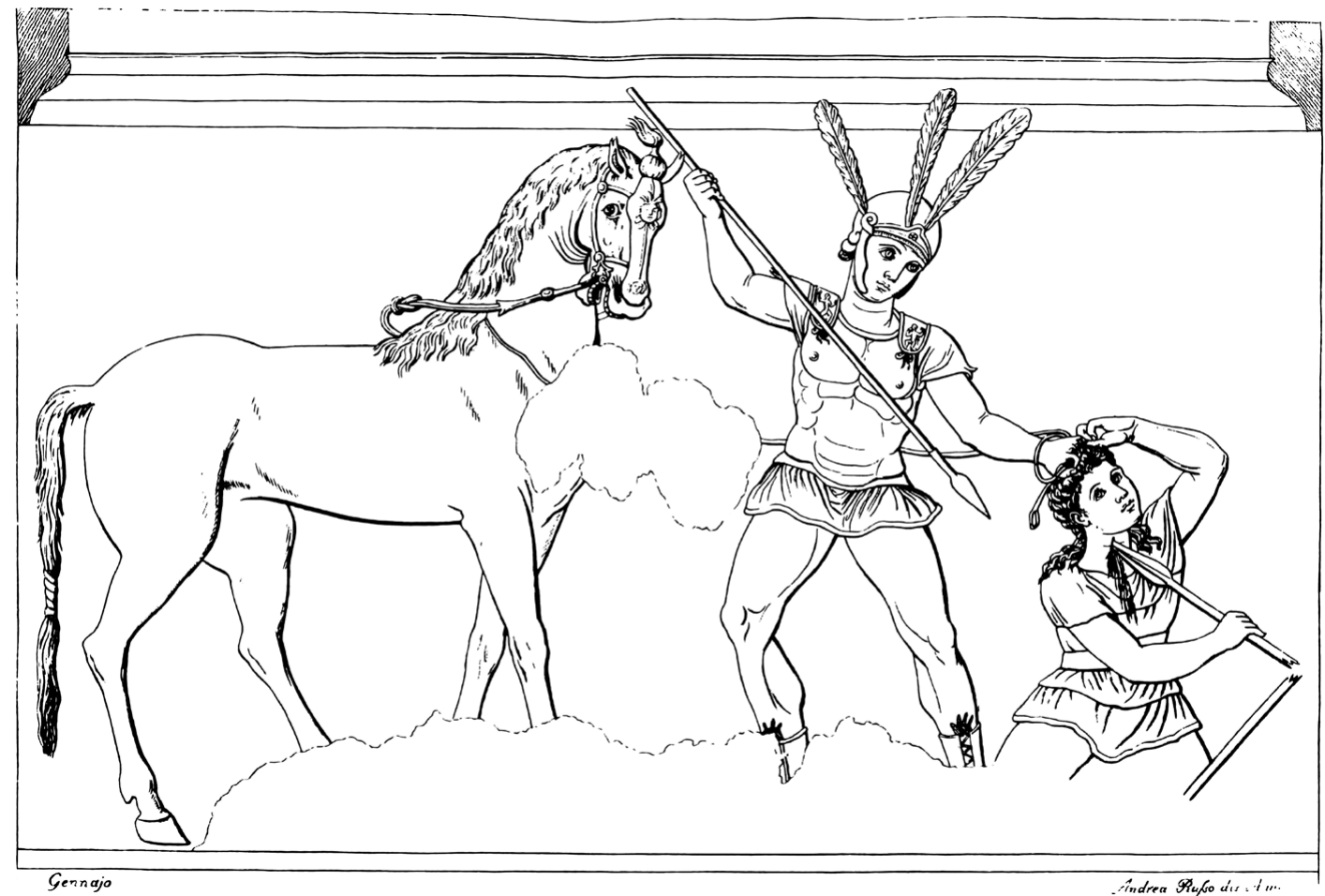

Figura 3: Lastra izquierda. A partir de Minervini, 1856, Tav. VI.

el sur de Italia que se acentuaron, más si cabe, cuando tanto E. Braun como, especialmente, G. Minervini vieron en las pinturas de esta tumba una mano lucano-pestana influenciada por una ascendencia griega (Pontrandolfo y Rouveret, 1992, 14). Esto evidenciaba la interacción en área pestana sin renunciar a la originalidad pestano-lucana de su estilo y de algunos detalles. Pese a esta singularidad, la tumba quedó a la intemperie, abandonada, y se perdió para la investigación y para el gran público, primero olvidada en el campo y luego olvidada en las publicaciones que únicamente $\mathrm{A}$. Rouveret ha recuperado para analizar, con gran detalle, las escenas de combate (Rouveret, 1997).

Ahora, a más de 150 años de su descubrimiento, es interesante (re-)estudiar este monumento de enorme valor para el arte y la historia de la Italia meridional del cambio entre el s. IV y III a.C. pues la descripción de la tumba permite el análisis de sus características estructurales e iconográficas y aporta datos acerca 


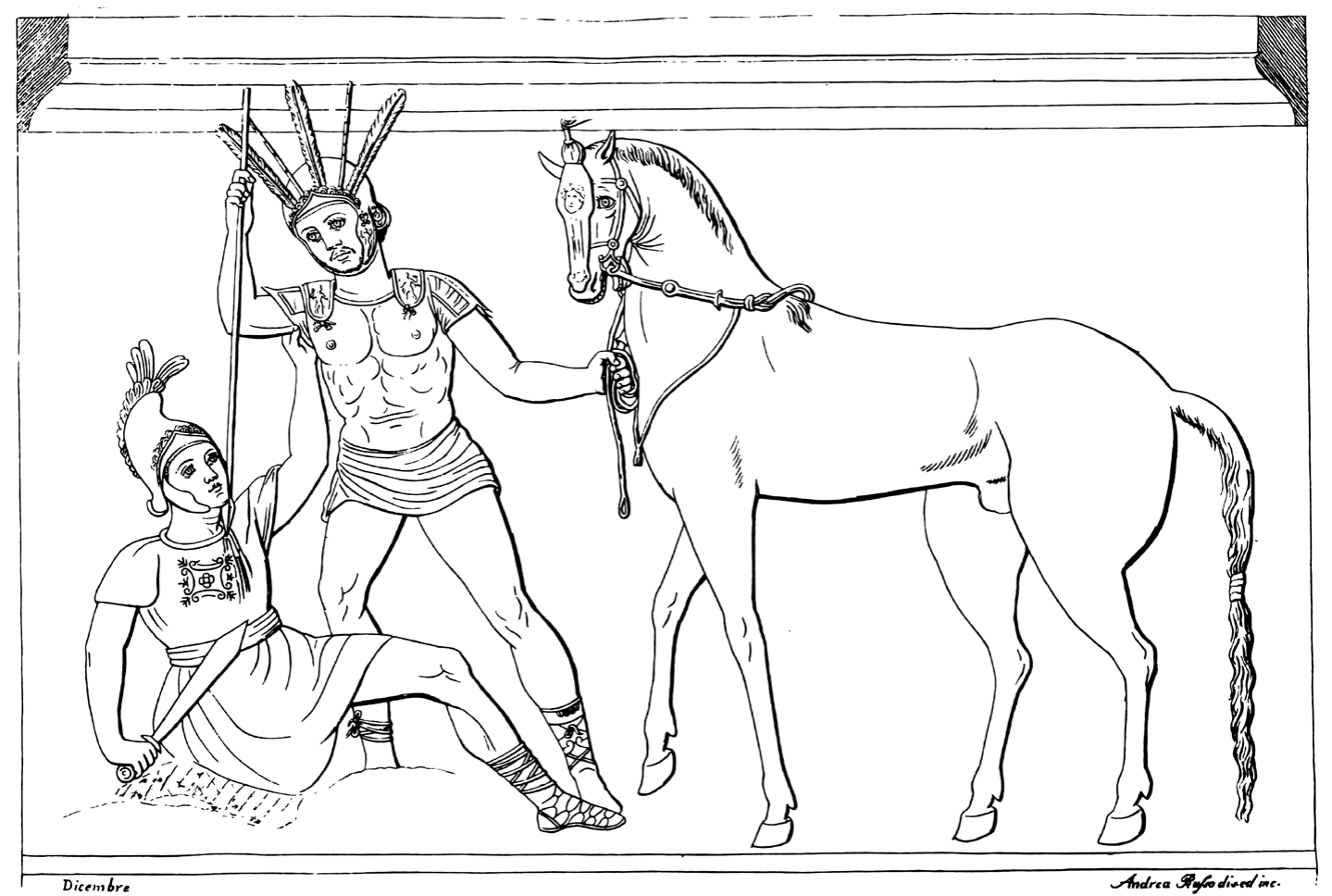

Figura 4: Lastra derecha. A partir de Minervini, 1856, Tav. V.

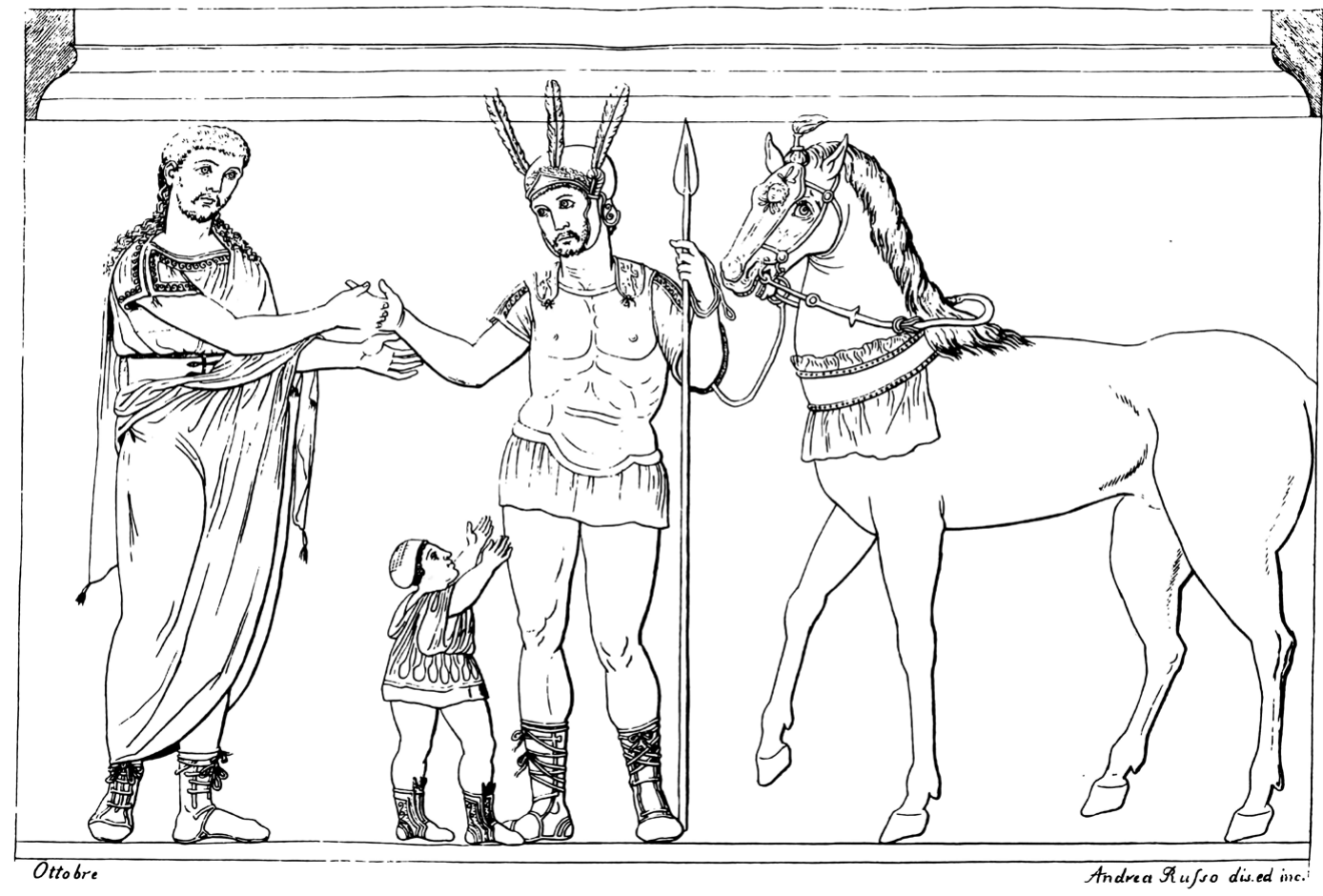

Figura 5: Lastra de fondo. A partir de Minervini 1856, Tav. IV.

de su cronología y filiación. El trabajo que presento se articula en base a la única documentación que ha perdurado de la tumba: los dibujos y las descripciones. Pero sobre estas fuentes debe hacerse una precisión, puesto que trabajar con dibujos y descripciones decimonónicas y no a partir de una documentación arqueológica moderna o fotográfica, si bien distinto, no debe crear escepticismo. La fiabilidad de estos documentos queda fuera de discusión con el análisis anticuario de los detalles que presentaré, lo que induce a no dudar sobre la validez de la documentación del descubrimiento. De este modo, partiendo de las 


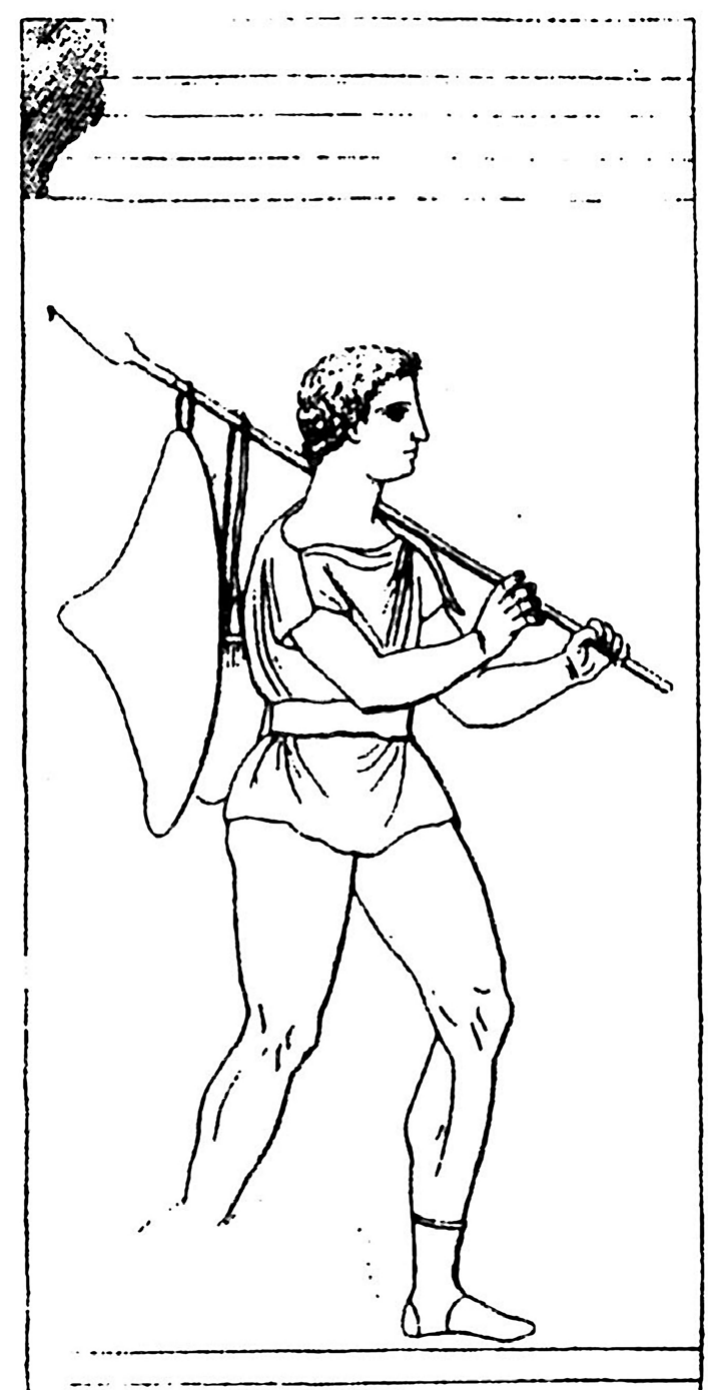

Figura 6: Lastra lateral del vano de la puerta, lado izquierdo. A partir de Minervini, 1856, Tav VIIa.

descripciones de Forchhammer, Braun y Minervini y de la reproducción de las pinturas de todas las lastras, surgen varias preguntas fundamentales: primero su localización, segundo su arquitectura anómala, tercero la interpretación de las escenas pintadas y por último el contexto histórico en el que se insertaba este monumento pestano.

La primera pregunta, pese a la importancia de la tumba, su identificación y exacta posición en la topografía pestana no ha podido realizarse. Sobre la segunda, la combinación entre descripciones y dibujos ofrece una propuesta en base a una forma cuadrada. La tercera implica una combinación entre datos anticuarios, realia e iconografía que proponen un discurso relacionado con el contexto histórico en el que se realizó la tumba, de este modo, en las páginas que siguen, se considera el análisis detallado de la arquitectura y de las pinturas a partir del estudio anticuario de los elementos representados que, inevitablemente, condiciona su interpretación histórica.

\section{LOCALIZACIÓN Y DATOS GENERALES}

La tumba se localizó en la propiedad del Principe de Centola, aproximadamente a una milla al sur de la ciudad (Minervini, 1856, 177), en línea recta desde la puerta della Giustizia ${ }^{2}$ hasta cruzar el riachuelo y, una vez cruzado, 100 pasos a la izquierda, en medio del campo (Forchhammer, 1854, 63). Formaría parte de un núcleo con, al menos, otras 5 tumbas de las que no tenemos más información que la cita de la existencia de restos de decoración pintada en su interior (Forchhammer, 1854, 63). Las pinturas de todas las tumbas del grupo quedaron a la intemperie, perdiéndose definitivamente con el paso del tiempo.

El ajuar de la tumba que aquí nos interesa, se conoce únicamente gracias a una descripción (posiblemente incompleta). Esta considera la inhumación de un único esqueleto cubierto por una coraza, acompañado por una lanza ${ }^{3}$. La panoplia es sorprendentemente escasa en comparación al resto de tumbas con coraza documentadas en Paestum, donde recurrentemente se asocian al casco o a las cnémides ${ }^{4}$.

Pese a estas indicaciones hoy sabemos que la tumba no pertenecía a un núcleo aislado sino que formaba parte de la necrópolis Spinazzo, de la que entonces se conocían núcleos inconexos resultantes de los distintos saqueos. Las investigaciones sobre la necrópolis Spinazzo (realizadas principalmente a partir de las excavaciones realizadas entre 1972 y 1973) han demostrado que empieza a utilizarse a partir del último cuarto del s. IV a.C. (Pontrandolfo, 1996a, 289), momento históricamente identificable con la instalación lucana en la ciudad (Pontrandolfo, 1996a, 291), aumentando su importancia a inicios del s. III a.C. (Rouveret, 1997, 134). Es especialmente significativa en esta necrópolis la relación y correspondencia entre organización social, urbanística y las representaciones pintadas, tal y como evidencia la acumulación de tumbas alrededor

2. A lo largo del trabajo se utilizan una serie de términos italianos, franceses, griegos o latinos para referirnos a distintos objetos, topónimos o conceptos que una traducción al castellano complicaría al perderse precisión en la traducción o precisar una aclaración.

3. Referencias a esta tumba en Greco, 1979, 14; Pontrandolfo, 1996b, 19.

4. Para una panorámica general de las corazas metálicas recuperadas en Poseidonia-Paestum vid. Graells, 2012: PaestumGaudo 2/1957 (con coraza, casco, espada, pareja de grebas y dos lanzas); Paestum-Gaudo 136 (con coraza, cinturón y una lanza); Paestum-Gaudo 164 (con coraza, casco, dos grebas y una lanza); Paestum-Gaudo 174 (con coraza, casco, espada, pareja de grebas y una lanza); Paestum-Gaudo 197 (con coraza, dos cinturones y una lanza); Paestum-Porta Aurea 2 (con coraza y una lanza, pero la panoplia militar estaba acompañada de una fíbula, un strígilis, una moneda, una kylix, un olpe, una crátera, una copa, dos skyphoi y una lekythos); Paestum Santa Venera 110 (con coraza, dos cinturones y una lanza, con dos monedas y una copa); Paestum- Fuscillo 2912-1955 (con casco, dos cinturones, dos grebas y una lanza). 
de tumbas monumentales pintadas. Esta concentración ha sido interpretada bajo una idea de agrupación familiar que encuentra confirmación en las mismas representaciones pintadas, donde la exaltación de la ciudadanía y de la gens son temas frecuentes (normalmente situándose en las paredes de fondo) (Pontrandolfo, 1996a, 289).

En este marco, tanto la decoración como el contenido de la tumba de 1854 exaltan, aparentemente, a una sola persona excepcional aunque, quizás, sea sólo una percepción que debe entenderse como representación de un grupo caracterizado por valores militares. Así, a la presencia de una inhumación individual de guerrero -anómala, especialmente si consideramos el tipo de panoplia, dominada por una coraza ${ }^{5}$ - son datos fundamentales de distinción social en el momento de clausura de tumba que, como veremos, acontece en un momento avanzado del proceso de cambio entre el s. IV y III a.C.

La falta de otros datos sobre el hallazgo, no permite caracterizar el tipo de coraza de la tumba de 1854 que, ante las excepcionales representaciones de guerreros con corazas anatómicas largas pintadas en las paredes de la tumba, obligan a considerar la posibilidad de que se tratase de una coraza anatómica, corta o larga, pues ambos tipos han sido documentados en Paestum ${ }^{6}$ pese a ser especialmente infrecuentes en esta área ${ }^{7}$.

\section{ARQUITECTURA DE LA TUMBA}

La excepcionalidad del ajuar se acentúa gracias a la elección de una arquitectura anómala respecto a la mayoría de tumbas de las necrópolis pestanas. Ésta corresponde a una tumba de cámara cuadrada con apertura en puerta flanqueada por dos lastras. A pesar de no estar descrito, no extrañaría si la tumba estuviera precedida por un dromos de acceso, previsiblemente escalonado, seguramente no excavado en 1854 . Recordemos que la presencia de dromoi escalonados en muchas de las tumbas de cámara pestanas está bien documentado y puede suponerse un desinterés hacia este aspecto en el momento del saqueo de la tumba, pues en el acceso a la tumba no se recuperarían materiales arqueológicos.

\footnotetext{
5. En esta necrópolis, la presencia de corazas no es extraña durante el s. IV a.C. si se considera que en la misma necrópolis se recuperó otra (trilobulada) en una tumba de guerrero excavada en 1955 (Sestieri, 1957).

6. Tumba de Paestum-Porta Aurea 1805 para una coraza anatómica larga; Paestum-Porta Aurea 1805 (2 ejemplares) y Paestum-Gaudo 1957, para las corazas anatómicas cortas.

7. Recordemos que las corazas anatómicas se presentarían aquí, como excepciones en los mapas de distribución de las corazas anatómicas, normalmente concentradas en áreas interiores, principalmente entre la Apulia, la Basilicata, el área bretia y el retro-tierra lucano y campano (Vid. infra).
}

Para conocer mejor los detalles arquitectónicos debemos considerar las descripciones. Así, según Forchhammer $(1954,63)$ : [los sepulcros] tutti posti nella direzione da levante a ponente, mentre avevano le porte dal lato occidentale. Consistevano tutti di una camera sola senza nicchie nè banchi, il cui soffitto era formato di varie lastre grandi di pietra, in guisa che il comignolo stava poco aldisotto della superficie del terreno...Il quinto sepolcro si distingue molto dagli altri. La cella sepolcrale forma un quadrato di m. 2,67, ed ha anch'essa nella parete occidentale la porta, chiusa al di fuori per mezzo di due sassi grandi, cosicché ora s'entra nella tomba per un'apertura nel frontone occidentale, le cui pietre son state levate [...] (Fig. 7).

Mientras que según G. Minervini (1856, 177): Il sepolcro è formato di Grossi pezzi di travertino proprii del luogo, ed ha le interne pareti rivestite di sottilissimo stucco, sul quale sono i pregevoli dipinti, [...] La covertura è una specie di tetto pectinatum: nella imposta all'interno è una cornice con gola rovescia, che ricorre ne'quatro lati. La porta d'ingresso è arcuata, e volta ad occidente: trovandosi richiusa da un masso rettangolare della medesima pietra, di che è formato l'intero sepolcro. La base della tomba è palmi 10,15 per 10,10: l'altezza è pal. 7,50 fino all'imposta della cobertura (Fig. 8).

El análisis arquitectónico está limitado por el uso de las informaciones de mediados del s. XIX, siendo pocos los datos acerca del material empleado, únicamente descrito en Minervini, según el que se habría utilizado el travertino local, material frecuente en Paestum (Pontrandolfo y Rouveret, 1992, 18-19; De'Spagnolis, 2005, 140) ${ }^{8}$. En cambio, la planta cuadrada resulta un problema en el contexto pestano (que G. Forchhammer ya advirtió) (Forchhammer, 1854, 63). Distinguiéndose del resto de tumbas de cámara con las que formaba ese, entonces, pequeño núcleo de tumbas (Fig. 9).

A nivel arquitectónico, pues, la tumba representa una anomalía respecto a las tumbas de las necrópolis pestanas, de la Campania y el Sannio, que presentan una estructura casi constante en forma de caja o cámara $^{9}$ de forma rectangular (Benassai, 2001, 127). La planta cuadrada es extraña en las necrópolis de Paestum (Fig. 7) donde mayoritariamente, se documentan tumbas de forma rectangular o cámaras pseudo-cuadradas con dromos $^{10}$. Únicamente las tumbas de la necrópolis Spinazzo conocidas como Tomba del Magistrato y la tumba recuperada por la Guardia di Finanza

8. En la Campania y en Pontacagnano el material habitual es el tufo (Benassai, 2001, 128).

9. En Paestum se han identificado 14 tumbas de tipo cámara pintadas, de las que 7 han sido identificadas en la necrópolis Spinazzo (cinco más sin pintura), 3 en Andriuolo, 3 en Gaudo y una en Contrada Vecchia di Agropoli (Pontrandolfo y Rouveret, 1992, 19).

10. Andriuolo 20, 80 y 81, Spinazzo 2/1955. 

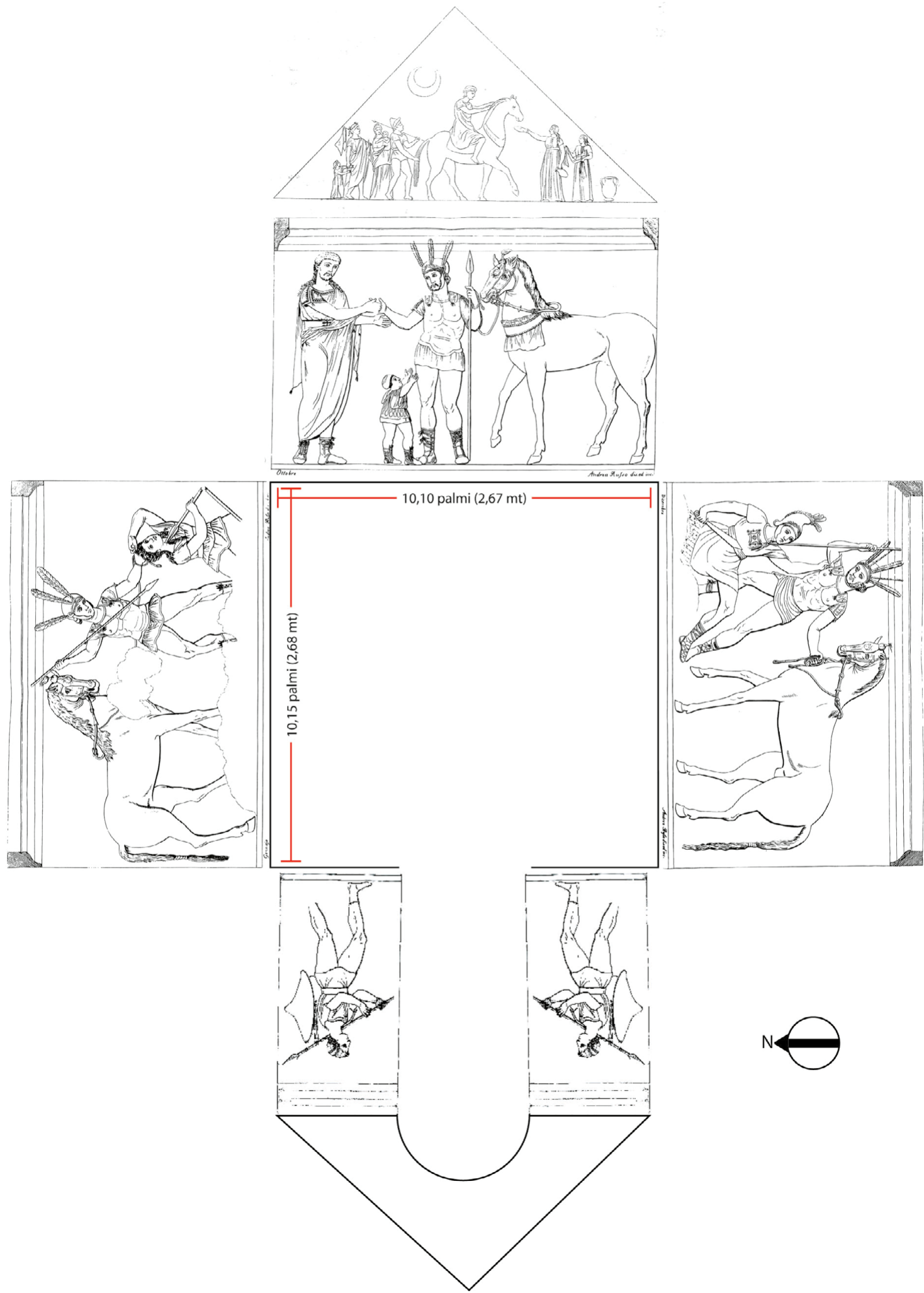

Figura 7: Reconstrucción ideal de la tumba combinando los dibujos, las medidas y demás datos de las descripciones. A partir de la combinación de los dibujos de: Braun, 1854 y Minervini, 1856.

(Pontrandolfo, 1996a) parecen ser de planta cuadrada y dimensiones similares a la que aquí se estudia.

Para el presente análisis resulta particularmente importante la forma de estas cajas, construidas con cinco lastras de base, que en ocasiones presentan una cobertura a doble caída, también realizada con lastras. Esta cobertura se consigue utilizando en la estructura inferior de la caja lastras cortas que tengan una forma pentagonal, divididas en dos partes: una parte rectangular (inferior), que formaría parte de una caja 


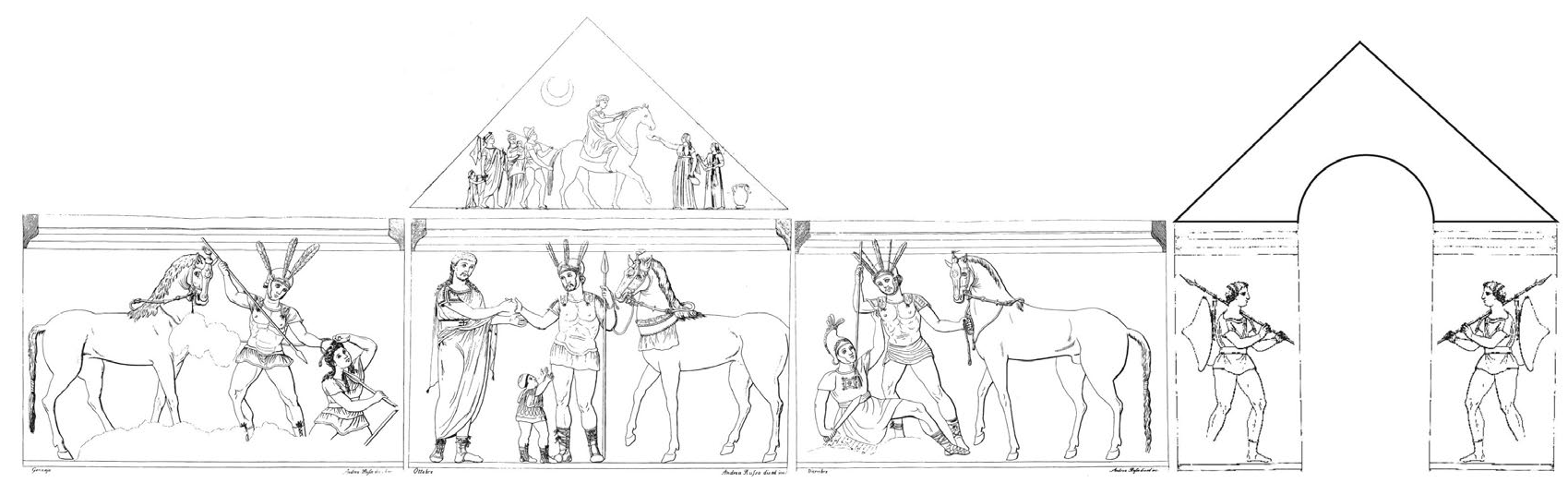

Figura 8: Desarrollo de la tumba con indicación de la cobertura encima de la puerta, siguiendo a Minervini. A partir de la combinación de los dibujos de Braun, 1854 y Minervini, 1856.

rectangular cúbica; y una parte triangular (superior). Estos dos registros, cuando están decorados pueden presentar temas distintos o complementarios, en función del motivo pintado en la tumba. Pero en la tumba que nos ocupa, los laterales de la entrada y el fondo están compuestos de manera diferente, condicionados por la superposición de una lastra triangular sobre otra de rectangular en el lado este (fondo) y de dos lastras rectangulares, sobrepuestas por una pared construida por diversas piedras (sustraídas durante el saqueo para poder acceder a su interior) en lado oeste (entrada). Este detalle implica que la tumba estaba aún cubierta cuando la visitaron tanto Forchhammer como, posteriormente, Minervini y Abbate.

En cualquier caso, el estado de conservación de la tumba evidencia una cobertura previsiblemente sólida, que no aparece reflejada en ninguna de las descripciones. Ello lleva a preguntarnos si correspondería a un techo a doble caída o a una cobertura de vuelta $a$ botte campane, ambas con la posibilidad de estar decoradas exteriormente por un motivo de pectinatum o rayado. El primer tipo, la doble caída, encuentra abundantes ejemplos en el área campana y en Paestum. En cambio, el tipo a vuelta, de ascendencia macedonia y con una cronología posterior al 330 a.C. (Benassai, 2001, 128), parece más adecuada a las necesidades de un techo para una gran cámara cuadrada, al no necesitar elementos de soporte centrales, de los que tampoco en ningún momento se hace mención.

A todo lo visto se suma que el acabado interno de la tumba de 1854 destaca por la ausencia de elementos estructurales internos (banqueta u otros), frecuente en Campania y documentado en otras tumbas pestanas, incluso de la misma necrópolis Spinazzo ${ }^{11}$. Únicamente la presencia en la parte superior de las lastras de un elemento esculpido a modo de moldura resulta significativo al no encontrar más paralelos en área campana, samnita o pestana que la tumba recuperada por

11. Tumba 2/1955 (Sestieri, 1957) o tumba del Magistrato (Pontrandolfo, 1996a). la Guardia di Finanza en Tarento (procedente de la misma necrópolis Spinazzo) y la tumba del Magistrato. En el resto de tumbas, la moldura viene sustituida por una decoración pintada. De esta manera, podemos ver en este elemento unas implicaciones arquitectónicas complejas y explícitas. Particularmente claro en la pared occidental (puerta), donde no actúa como dintel del muro de cobertura del frontón superior si no que deja la puerta acabada según uno de los tipos habituales en Paestum, pues el término usado en la descripción - arcuata - y el dibujo, no permiten una distinción entre las dos variantes y sólo asegura que no se trataba de una puerta rectangular.

Si bien las descripciones y detalles de la pared en la que se ubicaba la puerta son insuficientes para asegurar la luz de su puerta y por lo tanto impiden su reconstrucción precisa $^{12}$, las dimensiones del lado del cuadrado de la planta de la tumba y los paralelos de otras tumbas de cámara con puerta permiten algunas observaciones. El lado del cuadrado varía entre 2,67 y 2,68 mts en función de la fuente. Esto permite aproximarnos a la luz de la puerta y a las dimensiones de las lastras laterales. Las dimensiones de las 3 únicas puertas de tumbas pestanas que describen A. Pontrandolfo y A. Rouveret ${ }^{13}$ (coincidentes entre sí) permiten proponer que también en la tumba en estudio nos encontremos ante una puerta similar, con $126 \mathrm{~cm}$ de obertura. Si bien esta identificación con los paralelos de la misma necrópolis podrían suponer algunas reticencias en cuanto a que correspondan a cámaras de planta rectangular, la coincidencia de la altura de las lastras en los cuatro casos (191 cm para los paralelos y 198 en la tumba en estudio) admite esta asimilación.

12. Además de ligeramente discordantes si atendemos a las descripciones del tipo de cierre de la puerta: con una o dos lastras, según Minervini y Forchhammer (respectivamente). 13. Paestum Andriuolo 20, Contrada Vecchia di Agropoli 11/1967 y Paestum Gaudo 2/1957. 


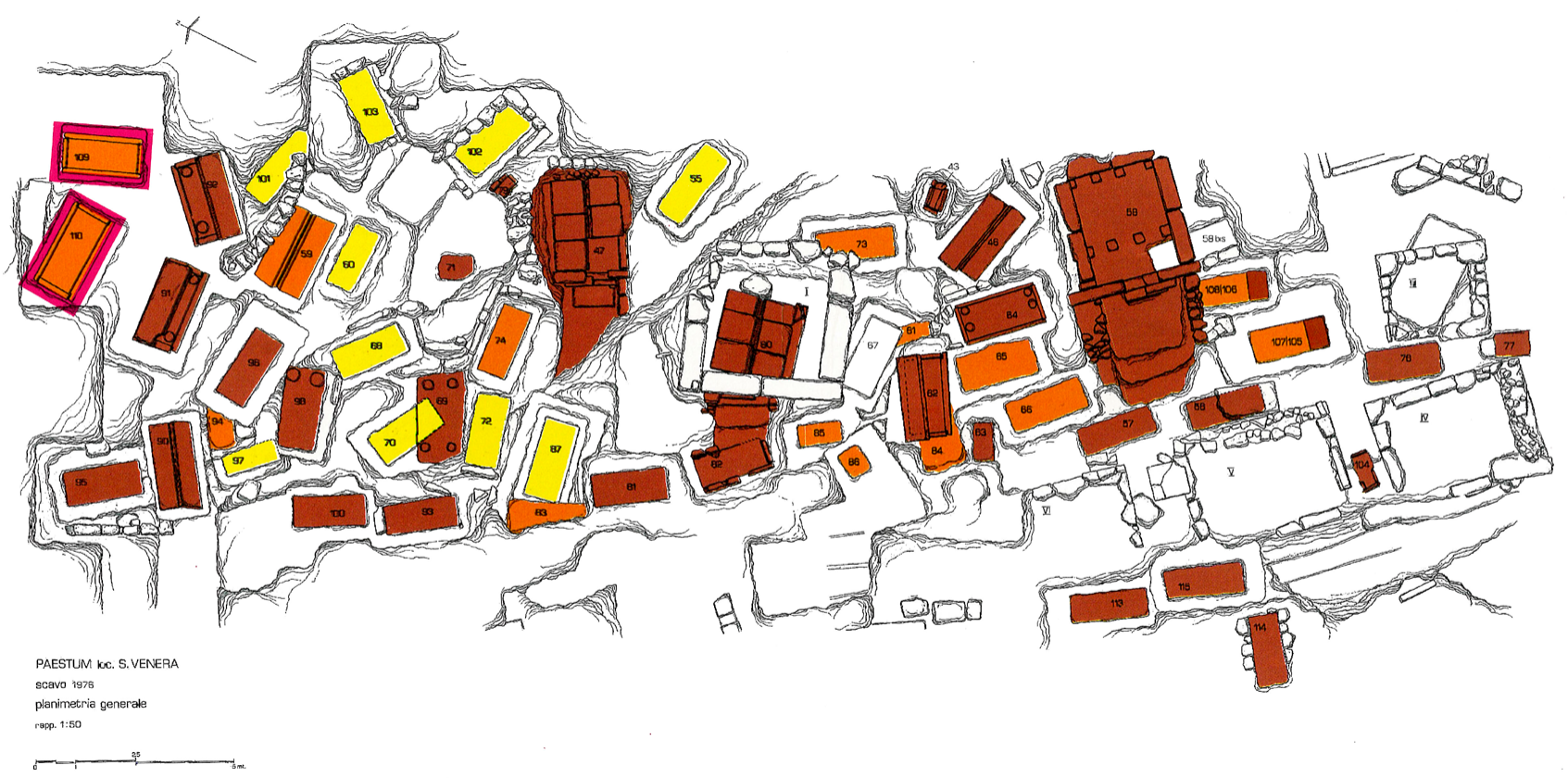

Figura 9: Planta de la necrópolis de Santa Venera. A partir de Pontrandolfo y Rouveret, 1992, 236.

\section{DESCRIPCIÓN DE LAS PINTURAS}

La descripción de las pinturas, sobre fondo blanco [...] che ne decorano le quattro pareti del suolo fino alla cornice, nonché il frontone orientale dirimpetto all'entrata [...] (Forchhammer, 1854, 63), fue realizada con extremo detalle por parte de Forchhammer y Minervini. A pesar de ello, ambas descripciones son demasiado interpretativas y confunden u obvian detalles en pro de una narración que justifique la lectura y el discurso previsto en cada trabajo. Aquí se describen de nuevo los dibujos y únicamente se incorporan los detalles de color indicados en las descripciones citadas. Se deja así para el apartado siguiente el análisis e interpretación de la iconografía.

La pintura encaja en la dinámica observada en las representaciones de finales de s. IV a.C. en la necrópolis de Spinazzo, con personajes pintados a tamaño casi natural utilizando una iconografía mixta que combina los motivos locales para la representación de la celebración del paso al más allá junto a otros detalles de clara influencia helénica. Pero no es sólo esta combinación el argumento por el que esta tumba destaca, si no por la compleja composición, el cuidado detalle de los elementos representados y la planificación de la composición especular de las paredes laterales, con motivos mitológicos, que dejan la pared del fondo para una representación de acogida y confieren a la tumba una personalidad única en el imaginario y catálogo pestano.

De todos modos, la técnica seguida, deducida a partir de las descripciones, coincide con lo documentado arqueológicamente en otras tumbas pestanas, es decir: una preparación o ductus sobre el que se pinta un fondo blanco y encima de este se superponen las figuras. En este caso, destaca la reutilización de cartones dentro de la misma composición que para algunos personajes permiten, incluso, sugerir se tratase de elementos parciales, independientes e intercambiables. Quizás un complicado catálogo de cartones de partes de la figura, para articular las representaciones de guerreros, y otros claramente correspondientes a figuras completas a los que se sumaron los de los caballos y los personajes de los vanos de la puerta, que de manera sencilla se consiguieron mediante la inversión de su orientación.

\subsection{LA LASTRA IZQUIERDA}

Corresponde a la lastra reproducida por Minervini en la tav. VI (Fig. 3), que sería la primera de la narración de la composición pintada en la caja de la tumba. La descripción valora los sujetos de manera independiente para, seguidamente, hacer la interpretación conjunta.

\section{Guerrero 1}

Se representa a un guerrero orientado hacia la derecha, en posición ligeramente descentrada hacia ese lado respecto al centro de la lastra. Tiene el brazo derecho levantado hacia atrás, extendido sujetando una lanza ${ }^{14}$ en actitud de atacar a un segundo personaje arrodillado

14. Idéntica posición del brazo, mano, lanza y arranque de la manga debajo de la coraza de tipo a corsetto en la figura del guerrero Griego 5 del sarcófago delle Amazzoni (Bottini y Setari, 2007, fig. 10). 
en el extremo derecho de la lastra, al que tiene sometido agarrándolo por los cabellos con la mano izquierda. La mano izquierda sujeta también, de manera forzada, el extremo de la rienda de un caballo.

El guerrero, que podemos considerar como el protagonista de la lastra, es joven, imberbe y con panoplia escasamente decorada. El casco, pintado en amarillo, corresponde a un tipo ático con frontón terminado en volutas $^{15}$, visto, como el resto de la cabeza, de tres cuartos ${ }^{16}$. Presenta paragnátides lisas y una decoración de tres plumas blancas dispuestas en posición transversal sobre la frente ${ }^{17}$.

La coraza, previsiblemente metálica a partir del color amarillo con el que se pintó, es de tipo anatómico largo, con base compleja (ergonómica) pensada para su uso por parte de un équites, con spallacci (epomides, hombreras) decorados con figuras que pueden proponerse como representaciones de Heracles repujadas sobre el metal, tal como se ha visto en otras pinturas $^{18}$. Debajo de la coraza surge un corto faldellín rojo, con pliegues verticales, y en los brazos se apuntan los arranques de las mangas lisas de una túnica que, ante la falta de detalles sobre su color, debemos entender también de color rojo como el faldellín.

El calzado, perdido en su mayor parte, parece corresponder a unas botas con sistema de sujeción mediante cordones cruzados que fijarían el calzado por su apertura frontal.

\section{Personaje femenino vencido}

El segundo personaje, verosímilmente una amazona, aparece vestida con una túnica corta de color blanco ceñida por un cinturón de lámina metálica, como parece indicar su color amarillo.

Levanta su brazo izquierdo hacia su cabeza, con la intención de liberarse del guerrero. La mano derecha, en cambio, sirve para sujetar una lanza, fracturada como expresión de movimiento y violencia ${ }^{19}$, que se

15. Para el tipo de casco y variantes vid. Dintsis, 1986, 105-133.

16. Esta posición es la habitual para representar los personajes centrales de las tres lastras inferiores de la tumba de $1854 \mathrm{y}$, además, es el estilo utilizado de manera preferente en las representaciones de los guerreros pintados sobre el sarcófago delle Amazzoni o sobre la tumba C.29 de Capua, mientras que en Paestum, resulta una posición poco testimoniada en comparación a las vistas laterales.

17. Sobre este tipo de decoración vid. Graells y Mazzoli, 2013; Castrizio, 2007, 81-108.

18. Puede recordarse el guerrero griego del sarcófago delle Amazzoni de Tarquinia (vid. Infra).

19. Representaciones de lanzas rotas por la mitad son relativamente frecuentes en área pestana, normalmente enmarcadas en representaciones de duelos: Paestum-Andriuolo t. 58, Paestum-Arcioni t. 271/1976, Paestum-Porta Aurea tumba de 1805, Paestum-Gaudo 7/1972, Paestum-Vannullo t. 2. En contextos campanos es menos frecuente, a pesar de documentarse en la tumba C.11 de Capua. clava en el cuello, bien como herida de guerra o como evidencia de suicidio. Golpe fatal en ambos casos, tal y como evidencia la sangre que mana de la herida.

\section{Caballo 1}

El caballo ocupa la mitad izquierda de la lastra. Tiene la cabeza ligeramente recogida y girada hacia el centro de la tumba ${ }^{20}$. Fue pintado en color amarillo intenso con larga crin marrón oscura mientras que la cola está recogida y atada ${ }^{21}$.

$\mathrm{Su}$ equipamiento lo componen riendas articula$\operatorname{das}^{22}$, freno y prometopidion pintado en amarillo que simularía el metal (cobre, bronce o plata dorada) ${ }^{23}$. Este último elemento, aparece decorado con un Gorgoneion en la parte superior y otros elementos que deben entenderse como motivos vegetales realizados en relieve, resultado del repujado del metal. Además, un penacho superior recoge el flequillo de la $\operatorname{crin}^{24}$.

20. Idéntica posición presentan los tres caballos representados en las lastras inferiores de la tumba de 1854. Esta representación reproduce la posición observada en las cabezas de caballo recopiladas por F. Coarelli procedentes de Lanuvio (Coarelli, 1981, fig. 23-24), Tarento (Coarelli, 1981, fig. 32), Melos (Coarelli, 1981, fig. 49), Roma-via Appia (Coarelli, 1981, fig. 53) o de la colección Weiller (Coarelli, 1981, fig. 50).

21. La cola aparece también atada en la lastra derecha de esta misma tumba (Vid. infra), y encuentra paralelos, con ligeras variaciones, en la tumba recuperada por la Guardia di Finanza y la Tomba del Magistrato, ambas, de la necrópolis Paestum-Spinazzo.

22. Riendas articuladas, mediante una inflexión en su desarro1lo, caracterizan los atalajes de los tres caballos representados en las lastras inferiores de la tumba de 1854 y encuentran dos paralelos en la tumba Paestum-Andriuolo 2/1971 y en la tumba recuperada por la Guardia di Finanza de la necrópolis Paestum-Spinazzo.

23. La representación de prometopidia dorados con idéntica decoración caracteriza a los tres caballos de las lastras inferiores de la tumba de 1854. Representaciones de prometopidia en otras tumbas del área pestana o campana son: la tumba Nola N.4 (Benassai, 2001), en una tumba de Capua (Schneider-Hermann, 1996, Pl. 47) y en la tumba recuperada por la Guardia di Finanza de la necrópolis Paestum-Spinazzo.

24. Los cuatro caballos representados en la tumba (tres en las lastras inferiores y uno en el tímpano) presentan este elemento que encuentra en área pestana y campana numerosos paralelos: Paestum-Andriuolo t. 48, 58, 86, 2/1971, 4/1971, Paestum-Spinazzo tumba recuperada por la Guardia di Finanza y Tomba del Magistrato, Nola N.4. Además, la representación de estos penachos encuentra correspondencia en algunas esculturas de caballos: de Herculano (Coarelli, 1981, fig. 40), MAN-Firenze (Coare1li, 1981, fig. 44-45) o MAN-Napoli (Coarelli, 1981, fig. 46) (Vid. infra). 
La boca se muestra muy abierta ${ }^{25}$, como expresión de la tensión infligida por los elementos de gobierno ${ }^{26}$, azules, que evidencian un sistema de control de muy rápida respuesta.

\subsection{LA LASTRA DERECHA}

La narración de las pinturas sigue en la lastra lateral de la derecha, publicada por Minervini en su tav. V (Fig. 4). La escena reproduce la organización de la lastra anterior en modo especular.

\section{Guerrero 2}

El guerrero aparece orientado a la izquierda, con el brazo derecho levantado en ángulo recto y clavando una lanza, paralela a la vertical del cuerpo, sobre un enemigo vencido en el suelo. El cuerpo está ligeramente inclinado hacia adelante, acentuando la sensación de fuerza que transmite el clavar la lanza sobre el pecho del vencido. Las piernas están abiertas, fijando el peso en la derecha con el pie, aunque perdido, visto de lado hacia el enemigo. La pierna izquierda, en cambio, está extendida y muestra el pie en vista frontal. Con la mano izquierda sujeta las correas del caballo.

Aquí también el personaje principal coincide con el guerrero, que aparece caracterizado de manera distinta al de la lastra anterior gracias a la presencia de una ligera barba.

El casco, pintado en amarillo, distinto del de los demás personajes armados pintados en la tumba, presenta paragnátides figurados, además de una decoración frontal a modo de peinado que permite identificarlo como un casco del tipo Pacciano-Catanzaro (Adam, 1982; Guzzo, 1990). Además, la decoración de la frente, transversal, se completa por el intercalado de cinco piezas verticales que formarían lo que Polibio describió como un pterinos stephanos (corona de plumas): tres pinnae (plumas) blancas separadas por dos vástagos o cannulae ${ }^{27}$.

Viste una armadura formada por una coraza anatómica metálica (pintada en amarillo) con la base

25. Esta posición y gesticulación de incomodidad, más que de dolor, encuentra correspondencia en dos cabezas de caballo procedentes de Herculano (Coarelli, 1981, fig. 40) y Lanuvio (Coarelli, 1981, fig. 23-25).

26. El detalle de los elementos de gobierno del caballo son idénticos en los tres caballos de las lastras inferiores de la tumba de 1854. Encuentran paralelos en la tumba recuperada por la Guardia di Finanza y la Tomba del Magistrato, ambas, de la necrópolis Paestum-Spinazzo y en la tumba C.1 de Capua.

27. Pol. VI, 23, 12-14. Sobre la decoración con estructuras transversales aplicadas a modo de cánulas vid. Graells y Mazzoli, 2013. Para una valoración de la decoración con aplicación de pinnae vid. Castrizio, 2007, 81-108. recta, fijada por hombreras decoradas con figuras, posiblemente como en el caso anterior, también de Heracles. El faldellín que surge de debajo de la coraza es rojo y muestra pliegues horizontales. Las mangas no aparecen descritas y por lo tanto desconocemos su color.

\section{Guerrero vencido}

En esta lastra se presenta una escena de combate muy similar a la del caso anterior, pero con la diferencia de que el enemigo vencido corresponde a un personaje masculino y en una posición distinta de la amazona de la lastra anterior. El vencido está en el suelo, con la pierna derecha perdida, flexionada bajo el cuerpo mientras que la izquierda está extendida. El brazo derecho, hacia abajo, soporta una espada y el brazo izquierdo está extendido hasta el guerrero heroizado.

La representación expresa el patetismo del momento repitiendo una iconografía pseudo-arrodillada, con la pierna derecha perdida y la izquierda extendida, especialmente coherente con la posición del brazo izquierdo, levantado y agarrando el brazo del héroe. La mano derecha, que soporta la espada está abajo, detrás del cuerpo y sin posibilidad de ofrecer resistencia ${ }^{28}$. Es una elocuente imagen de derrota, en el último intento de clemencia e infructuoso freno a su ejecución.

El vestido es una túnica corta formada por dos partes separadas por un cinturón rojo: la superior, amarilla con un motivo en el centro del pecho de color rojo; y la inferior, violeta, corresponde a un faldellín. Como armamento, una espada corta y en la cabeza un casco azul tocado con plumas rojas, a imitación del alopekis (bonete de tipo frigio), muy similar al casco de Conversano o al de la colección Ceccanti tal y como indica su cresta, la articulación de sus paragnátides y el ligero detalle del cabello sobre la frente (vid. infra).

\section{Caballo 2}

El caballo, ahora grisáceo y con crin sustancialmente más corta que en el caballo anterior, es claramente de sexo masculino ${ }^{29}$. Presenta unos atalajes idénticos al del caballo de la lastra precedente (riendas, freno

28. Variantes de esta iconografía, que se ha propuesto como alusiva a la victoria de Aquiles sobre Héctor, se documentan en la lastra XVIII del Mausoleo de Halicarnaso o en el guerrero Griego 13 del sarcófago delle Amazzoni y posiblemente el guerrero Griego 17 del mismo sarcófago, que correspondería a una variante de la misma posición (Bottini y Setari, 2007, 82-83, fig. 4b-c).

29. Caballos con indicación del sexo masculino se documentan raramente sobre pintura funeraria. Entre ellos destaca el de la tumba recuperada por la Guardia di Finanza en Tarento procedente de la necrópolis Spinazzo de Paestum (Pontrandolfo, 1996a). 
azul y prometopidion amarillo, decorado con Gorgoneion), con la boca abierta. La principal diferencia con el caballo anterior es la menor longitud de la crin y el número de vueltas del nudo en la cola (cinco en el ejemplar anterior y cuatro en este).

\subsection{LA LASTRA DE FONDO}

La narración termina en la lastra de fondo, publicada por G. Minervini en su tav. IV (Fig. 5). Recuerda a la escena de pacto de Fides del héroe con el Pater Familias $^{30}$, siguiendo un esquema habitual en las tumbas de la necrópolis Spinazzo de finales del s. IV a.C. que (prácticamente siempre) presentan este tipo de escenas sobre la pared opuesta a la entrada (Pontrandolfo, Rouveret y Cipriani, 1998, 69).

\section{Guerrero 3}

El personaje que concentra la atención sigue siendo un guerrero. Esta vez, el guerrero aparece ricamente equipado con una panoplia militar completa, aunque contrasta respecto a las representaciones de las dos lastras anteriores al adoptar ahora una posición de reposo y no de combate. El guerrero, con las piernas ligeramente separadas, tiene la pierna derecha extendida con el pie visto de lado y la pierna izquierda suavemente flexionada con el pie en vista frontal. A pesar de su calmada representación aparece armado, con la coraza anatómica metálica (amarilla) con hombreras con decoración figurada idéntica a las dos lastras anteriores y con la base modulada para adaptarse al cuerpo. Debajo presenta un faldellín rojo. Las mangas muestran una túnica decorada con una doble cenefa de olas violeta en el centro de las mangas, muy parecidas a las del personaje togado de la misma lastra.

El casco, amarillo y asimilable al tipo PaccianoCatanzaro, presenta el paragnátide liso y está tocado con tres plumas blancas dispuestas sobre la frente de manera transversal y, en la sien izquierda, por una aleta metálica ${ }^{31}$.

30. Ante los resultados del análisis y la propuesta interpretativa que se desarrolla para esta tumba surge un problema de método y de reflexión. El trabajo utilizará repetidamente una serie de términos latinos (Fides o Pater Familias) que, por convención, se refieren a comportamientos sociales o imágenes sociales con una fuerte carga romanocéntrica. Estos términos, que seguimos utilizando aquí por comodidad, deben considerarse en su acepción más aséptica y literal y no con las connotaciones culturales romanas pues, recordémoslo, estamos ante un contexto netamente lucano.

31. La presencia de aletas, excepcional en área pestana, encuentra dos paralelos esquemáticos en la tumba Vannullo 2 y, en área campana, en la tumba C.14 de Capua. Sobre la decoración de cascos mediante pteroi (aletas) vid. Castrizio 2007, 81-108.
Sostiene una lanza, esta vez en la mano izquierda, con la punta hacia arriba. Esa misma mano sostiene las riendas del caballo.

Calza botas distintas a las del personaje togado de esta misma lastra. Los rasgos faciales del guerrero lo distinguen de los de las lastras 1 y 2 , pues la barba es evidente, más que en el de la lastra 2 , quizás como expresión de edades distintas.

Ocupa la posición central de la lastra orientado hacia la izquierda. A su lado izquierdo y delante se pintaron otros dos personajes: un adulto y un niño. Este ligero desplazamiento del héroe hacia el centro, que en las lastras anteriores se situaba en el tercio delantero, provoca que el caballo aparezca también desplazado (hacia la derecha) hecho que impide su representación completa por falta de espacio ${ }^{32}$.

\section{Togado}

El personaje masculino frente al guerrero se presenta, voluntariamente, como un sujeto de edad avanzada. Para ello se ha representado con barba y una morfología particular de su cuerpo. Únicamente extraña la larga cabellera rojiza que desciende más allá de los hombros, para la que no encontramos paralelo. Su vestimenta es una rica túnica blanca decorada con una cenefa de olas de color violáceo en el cuello, en el centro y el borde de la manga derecha. Cubriéndola, se presenta un himation blanco acabado con colgantes de color violeta, que no impide que se vea el cinturón de lámina metálica (pintado en amarillo) con dos garfios de color oscuro (violáceo), del llamado tipo samnita a palmeta.

La decoración de la vestimenta encuentra paralelos en otras tumbas de la necrópolis Spinazzo, en una tumba recuperada por la Guardia di Finanza y en la tumba del Magistrato de la misma necrópolis, donde los dos togados de las lastras de fondo presentan idéntico motivo decorativo (Pontrandolfo, 1996a, 282 y 284).

En la misma necrópolis se identifican otras variantes de esta decoración en rojo, en forma de cenefa de roleos (Pontrandolfo, 1996a, 283 y 285-287): en la tumba recuperada por la Guardia di Finanza, sobre la vestimenta del jinete de la lastra lateral y de los dos guardianes situados a los lados de la puerta; en la tumba del Magistrato, sobre la vestimenta del jinete de la lastra lateral; y en la tumba 11, sobre las túnicas de los dos togados.

El detalle del dibujo del cinturón aproxima el tipo de garfios a los representados en forma de palmeta. Cabe recordar que ya $\mathrm{A}$. Pontrandolfo indicaba la presencia habitual de este elemento en la mayoría de

32. El cambio de posición obligó a sacrificar la cola del caballo, hecho que evidencia el reaprovechamiento de plantillas dentro de la misma tumba. 
togados de la misma necrópolis (Pontrandolfo, 1996a, 289), aunque el detalle no es en ninguna otra representación tan relevante como el de la tumba de 1854 .

En los pies calza unas botas con cordones rojos.

El adulto se presenta en una posición afable, con los brazos extendidos hacia el guerrero: su mano derecha encajada con la del guerrero y la izquierda en actitud de coger el antebrazo derecho del guerrero.

\section{Individuo Infantil}

El individuo infantil se presenta con los dos brazos extendidos hacia el guerrero. Viste una túnica corta blanca, con detalles de color violeta, gorro y botas ricamente decoradas mediante líneas en forma de volutas que, quizás, evidenciarían un bordado o un repujado en el cuero.

\section{Caballo 3}

El caballo, de color amarillo claro y crin larga de color oscuro, presenta las mismas riendas, freno azul y prometopidion amarillo que las demás lastras, pero completa su equipamiento la presencia de un prosternidion $^{33}$ que estaría realizado en cuero y tejido si seguimos las indicaciones de color de Minervini (Minervini, 1856, 179). La boca del caballo se muestra, otra vez, muy abierta como expresión de su agresividad y exaltando a su vez su condición de caballo de combate.

\subsection{LAS LASTRAS LATERALES DE LA PUERTA}

El lado de apertura de la tumba, donde se ubicaba la puerta, fue reproducido por Minervini en su lámina VII (Fig. 6). G. Minervini describió la decoración como [...] nelle due porzioni di muro latereli alla porta sono due imberbi giovani con bianca túnica e gialla cintura, e calzari rosso bruno, ognun de'quali tiene con ambe le mani un'asta dalla quale mercè un rosso nastro è sospeso un oggetto di colore oscuro, che può riputarsi un ampio pileo, e presso un sacco di giallo. $\dot{E}$ notabile che $i$ capelli di queste due figure son rossi [...] (Minervini, 1856, 178).

Así, la puerta se presenta flanqueada por dos tramos de pared, ocupados respectivamente por un personaje

33. La representación de bandas pectorales petrales, en función de prosternidia en representaciones de caballos pestanos, encuentra un paralelo en el tímpano de la misma tumba de 1854 y en las tumbas Paestum-Andriuolo t. 28 y 104, así como en la tumba recuperada por la Guardia di Finanza en Tarento procedente de Paestum-Spinazzo. Sobre escultura, la cabeza de Lanuvio, hoy en el Bristish Museum (Coarelli, 1981, fig. 23) y la de la colección Weiller (Coarelli, 1981, fig. 50) presentan idénticos elementos. masculino imberbe con túnica blanca y cinturón metálico (evidenciado por el uso del color amarillo) ${ }^{34}$, con asta de la que cuelga un elemento oscuro y un segundo elemento amarillo que puede interpretarse como un gran escudo circular ${ }^{35}$.

Cada personaje está representado en posición de marcha hacia a la puerta. La composición recuerda más el regreso triunfante con el equipo militar colgando de la lanza que no la representación de portadores de trofeos ${ }^{36}$. La iconografía, en cualquier caso, se aproxima a la del Mars Tropaeophorus (Deona, 1953) especialmente por la posición del cuerpo ligeramente arqueado hacia atrás y los pies con apoyo ligero en el suelo, que se refuerza por la diferencia entre los elementos colgantes y la tradicional representación del trofeo militar, donde la túnica ensangrentada sería un elemento indispensable ${ }^{37}$.

\subsection{EL TÍMPANO}

El tímpano, conocido tanto por el dibujo de E. Braun (Fig. 1) como por otro, más detallado (Fig. 2), de Minervini, representa la apoteosis del personaje heroizado. Éste aparece en una imagen de eterna juventud: imberbe, desarmado, vestido con una túnica blanca y montando por primera vez el caballo, idéntico al de las lastras inferiores. Esta iconografía, si bien no idéntica, es frecuente en Paestum en cuanto a sus particulares y se acepta una interpretación alusiva a la heroización del guerrero.

Jinete

El personaje principal de la escena ocupa una posición ligeramente desplazada hacia la derecha del centro del

34. La presencia de cinturones de lámina metálicos en representaciones de guerreros secundarios en tumbas pestanas en: Contrada Vecchia di Agropoli t. 11/1967, Paestum-Gaudo 2/1957, Paestum-Vannullo t. 1, Paestum-Andriuolo t. 28, 53, 104 y tumba recuperada por la Guardia di Finanza de Paestum-Spinazzo. En área campana en: Capua C.11 y Nola N.6 y N.8.

35. Representaciones de idénticos escudos en escenas de combate de Paestum en: Andriuolo t. 12 (Pintado de amarillo), 90 (Pintado de amarillo), 1937 (Pintado de amarillo), 114 (Pintado de marrón), 53 (Pintado de gris), Arcioni 271/1976 (Pintado de blanco) y Spinazzo tomba del Magistrato (Pintado de negro).

36. Representaciones de escudos colgando de lanzas en representaciones de portadores de panoplias militares o trofeos, normalmente en representaciones de équites en: Contrada Vecchia di Agropoli t. 11/1967, Paestum-Vannullo t. 3 y 4 , Paestum-Porta Aurea tumba de 1805, Paestum-Laghetto t. LXIV, Paestum-Andriuolo t. 1937, 114 y 84, PaestumSpinazzo uno de los dos guardianes de la puerta de la tumba recuperada por la Guardia di finanza en Tarento.

37. Sobre esta discusión vid. Graells, 2012. 
triángulo que forma el tímpano. Está orientado hacia la derecha donde es recibido por dos mujeres, del modo habitual en área pestana ${ }^{38}$ mientras que detrás suyo aparece una comitiva de personas de distintas edades y sexos.

\section{Pareja de mujeres}

Aparecen ambas con calzado negro, vestidas con túnica blanca decorada por una franja violeta vertical al centro de su pecho ${ }^{39}$ que queda interrumpido por el cinturón $^{40}$. Ya A. Pontrandolfo indicaba la presencia habitual del cinturón en la mayoría de mujeres de la misma necrópolis, que sistemáticamente calzan botines negros (Pontrandolfo, 1996a, 289).

La mujer representada más cerca del caballero, de mayores dimensiones que la segunda, porta una pátera dorada en la mano derecha que ofrece al jinete ${ }^{41}$, mientras que en la mano izquierda sostiene una jarra. Los dos elementos fueron pintados en color amarillo para expresar su naturaleza metálica.

La segunda mujer, en cambio, aparece tocada con una diadema roja en el pelo mientras que presenta en sus manos un tejido rojo a modo de festone.

Detrás de las dos figuras se pintó un gran vaso metálico (también amarillo) que según el dibujo de Braun correspondería a un ánfora con dos asas (Fig. 1) pero que en el dibujo de Minervini se presenta como un gran enócoe (Fig. 2) ${ }^{42}$.

38. Esta representación, idéntica, con la mujer más próxima al personaje heroizado de mayores dimensiones que la que la sigue, encuentra un paralelo en la tumba Paestum-Andriuolo t.20.

39. Esta decoración se documenta también en las dos tumbas de la necrópolis Spinazzo, la del Magistrato y la recuperada por la Guardia di Finanza en Tarento.

40. La representación de cinturones en damas está poco testimoniada en Paestum (Andriuolo t. 1937 y Laghetto t. X). En relación con ello pueden considerarse las bailarinas con cinturones (Paestum-Andriuolo t. 27) y auloi, que si bien no son necesariamente individuos de sexo femenino, la proximidad entre su indumentaria y el de las damas representadas en este punto lo proponen como un paralelo plausible (Paestum-Gaudo t. 1/1972).

41. Esta posición y elemento ofrecido encuentran correspondencia en las tumbas Paestum-Andriuolo 84 y en la tumba recuperada por la Guardia di Finanza en Tarento procedente de la necrópolis Spinazzo.

42. La representación de vasos de grandes dimensiones en tumbas pestanas y campanas es frecuente, tanto en posición aislada en el tímpano como encima de banquetas o mesas o, incluso, llevadas por damas. A tal efecto se citan aquí las principales representaciones.

- Crátera Negra: Paestum-Arcioni t. 271/1976, PaestumCapaccio Scalo 1/1964, Paestum-gaudo 1/1972, Paestum-Laghetto t. X, Paestum-Andriuolo t. 51.

- Enócoe Negro: Paestum-Capaccio-Scalo 1/1964, Paestum-Andriuolo t. 23, Nola, N.8.

- Enócoe Dorado: Sarno S. 1.

\section{Comitiva}

Detrás del caballo se pintaron cinco personajes que completan la escena ${ }^{43}$, verosímilmente una familia tal y como indica la presencia de una mujer con un individuo infantil en sus brazos y un segundo niño/a cerrando la comitiva.

El grupo lo integra: un adulto caracterizado como guerrero, con corta túnica blanca, cinturón metálico (amarillo) y pileo rojo con corona amarilla (¿corona de oro ${ }^{44}$ ), cogiendo la cola del caballo ${ }^{45}$ y con lanza sobre el hombro; una mujer vestida de azul, en condición de madre, con el bebé envuelto en un tejido amarillo en sus brazos; y un tercer adulto con toga blanca, cinturón, diadema roja y trofeo colgando de la lanza (dos elementos, de imposible identificación), quizás en condición de magistrado, que coge de la mano al último individuo, infantil, vestido de amarillo y con el cabello rojizo.

Además, un elemento pintado encima de la comitiva, interpretado por Braun como representación de la luna en posición creciente, parece más probable leerlo como restos de una corona, habitual en representaciones funerarias del entorno pestano. Pero la falta de detalles en la descripción del motivo hace que toda propuesta sea especulativa. En cualquier caso, la identificación con una corona encuentra mayor lógica en una representación de apoteosis heroica y conmemorativa, como se desarrolla seguidamente.

\section{Caballo montado}

El caballo, amarillo y con la crin marrón, sigue siendo el mismo que hemos visto en las lastras de la caja, pero su detalle difiere entre la reproducción de Braun y la de Minervini.

En la de Braun aparece aderezado únicamente por un tejido sobre su lomo, sobre el que monta el jinete.

- Ánfora Dorada: Paestum-Spinazzo tumba recuperada por la Guardia di Finanza en Tarento.

- Stamnos Dorado: Paestum-Andriuolo t. 114, Sarno S. 1, Nola N.8.

43. Una comitiva similar, formada también por cinco personajes, en Paestum-Andriuolo t. 51. El grupo lo integran una alternancia de adulto, individuo infantil, adulto, individuo infantil y adulto, que presenta idéntica distribución de edades que en la representación en análisis.

44. Sobre las coronas de oro vid. Colonna, 2007.

45. La representación de personajes cogiendo la cola del caballo, bien a modo de escudero o de acompañante, se documenta en Paestum por parte de personajes vestidos con toga (Laghetto III, Contrada Vecchia di Agropoli 11/1967 y tumba recuperada por la Guardia di Finanza en Tarento procedente de la necrópolis de Spinazzo), menos clara es la representación de la tumba 1/1972 de Paestum-Gaudo. Esta representación encuentra correspondencia en área campana, en la que los dos únicos casos de personajes en esta actitud (Nola N.4 y N.8) corresponden a togados. 
Nada queda de los elementos para su gobierno, claramente ausentes, acentuando esta falta la boca cerrada del caballo y la posición de los brazos extendidos del jinete, que se agarran a la crin. Únicamente una faja en el pecho, podría relacionarse con el prosternidion de la lastra 3. En cambio, en la representación de Minervini se presenta equipado con el prometopidion y el resto de elementos para su gobierno, faltando el manto.

Dejando de lado las diferencias entre las dos fuentes, cabe considerar la dicotomía en las representaciones del caballo. Por un lado en la caja y, por otro, en el tímpano, siendo imposible distinguir para el caballo una correspondencia con el héroe, es decir, si también presentaría dos estados en esta tumba - el de combate, con su equipo para un gobierno fuerte y rápido; y el de parada, únicamente con el manto - que encajaría perfectamente en un discurso articulado entre la narración de la caja y la del tímpano.

\section{LECTURA E INTERPRETACIÓN DEL PRO- GRAMA ICONOGRÁFICO}

Tradicionalmente, la lectura histórica de las pinturas pestanas se ha basado en las ininterrumpidas y brillantes contribuciones de A. Pontrandolfo y A. Rouveret, que han demostrado como en el transcurrir del s. IV a.C. las elites pestanas se afirman y auto-representan en sintonía con los importantes acontecimientos bélicos entre Poseidonia, Tarento y Roma (Pontrandolfo, 1996a, 289), en los que participaron de manera activa. De este modo, podemos ver las pinturas funerarias como expresión de una koiné helenizante, común entre diversas culturas itálicas ${ }^{46}$, capaz de desarrollar modelos locales distintos y autónomos con unas lógicas narrativas e iconográficas próximas entre sí en toda la Italia meridional.

Para las tumbas pintadas de las necrópolis pestanas, en particular la necrópolis de Spinazzo, se observa como presentan los personajes orientados de manera convergente hacia el punto central de la lastra de fondo. Esta idea integra en un único discurso la totalidad de las lastras y, a pesar de la rigidez del modelo, admite dos posibilidades:

- mostrarlas todas siguiendo un único discurso, lineal;

- representarlas en un doble discurso en el que, desde la puerta surgen dos líneas narrativas que convergen en el punto central de la lastra de fondo.

Sea como fuere, la tumba de 1854 no cumple ninguna de las dos. Pero para entender el porqué se utiliza una alternativa, conceptualmente mucho más compleja, es necesario volver sobre conceptos teóricos y recuperar la posición de las lastras (Figs. 7 y 8). Así, el discurso

46. Para una aproximación a las características de la pintura funeraria en la Italia meridional vid. Steingräber, 1991. aparentemente incoherente en el que cada lastra representa escenas finitas, obliga a reflexionar y a pensarlas como partes de un mismo discurso en el que su combinación o sucesión desembocan en la lastra del fondo.

De acuerdo con F. Coarelli, A. Rouveret indicaba la relación entre la representación histórica y la evocación mítica como un proceso de creación genealógica y, por lo tanto muestra de una toma de consciencia histórica (Rouveret, 1997, 135). De esta manera, A. Rouveret en su análisis de las pinturas de esta tumba, consideraba convincentemente que la representación estaría enmarcada en la iconografía de la Guerra de Troya (Rouveret, 1997, 135). Particularmente importante si tenemos en cuenta que (en opinión de la misma investigadora) ese mito (y sus derivados), entre finales de s. IV e inicios del III a.C., sería un elemento importante del lenguaje compartido entre las élites suritálicas. Este relato mítico transversal entre distintos grupos fue excepcionalmente representado en las lastras laterales de la caja de la tumba de 1854 completándose con una serie de motivos iconográficos, locales y exógenos. Los detalles confieren singularidad al conjunto y se analizan bajo 3 niveles: por un lado, la pintura alegórica de las tres lastras de la caja, con representaciones de guerrero y caballo, claramente relacionadas estilística y temáticamente entre sí; en segundo lugar, la pintura étnica-local de la pared de fondo, lastra de fondo y tímpano - ambas como evolución o variante de representaciones de carácter pestano -; y, finalmente, la irrupción extraordinaria de motivos foráneos: en los detalles de la panoplia y del equipo equino así como en la posición de los cuerpos y el uso de una pareja de armados en los laterales de la puerta.

\subsection{PINTURA ALEGÓRICA}

En las representaciones de las tres lastras rectangulares inferiores, el personaje principal es con claridad un guerrero con coraza anatómica y casco tocado con tres plumas, acompañado por un caballo con prometopidion decorado con Medusa, y armado siempre con una lanza. Se refuerza con la ostentación de una panoplia defensiva metálica su condición privilegiada y su pertenencia al grupo de los équites. Esta figura de Condottiero sería la máxima expresión de rango tanto en la Italia meridional como, particularmente, en la necrópolis Spinazzo ${ }^{47}$.

47. Una de las tumbas citadas por A. Pontrandolfo de la necrópolis Spinazzo, presentaba como enterrado a un individuo infantil incinerado al que se ofrendó un esperón de bronce miniaturizado que la investigadora no ha dudado en interpretar como símbolo de su ascendencia a un grupo de equites del que habría formado parte (Pontrandolfo, 1996a, 291). 
Los cascos y las corazas están pintados en todos los casos en color amarillo, simulando el metal. Aunque, es importante resaltar que en las tres representaciones cascos y calzado se pintaron con diferencias entre sí mediante la incorporación de algunos detalles decorativos importantes. Esta distinción encuentra correspondencia con una serie de variaciones en las representaciones de la barba del personaje principal (ausente, insinuada y acentuada en cada una de ellas), que Minervini interpretó como una voluntad de evidenciar tres edades del mismo guerrero (Minervini, $1856,177)$, aunque podrían corresponder a imágenes de tres personajes distintos, quizás pertenecientes a una misma gens que participan en episodios complementarios. Pero discernir entre las dos opciones implica (si seguimos la propuesta de Minervini), identificar las escenas de las dos lastras laterales como alusión a dos episodios de combate acontecidos en momentos distintos (Figs. 3 y 4) o, si consideramos la interacción de varios personajes, ver en las dos lastras dos escenas de un mismo combate.

Aún así, el peso de la composición recae en la pared de fondo (Fig. 5). Desde la entrada los caballos de las lastras laterales guían el punto de atención hacia el fondo de la cámara, con la escena del compromiso del héroe con la gens, expresado mediante el pacto de fidelidad con el Pater Familias ${ }^{48}$ y la apoteosis del propietario de la tumba, en el tímpano.

Pero esta estructura está precedida por un espacio que focaliza la atención, de manera especular, con dos escenas que repiten una misma estructura en la que el héroe se representa en el momento de vencer a un enemigo. Ahora cabe identificar las escenas de combate y ver si se trata de dos ciclos distintos o de uno solo. Si correspondiera a dos ciclos distintos, podría proponerse una representación alegórica del héroe en dos momentos de su vida. Si, en cambio, corresponde a un solo ciclo, deberíamos considerar que las representaciones del héroe no son tales sino que serían aplicaciones de topoi iconográficos, sin mayor voluntad narrativa que el uso del recurso mitológico para enfatizar una condición heroica y privilegiada.

El esquema, a mi entender, corresponde al siguiente orden:

48. La escena se repite en la necrópolis Spinazzo, en varias tumbas, como la recuperada por la Guardia di Finanza, donde la lastra de fondo presentaría también un pasto de Fides entre dos personajes togados, uno joven y otro senil (Pontrandolfo, 1996a, 282) y las tumbas 11 y 48 . Con la extensión de los dos brazos del Pater Familias hacia el brazo del joven en la tumba 11 (Pontrandolfo, 1996a, 287) y el saludo entre ambos en la 48. Una representación similar se localiza sobre una lastra de una tumba pintada de Isernia (Mazzei, 1995, fig. 137; Benassai, 2001, fig. 234) aparece un togado extendiendo la mano a un segundo personaje, verosímilmente Hermes como indicaría su caduceo. Ello implica la circulación de un modelo iconográfico preciso en el momento de cambio entre el s. IV y III a.C.

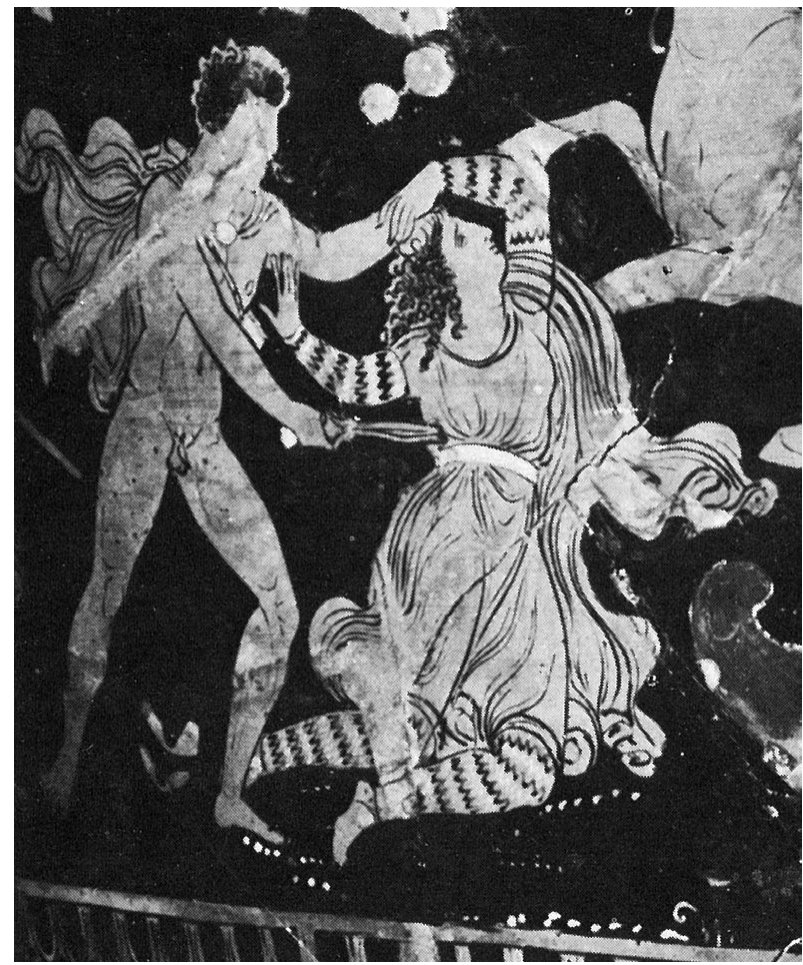

Figura 10: Representación de amazonomaquia sobre crátera ápula. A partir de Moret, 1975, Tav. 82.1

En primer lugar la lastra 1 (Fig. 3), a la izquierda, en la que la escena puede claramente identificar el personaje femenino como una amazona, representada en el conocido esquema llamado motif de la saisie par les chevaux (Fig. 10) (Moret, 1975, 193), en la posición agenouillée (Moret, 1975, 117-118) de espaldas al héroe, siendo imposible saber si la imagen se completa con el pie del guerrero pisando la pierna de la amazona caída (Bottini, 2007, 16). Este esquema, formado por dos motivos bien conocidos y ampliamente estudiados, es un dato más que permite caracterizar las influencias de la representación para lo que parece clara una adopción de este motivo iconográfico de las producciones ápulas, que lo habrían desarrollado a partir de de modelos áticos.

Por contra, la lastra derecha (Fig. 4), representa a un personaje con alopekis crestado y con espada, también en la posición agenouillé (Moret, 1975, 117-118) aunque enfrentado al héroe (Figs. 11, 12 y 13). Este personaje podría relacionarse con un esquema de victoria del griego sobre el bárbaro ${ }^{49}$, alusión a la guerra entre griegos y persas (Iliupersis), particularmente importante a partir de la frecuente representación del enemigo troyano con este tipo de casco o tocado frigio. La composición fue especialmente habitual en área ápula con posterioridad a la expedición de Alejandro

49. Sobre la representación del bárbaro en área Magno-griega y el desarrollo de la iconografía a partir de las guerras persas vid. Pontrandolfo y Rouveret, 1983a. 


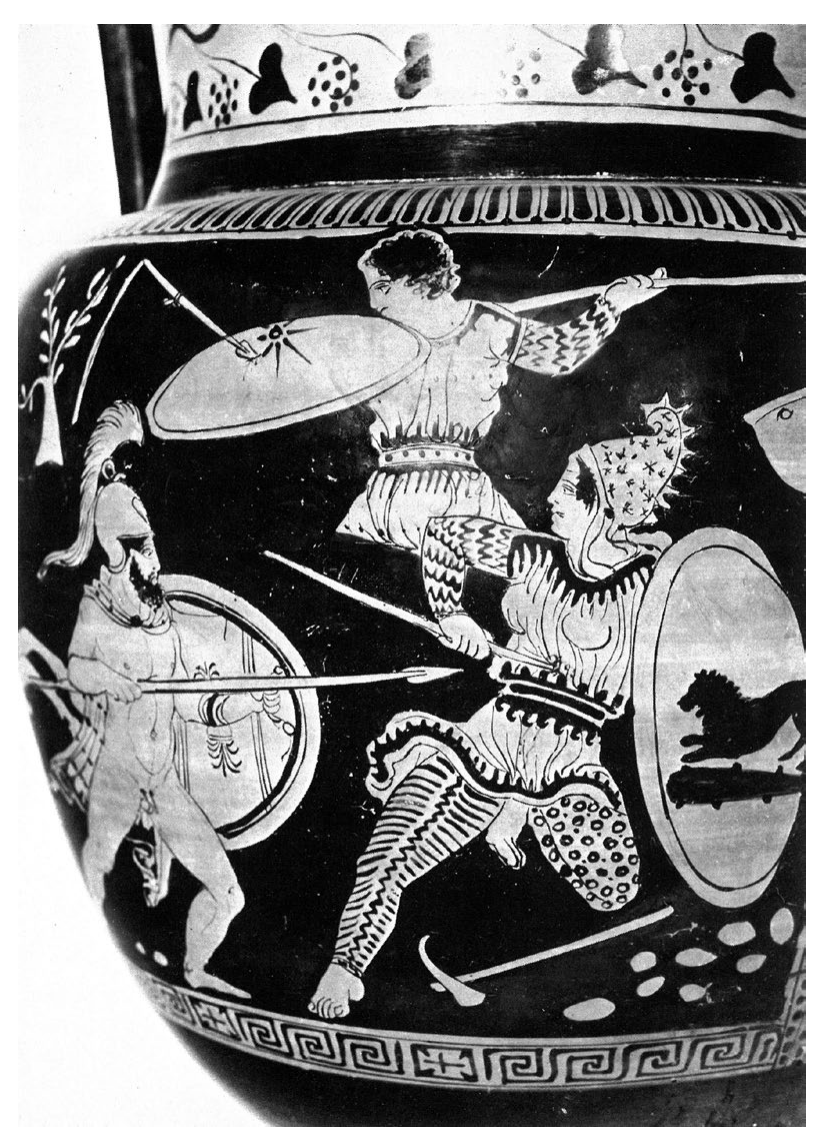

Figura 11: Representación de lucha contra el bárbaro/amazonomaquia sobre crátera ápula. A partir de Moret, 1975, Tav. 64.2.

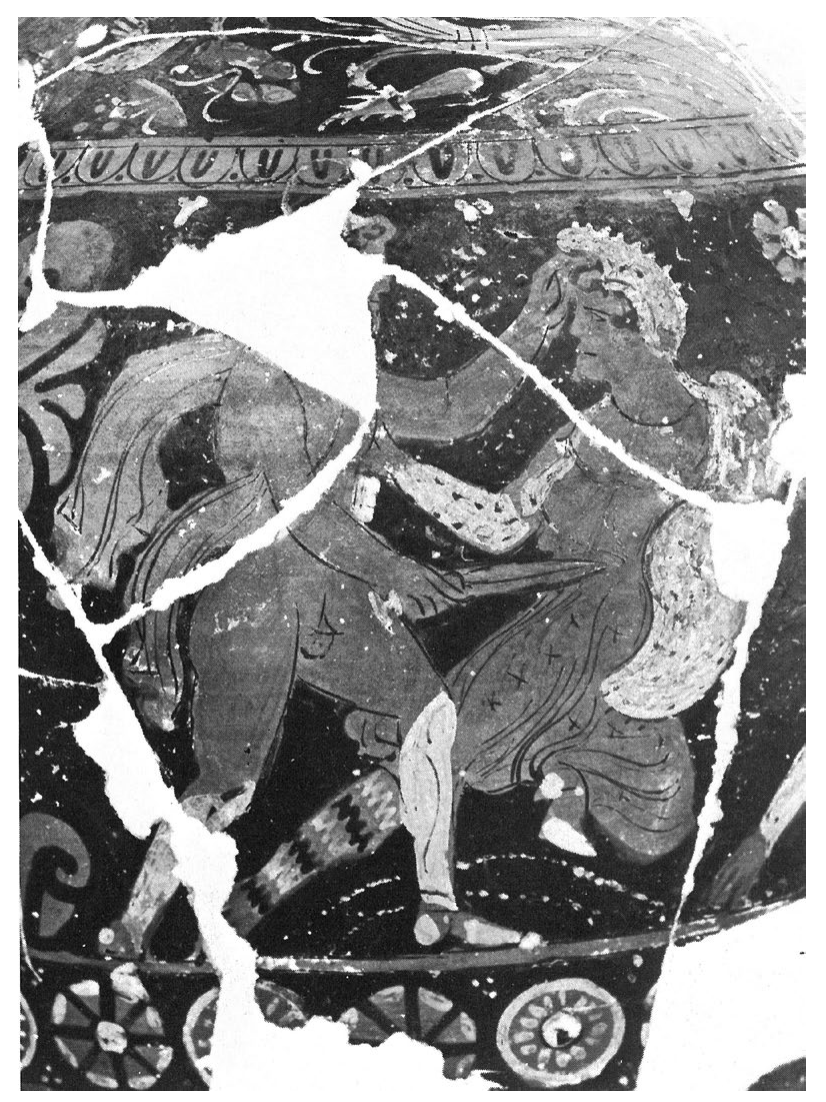

Figura 12: Representación de lucha contra el bárbaro/amazonomaquia sobre crátera ápula. A partir de Moret, 1975, Tav. 65.2.

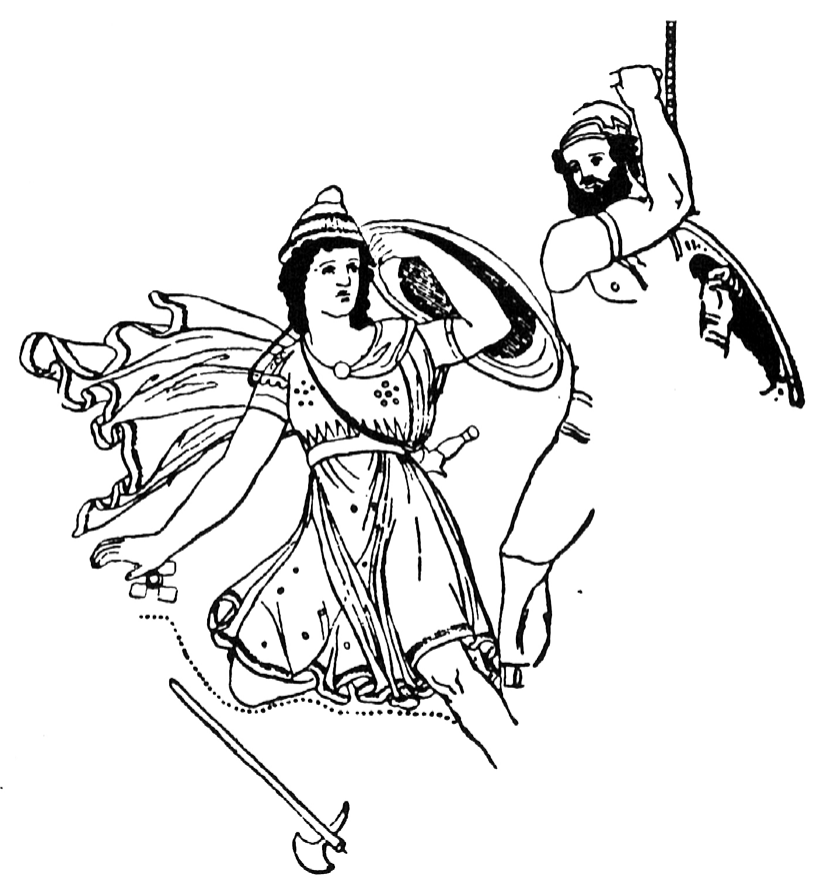

Figura 13: Particular de la representación de lucha contra el bárbaro/amazonomaquia a partir de dibujo de la escena sobre crátera ápula. A partir de Moret, 1975, Tav. 83.2.

Magno en Oriente ${ }^{50}$, que permitiría una aproximación cronológica tal y como se ha propuesto para otros monumentos (Bottini y Setari, 2007, 87).

Pero el detalle de ambas representaciones es ambiguo y obliga a considerar particularmente la túnica lisa $^{51}$, la ausencia de coraza, el uso de un alopekis ${ }^{52}$ y la representación de estas características y posición escenográfica, tanto para amazonas (Moret, 1975, Pl. $64.2,65.2,66,83.2)$ como para persas/bárbaros ${ }^{53}$. De todos modos, Rouveret interpretó las escenas de combate de manera distinta, considerando que fuera una evocación paradigmática de las res gestae del difunto,

50. Recordemos el caso de la crátera de Ruvo conocida como delle Amazzoni, actualmente reinterpretada como representación de combate entre griegos y persas. En cualquier caso, la representación surge durante la segunda mitad del s. V a.C. en área griega.

51. Bottini ha indicado la frecuente aparición de la amazona que combate a pie como una amazona vestida al estilo griego más que al estilo oriental, frecuente en otras escenas (Bottini y Setari, 2007, 78).

52. La asimilación del troyano con la amazona y la adopción por parte de la amazona, en mundo italiota, de los elementos del primer grupo ha sido ampliamente reconocido (Moret, 1975, 151-159).

53. Como propusieron Pontrandolfo y Rouveret, la confusión entre troyano, persa y amazona era voluntaria para simplificar la iconografía del bárbaro (Pontrandolfo y Rouveret, 1983a, 1057 y 1065). Esta dicotomía entre bárbaro/persa y amazona es un elemento intercambiable y voluntariamente ambiguo que evidencia un mismo modo de representar lo opuesto a lo griego. 
lucano, enfrentado a una amazona y a un griego (Rouveret, 1997, 136). Según la autora, la descripción de la escena de amazonomaquía (Fig. 3) incide en esta transformación de la iconografía en la que la amazona permanece pero el griego es sustituido por un lucano (Rouveret, 1997, 138). La segunda confrontación es más problemática (Fig. 4). El guerrero, lucano, se enfrenta y vence a un enemigo con un casco de tipo Conversano (Figs. 16, 23 y 24) que Rouveret, en cambio, identificó con un casco de tipo frigio y lo relacionó con el entorno tarentino o ápulo (Rouveret, 1997, 138). Ante este detalle son necesarios algunos comentarios, especialmente si tenemos en cuenta los particulares de la panoplia y lo propuesto por A. Rouveret, que identificó esta escena con la de la muerte de Héctor por Aquiles (Rouveret, 1997, 139). De ser correctas las posiciones de Rouveret, la filo-romanidad de las pinturas pestanas estaría expresando un acontecimiento absolutamente opuesto al mito del discurso romano, pues evidenciaría la identificación de los lucanos con Aquiles y el vencido con el troyano ${ }^{54}$, que podría extender las implicaciones y ver en ello una alegoría precedente a la instauración del mito del antepasado de Roma, Eneas, y por lo tanto, una victoria sobre Roma.

De esta manera debemos proponer que la decoración lateral de la tumba represente una escena de amazonomaquia, como alegoría de la victoria sobre el enemigo, y en la otra lastra, una representación de victoria más explícita sobre la identidad del enemigo, representado como oriental, reproduciendo un esquema iconográfico de clara componente ápula basado en la ambigüedad y la confusión de conceptos, posiblemente intercambiables entre el concepto de oriental y el femenino ${ }^{55}$.

Por otro lado, la representación del guerrero con coraza anatómica metálica sosteniendo las riendas del caballo encuentra sobre la cerámica ápula de segunda mitad del siglo IV a.C. numerosas representaciones. Se trata de escenas situadas dentro de naiskoi donde el guerrero, heroizado y sólo ${ }^{56}$, es recibido o despedido

54. A todo ello, cabe recordar que Aquiles era antepasado de los Molossos y que recibió culto en las principales localidades del desarrollo lucano (Rouveret, 1997, 139).

55. Planteamiento que en opinión de A. Bottini corresponde a un desprecio y disminución de la dignidad del enemigo (Bottini y Setari, 2007, 88).

56. Crátera de volutas con máscaras atribuida al Pintor dell'Ilioupersis, de la antigua colección Caputi (n. 275) en el Palazzo Leoni Montanari de Vicenza (Lippolis, 2011, fig. 7), con representación de naiskos con jinete de pie con lanza, casco con alto lophos y coraza anatómica y detrás caballo a derecha. Se fecha en el tercer cuarto del s. IV a.C.; Ánfora del mercado anticuario londinense (Sotheby's 10/07/1992, lote 353; Sotheby's 10/12/1993, lote 191) atribuida al pintor de Baltimore, con representación de naiskos con caballero de pie y detrás caballo. El caballero lleva un casco, la coraza y la lanza, mientras que del naiskos cuelga una pareja de cnémides. Fechada en la segunda mitad del s. IV a.C.; Crátera de volutas de la tumba 1 de la necrópolis por parte de un Pater Familias ${ }^{57}$ o de una dama ${ }^{58}$. No hay representaciones enmarcadas en duelos o acontecimientos bélicos (reales o imaginarios). Si bien las representaciones de corazas anatómicas son habituales sobre la cerámica ápula, poco tienen que ver con las representaciones de la tumba pestana. De esta manera, la escena de la lastra de fondo, encuentra una lógica iconográfica precisa en la serie de naiskoi con guerrero con coraza anatómica y anciano, que en la cerámica aparece a menudo sentado, como manifestación del respeto para la familia y la gens según un patrón iconográfico de influencia ápula.

de Via Reno en Altamura (Venturo, 2001, 70-71, Tav. IV.8). Con representación de naiskos dentro del que se representa un caballero de pie con su caballo detrás. Endosa coraza y casco crestado; Crátera de volutas con máscaras del Seated Women Group del Museo de l'Hermitage de San Petersburgo N. Inv. 581 (Trendall y Cambitoglou, 1978, N. 23/239, P1. 281.1), con representación de naiskos con jinete de pie con coraza anatómica y lanza, detrás del que aparece un caballo blanco y, a la izquierda y colgando, un casco de tipo a Pilos.

57. Crátera de volutas atribuida al Pintor de Loebbecke (Staatliche Museen Berlin N. Inv. 1984.42) (que se propone que pueda proceder de Canosa), con un naiskos en el que se representa un anciano sentado que recibe/despide a un jinete joven de pie que endosa la coraza y sujeta los atalejes de un caballo. Fechada entre el 340-330 a.C.; Crátera de volutas atribuida al Grupo de Bassano de una colección privada napolitana (Trendall y Cambitoglou, 1978, N. 30/20, Pl. 393.2), con representación de naiskos con tres personajes en el interior: en el centro un joven con lanza y coraza anatómica, enfrente un anciano sentado, detrás del joven un caballo y un escudero desnudo. Encima, colgando, un escudo circular.

58. Crátera del Pintor de Baltimore del Musée du Louvre GR 018 (Moreno 2010, fig. 18), con representación de caballero con coraza anatómica, con casco ático (?) con paragnátides móviles. Detrás caballo blanco. Delante dama que le ofrece un kántharos mientras sostiene una sítula. Colgando del techo aparece una espada y, posiblemente, una cnémide; Olla atribuida al Pintor de Baltimore del Musée d'Art et d'Histoire de Ginebra, con representación de jinete que endosa coraza anatómica y casco a pilos, de pie al lado de su caballo, en un contexto con otros personajes y en el que es recibido por un joven sirviente de una dama, sentada enfrente del jinete. Fechada en la segunda mitad del s. IV a.C.; Crátera de volutas del mercado anticuario londinense (Sotheby's 8/12/1994, lote 164) atribuida al pintor de Baltimore con representación de naiskos con representación de retorno de caballero, de pie con coraza endosada, con caballo detrás y mujer delante. Colgando aparece una representación de casco a Pilos. Fechada entre el 340-320 a.C.; Crátera de volutas del mercado anticuario londinense (Sotheby's 11/07/1988, lote 184) atribuida al pintor de Baltimore, con representación de naiskos en el que aparece una escena de retorno/despedida de caballero, de pie, con la coraza y casco y detrás el caballo, orientado hacia el lado opuesto en el que se sitúa una dama sentada que toma la mano del caballero. De la parte encima de la dama cuelga una pareja de cnémides y un escudo. Fechada en la segunda mitad del s. IV a.C. 


\subsection{El PESO DE LA TRADICIÓN}

La escena del tímpano (Figs. 1 y 2), fue motivo de discusión al considerarse en un primer momento como una representación del mundo de ultratumba (Forchhammer, 1854, 63) y, en un segundo momento, proponerse que fuere un pasaje sumamente importante de la vida del protagonista, como Condottiero lucano (Minervini, 1856, 180-181). Se trataría, siempre según G. Minervini, de la representación de la llegada de la población lucana a Poseidonia, bajo la guía del difunto y propietario de la tumba. Este fundamental acontecimiento fue escogido para ocupar el lugar más destacado de la tumba. Pero recientes estudios sobre la pintura de finales del s. IV a.C. en la necrópolis de Spinazzo identifican este tipo de representaciones como valoración de la familia del aristócrata que ocupaba la tumba (Pontrandolfo, Rouveret y Cipriani, 1998, 69), lectura que se acentúa cuando en la lastra situada debajo del tímpano aparece la representación del pacto de fidelidad con el Pater Familias (Fig. 5). Así, la escena del tímpano viene interpretada como representación del Retorno del Caballero ${ }^{59}$, mientras que la de debajo representa el motivo de la Dexiosis, exaltando la continuidad de la estirpe con las tres edades del hombre (Rouveret, 1997, 135): infantil, adulta y senil.

La lógica observada en otras tumbas de la misma necrópolis, donde el destinatario de la tumba aparece en un momento de parada expresando su rango como caballero (Pontrandolfo, 1996a, 291) ${ }^{60}$ tiene cierta correspondencia con la representación del tímpano donde, además, la presencia de un cortejo que le sigue se propone como expresión de heroización por parte de su gens (Pontrandolfo, 1996a, 291) ${ }^{61}$.

En este contexto altamente representativo como es la pintura funeraria y, más particularmente, el tímpano, estas pinturas podrían representar a los antepasados y la ascendencia noble de la gens a la que pertenecía el propietario de la tumba.

59. Para una discusión del modelo vid. De’Spagnolis, 2005, 136-139.

60. Las escenas de retorno del caballero encuentran importantes paralelos en Capua (10 tumbas), Nola (2 casos) y Sarno (Benassai, 2001, 183; De'Spagnolis, 2005, 137-139).

61. La escena del tímpano tiene un paralelo en la parte inferior de la lastra de fondo de la tumba Andriuolo 20 (Pontrandolfo y Rouveret, 1992, 92), con orientación invertida y con cuatro personajes detrás del jinete, que parece estar armado. También la tumba Andriuolo 28 presenta una lastra de fondo con jinete recibido por mujeres y comitiva detrás del jinete. Lamentablemente, el estado de conservación no permite precisar las características ni número de personajes detrás del jinete (Pontrandolfo y Rouveret, 1992, 159) que como en la tumba 20, presenta una orientación opuesta a la de la tumba del Fondo Fuscillo.

\subsection{INNOVACIONES Y ADOPCIONES EXTERNAS}

El factor local, claramente demostrado por detalles estilísticos de la composición de la lastra de fondo y de la escena del tímpano, queda fuera de discusión. En cambio, el peso de las influencias externas que se detecta por el uso de una iconografía alegórica ausente en Paestum, es especialmente clara en los detalles de las panoplias (Figs. 15, 16, 33 y 41) y por el uso de dos motivos foráneos para las composiciones: las dos representaciones de los laterales de la puerta (Fig. 6) y detalles de la representación anatómica de los personajes.

El análisis anticuario permitirá ahondar en la cuestión de las armas representadas, pero aquí merece la pena un comentario sobre los aspectos foráneos de las composiciones:

Primero: sobre el recurso de la aplicación de guardianes armados en los laterales de la puerta. Es posible que esta representación tenga unas connotaciones de inmortalidad donde la combinación de jóvenes vestidos de blanco con tocado o cabello rojo ${ }^{62}$ se combine con la escena de apoteosis del tímpano. Pero también puede entenderse de manera más sencilla, en la que la lanza se acompaña por un escudo dorado, como sucede en otras representaciones de personajes que custodian puertas de tumbas y que seguidamente desarrollamos.

$\mathrm{Su}$ presencia se documenta de manera extraordinaria en las necrópolis pestanas, aún así, en la tumba 3/1972 de la necrópolis Gaudo se documentaron dos, uno en cada lastra al lado de la puerta, aunque desnudos, elemento que se contrapone a la idea, cuidada en la tumba en estudio, de representar la panoplia militar. Los mejores paralelos son los de los vanos de la tumba de la necrópolis Spinazzo recuperados por la Guardia di Finanza (Pontrandolfo, 1996, 283) que, aunque con una orientación opuesta al ingreso, reproducen la posición de armados de grandes dimensiones (acorde con el resto de figuras de la tumba). Por la descripción de la vestimenta, la lanza, el pileo y el sacco di giallo ${ }^{63}$ (escudo), debemos recuperar otros paralelos que evidencian una influencia macedónica reinterpretada en área pestana: en primer lugar los dos guardianes de la tumba III de Aghios Athanasios (Tsimpídou-Ayloníti, 2005, pl. 38 y 39), ambos con lanza y equipo militar sin casco ni coraza; de manera individual, pero relacionado con el acceso a la tumba, el guerrero de una de las métopas de la fachada de la tumba del Juicio de Leukadia (Romiopoúlou, 1997, fig. 22), vestido con túnica blanca acabada con elementos en rojo que se apoya en una larga lanza, en la mano derecha, y sostiene un escudo pintado en amarillo en la mano izquierda;

62. Los bonetes cónicos de color rojo se documentan hasta cuatro veces en Paestum, siempre portados por aurigas. El catálogo es: Andriuolo 12, 18; Gaudo 7/1972; Sequestro Finanza 1. Otro lo lleva el Guerrero 3 del Sarcófago delle Amazzoni de Tarquinia (Bottini, 2007; Bottini y Setari, 2007).

63. Según la descripción original. 


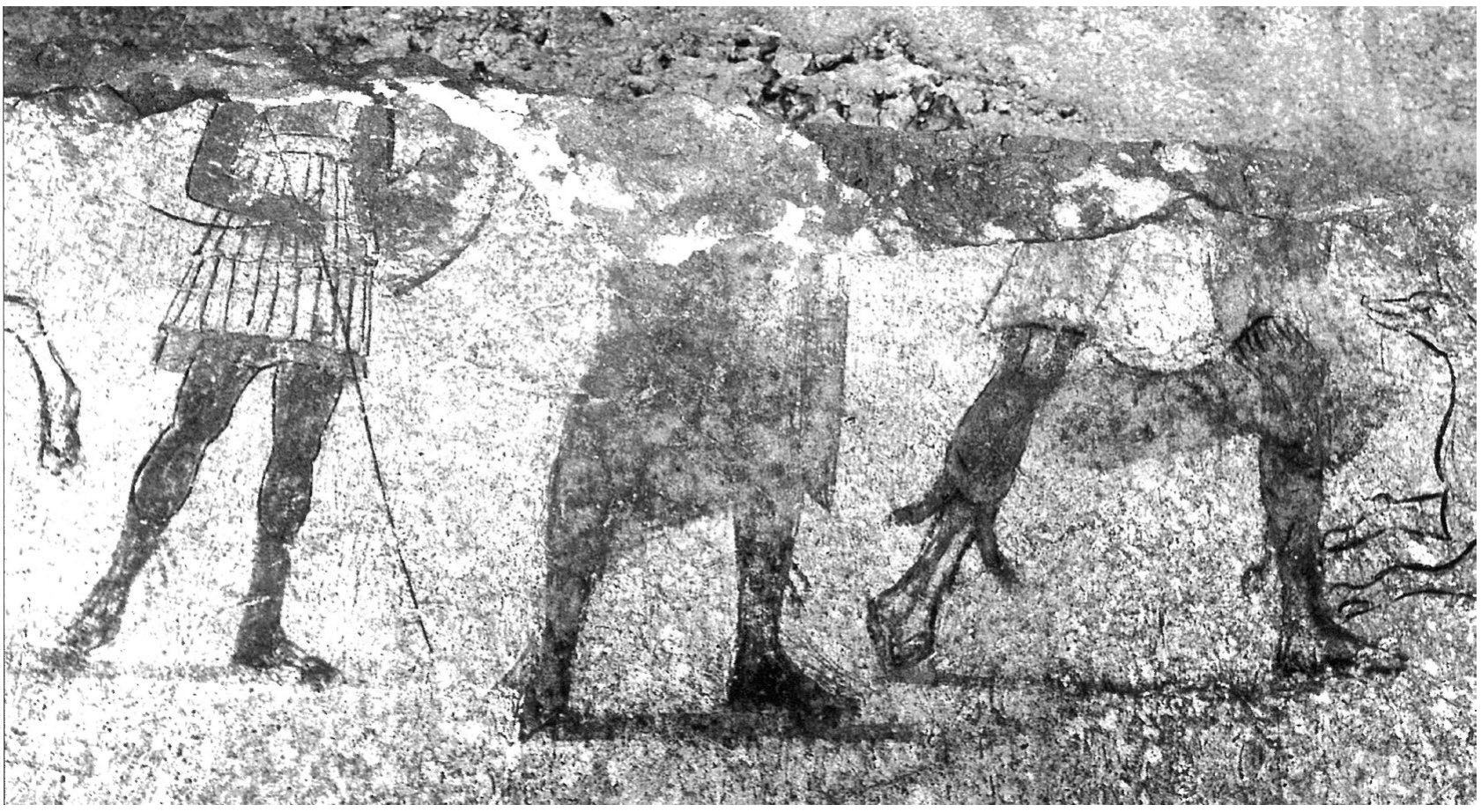

Figura 14: Lastra del Ipogeo del Cerbero de Canosa. A partir de Mazzei, 1995, fig. 133.

por último, la representación de la tumba II del túmulo de Bella (Vergina) (Andronikos, 1984, fig. 15), con un único soldado encima de la puerta de ingreso.

Otro detalle atribuible a una influencia externa (ni campana ni, aparentemente, itálica), es el detalle de las representaciones de las cabezas y de la posición de las piernas y los pies de los personajes de las lastras inferiores.

La característica de las tres representaciones es la ligera inclinación de la cabeza (Fig. 16): acentuando la posición del cuerpo en las lastras 1 y 2 y, oponiéndose a la inclinación del cuerpo en la lastra 3. Este ligero movimiento parece corresponder a una estructura desarrollada a partir de la obra de Lisipo (Moreno, 1994, 152). Particularmente, la faz del guerrero de la lastra 1 podría corresponder a una adaptación del motivo iconográfico de la efigie de Seleuco Nikátor (359281 a.C.) (Moreno, 1994, fig. 194-195), a partir de la representación con un casco ático con paragnátides anatómicos largos. El modelo tuvo rápida aceptación y difusión como representación del legado victorioso greco-macedonio y tuvo, entre otras adopciones, la imitación que hizo Pirro (Moreno, 1994, 151). La mayor proximidad de la representación de la lastra 1 con la representación seleucida y no con la pírrica, principalmente por el tipo de casco y la ausencia de corona además del detalle del cabello, presente en la segunda, sugieren que la pintura corresponda a un momento anterior a la llegada de Pirro a la Italia meridional.

Por otro lado, la representación de pies en las pinturas de las tumbas de Paestum acostumbran a presentarse de lado (Fig. 15), siendo extremadamente inusuales en vista frontal ${ }^{64}$. Esto incide directamente en la posición de las piernas, donde el artista aplicó un modelo desarrollado en área no pestana para la representación del guerrero. Este tipo de representaciones encuentran correspondencia en la pintura del Ipogeo del Cerbero de Canosa (Fig. 14) (Mazzei, 1995, 206, fig. 133), con hasta tres representaciones de piernas de personajes masculinos calzados con botas y sandalias (raras en área pestana ${ }^{65}$ ), con un pie en vista lateral y el otro en vista frontal. Además, las posiciones de las piernas de esta lastra reproducen las de los tres guerreros de la tumba de Paestum de 1854: entreabiertas, abiertas con peso desplazado hacia adelante, abiertas con movimiento hacia adelante.

Relacionado con esto, las representaciones del calzado, corresponden a variantes del calceo o bota

64. Un ejemplo podrían ser los guerreros de la derecha de la lastra norte de la tumba Andriuolo 58 (Pontrandolfo y Rouveret, 1992): el de la derecha con la pierna izquierda avanzada y flexionada, muestra la pierna derecha extendida y retrasada sin indicación del pie, posiblemente con una voluntad de escorzo para dar profundidad a la escena. Incide en esta idea el dibujo del pie izquierdo del personaje. El de la izquierda, acentúa esta sensación de volumen con la pierna izquierda flexionada hacia adelante y la derecha ligeramente extendida hacia atrás con el pie visto de frente.

65. En Paestum se identifican sandalias o calcei en el aulós de la lastra este de la tumba Andriuolo 53, en el guerrero de la lastra norte de la tumba Gaudo 2/1957. En cambio en la tumba recuperada por la Guardia di Finanza de la necrópolis Spinazzo y en la tumba llamada tomba del Magistrato, de la misma necrópolis, todos los personajes aparecen pintados con sandalias (vid. Pontrandolfo, 1996a, 282-286). 


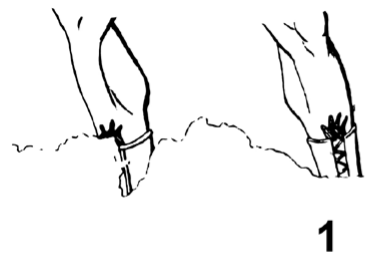

Lastra 1

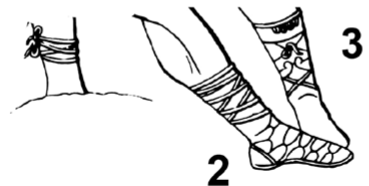

Lastra 2
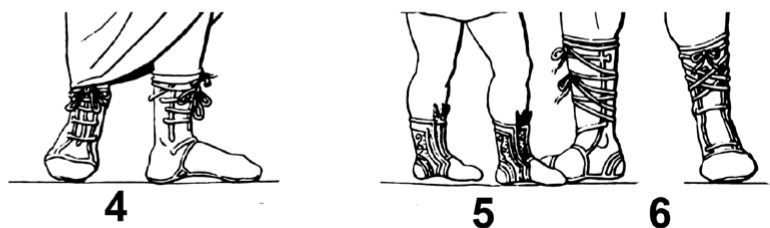

Lastra 3

Figura 15: Particular del calzado pintado en la tumba. A partir de Minervini, 1856, Tav. IV-VI.

cerrada y, en un único caso (Fig. 15.2) a una crepida o sandalia abierta. De todos modos, los estudios sobre calzado antiguo permiten algunas precisiones acerca de los distintos tipos (Dohan Morrow, 1985; Goldman, 1994), principalmente de las botas ${ }^{66}$, pues cada uno presenta particularidades que refuerzan el realismo de la pintura. En cualquier caso, la identificación de calzado abierto como 'griego' y calzado cerrado como 'romano' es un discurso no aplicable para el caso de un contexto lucano pues la caracterización de su indumentaria admite un variado número de tipos de calzado (Vid. Schneider-Hermann, 1996, 20-37) y precisa de un estudio particular, aún pendiente.

Las botas del guerrero de la lastra 1 (Fig. 15.1), incompletas, corresponden a unas botas lisas, con apertura frontal, cerrada por la tensión cruzada de los cordones. Estas encuentran similitud en las que aparecen representadas sobre el guerrero derrotado de la crátera de la colección Astarita, hoy en los Museos Vaticanos (Moreno, 1994, fig. 87). Las botas abiertas tipo crepida, de la lastra 2 (Fig. 15.2), son un calzado prevalentemente militar con gruesa suela de ascendencia macedonia (Coarelli, 1981, 241-242), presentan una perduración y uso de muy largo recorrido temporal en el que evolucionarán a lo que los romanos llamaron caliga, pues se documentan especialmente en representaciones helenísticas como la columna de Efeso (BM n. 1206), en Olimpia (n. 269), en el monumento de Daochos I en Delfos y abundantemente en el altar de Pérgamo (Gigantomaquia, Lastra de Telefos o cortejo de Agamemnon). Las Botas tipo 3 (Fig. 15.3), otro tipo de calcei respecto a los vistos en la lastra 1, presentan un sistema de lazo superior que dejaría una superficie lisa en la mayor parte del tobillo y el pie. Este tipo encuentra representaciones en equipos de caballeros montando a caballo. Las botas del $\mathrm{Pa}$ ter Familias, en la lastra 3 corresponden al Calceus Patricius (Fig. 15.4). Las botas del individuo infantil (Fig. 15.5) corresponden a unas botas de parada infantiles que Goldman ha clasificado como tipo W (Goldman, 1994, 102). Finalmente, las botas del guerrero de la lastra 3 (Fig. 15.6) corresponden al tercer tipo de

66. También llamadas calcei, endromides o embades, en función del tipo y momento. calcei militares representados en la tumba. Botas similares son las presentes en la métopa de Via Calabria de Tarento, con representación de Pirro (Moreno, 1994, fig. 88 y 129), en el pie derecho del Apolo de Epidauros (NM-Athens n.174) y en distintos personajes del cortejo de Agamenón y de la Gigantomaquia del Altar de Pérgamo.

Los escasos paralelos son suficientes para mostrar cómo cada personaje presenta el calzado adecuado a su condición. De esta manera, los tres guerreros llevan calcei que corresponden a un calzado masculino y, normalmente, asociado a caballeros, el Pater Familias lleva el calzado de senior, el individuo infantil presenta un calzado de parada que recuerda su pertenencia a una estirpe privilegiada y, por último, el vencido es el único que presenta un calzado abierto, claramente distinto del resto de los personajes de la tumba. El cuidado y selección de los modelos no es casual sino que forma parte de un meticuloso estudio previo en el que todos los detalles tienen como intención evidenciar una dicotomía entre los 'nuestros' y los 'otros'.

Esta dicotomía toma fuerza, como hemos visto, en la utilización de una iconografía habitual en la cerámica ápula para expresar la dualidad entre el héroe y el bárbaro. Así, además de los detalles particulares, sobresale el recurso de la Amazonomaquía y la Iliupersis, claramente iconografías foráneas a la tradición pictórica pestana, lucana y campana. Tal iconografía se convierte en evidente transmisor, en Italia ${ }^{67}$, del modelo de representación ${ }^{68}$ de las luchas entre griegos y 'los otros', que en este caso podemos interpretar como derivada de la lucha entre Tarento y Roma.

\section{PRECISIONES ANTICUARIAS}

El análisis de la decoración de la panoplia de los guerreros y de los caballos aporta elementos de discusión

67. El mismo esquema encuentra representaciones próximas en el Mausoleo de Alicarnaso (Lastras VIII, IX, XV y XVI).

68. Para la escena de la lastra izquierda cabe recordar la representación de la crátera H.3256 del MAN-Napoli (Moret, 1975, N. 82.1), mientras que para la escena de la lastra derecha la reproducción de Tischbein II.2 (Moret, 1975, N. 83.2). 
y filiación importantes pese a las limitaciones para analizar el conjunto, que completan aspectos ya avanzados en cuanto a iconografía.

Recientemente, A. Bottini ha estudiado el armamento representado sobre el sarcófago delle Amazzo$n i$, que es, quizás, el mejor paralelo de la tumba que aquí se analiza. Bottini indicaba la estrema cura con la que habían sido reproducidas las armaduras (cascos, cnémides y corazas) en aquél sarcófago (Bottini y Setari, 2007, 74), tanto como ocurre en las pinturas de esta tumba. El ejemplo y resultados del estudio anticuario de las armas del sarcófago de Tarquinia nos anima en este estudio.

\subsection{LA PANOPLIA PINTADA}

El detalle de las armas representadas en las pinturas de la tumba permite una identificación tipológica precisa para los principales elementos de la panoplia defensiva. En cambio, las armas ofensivas no admiten identificación ninguna a causa de un trabajo grosero que descuidó su detalle, seguramente, por su recurrencia ${ }^{69}$. Tal es el detalle de la panoplia defensiva que permite una identificación tipológica con concretas implicaciones históricas. Esta precisa reproducción rebate la duda de quien ante tal excepcionalidad sugiriera se tratara de una invención deliberada por parte de los descubridores o investigadores que las publicaron. El estudio anticuario de los elementos pintados asegura la imposibilidad de una invención de las panoplias representadas dada la coherencia tipológica y cronológica de todos los detalles, imposibles de conocer en el momento de su publicación.

\section{Cascos}

La representación de los cascos en esta tumba es compleja y variada (Fig. 16). La tipología de los cascos, para los que se ha avanzado que corresponden a tres tipos distintos (tipo ático para la lastra 1, tipo Pacciano/Catanzaro, para las lastras 2 y 3 , y tipo Conversano en la Lastra 2), responde a una lógica ya advertida en otros casos (sarcófago delle Amazzoni) que evidencian la diversidad y heterogeneidad de los cascos usados por un mismo grupo aunque no es descartable que tenga también unas implicaciones narrativas que aquí escapan ${ }^{70}$ y que tengan que ser analizadas conjuntamente

69. En cambio, otros contextos pintados, por ejemplo el de la tumba de Egnatia recuperada a mediados del s. XIX o las tumbas macedónicas a las que hemos hecho referencia anteriormente, muestran un detalle exquisito para las armas ofensivas (particularmente espadas).

70. Bottini, 2007, 15, también indica este elemento en relación al citado sarcófago de Tarquinia, proponiendo que pueda aludir a criterios de edad.

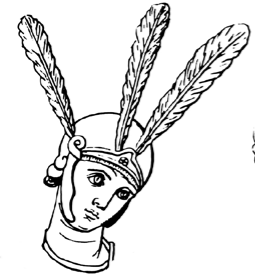

Lastra 1

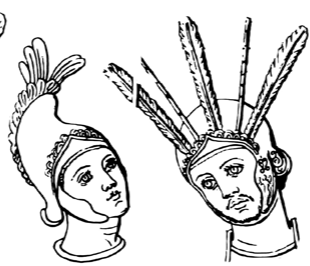

Lastra 2

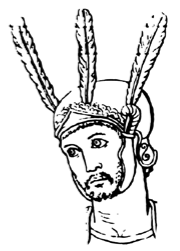

Lastra 3
Figura 16: Particular de los cascos pintados en la tumba. A partir de Minervini, 1856, Tav. IV-VI.

con las diferencias entre los elementos aplicados sobre ellos (alas, pteroi / pinnae y cannulae) ${ }^{71}$.

La pluralidad tipológica de los cascos contrasta con la información que aporta el registro documental de las otras pinturas pestanas, donde los cascos áticos son el tipo prácticamente exclusivo para los guerreros pestanos. En cambio, en contextos campanos, los cascos pintados muestran una mayor variedad de tipos (Italo-calcídicos ${ }^{72}$, Montefortino $^{73}$ y áticos ${ }^{74}$ ), igual que las corazas (anatómicas largas ${ }^{75} \mathrm{y} \operatorname{cortas}^{76}$, no documentándose las trilobuladas, exclusivas de representaciones del Ager pestano) y los escudos ${ }^{77}$. Esto no debe confundirse con una mayor permeabilidad de las poblaciones campanas en cuanto a adopción e innovación del armamento, pues la diversidad tipológica representada en contexto pestano es también amplia ${ }^{78}$.

Mientras que el registro de armas documentado en área campana es menor que el de los tipos representados en sus pinturas, el registro material de los contextos pestanos demuestra una importante variedad de tipos tanto de corazas (tanto las corazas anatómicas largas y cortas como las corazas trilobuladas, faltando

71. Sobre el argumento vid. Castrizio 2007; Graells y Mazzoli, 2013.

72. Capua Cappella dei Lupi C.1 (con pluma central y dos cuernos semilunados); Capua Fondo Tirone C.11 (2 representaciones en un duelo, sin decoración); Capua C.14 (con aletas, cresta y dos plumas); Capua San Prisco C.27 (sin decoración); Nola Via Seminario N.6; Nola Cimitille (con 2, 5 y 3 plumas cada uno de ellos).

73. Nola Via Seminario N.4 (con cuernos, uno dorado y el otro argénteo?).

74. Capua C.19 (con cresta y dos plumas); Capua San Prisco C.29 (con cresta y dos plumas y un segundo ejemplar con dos plumas), C. 31 (con cresta y dos plumas).

75. Nola Via Seminario N.4.

76. Nola Via Cimitille N.8.

77. Aunque aquí no sirve para la discusión, es significativo identificar la presencia de escudos circulares (N.8, C.11), escudos circulares con nervio (N.4) y escudos ovales con nervio (C.1, C.31).

78. El caso del Abbruzzo y del Molise, por ejemplo, también evidencian arqueológicamente una circulación importante en cuanto a número de tipos de armas distintas (Tagliamonte, 2003), hecho que debe hacernos pensar que las diferentes culturas de la Italia centro-meridional tendrían un comportamiento similar en cuanto a permeabilidad y adopción de innovaciones militares y técnicas de orígenes distintos. 


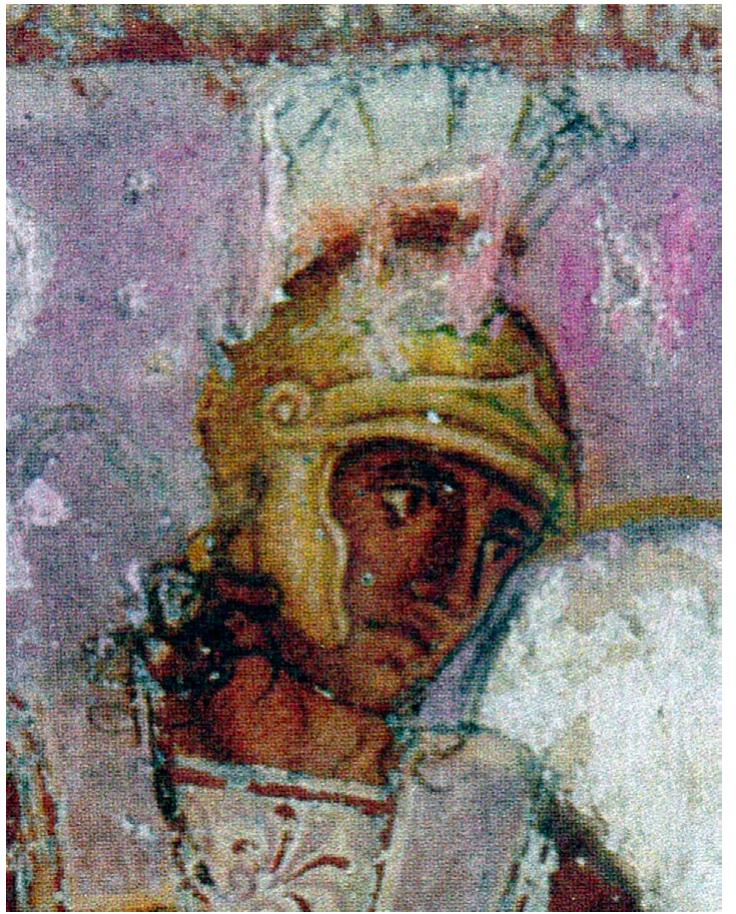

Figura 17: Particular del Guerrero Griego 8 del Sarcófago Delle Amazzoni. A partir de Bottini y Setari, 2007, 42, Fig. 19.

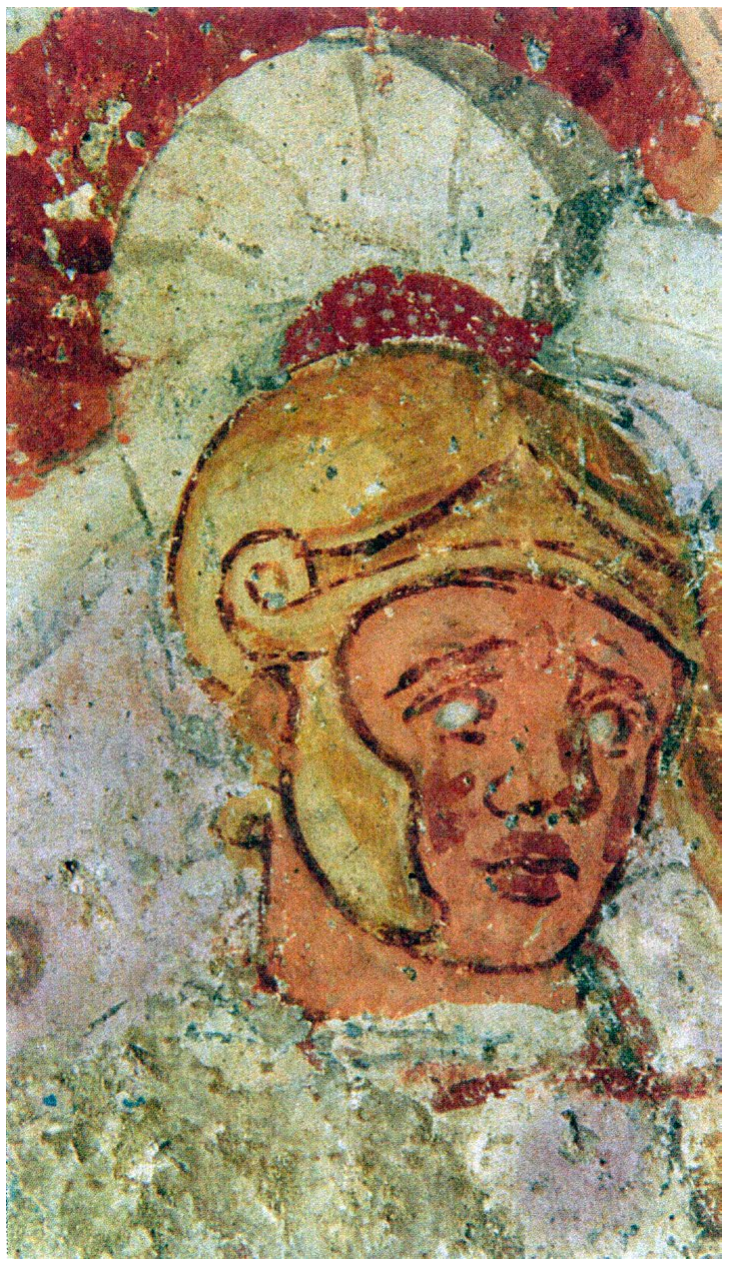

Figura 18: Particular del Cuerrero Griego 20 el Sarcófago Delle Amazzoni. A partir de Bottini y Setari, 2007, 66, Fig. 8. únicamente las corazas cortas con detalle anatómico esquemático, Vid. Graells, 2012) como los cascos (cascos calcídicos, italo-calcídicos y a pilos).

El detalle de las representaciones aporta ulteriores matices: así, la posición y detalle del casco de tipo ático y la cabeza del guerrero de la lastra 1 coincide con la de los guerreros Griegos 8 y 20 del sarcófago delle Amazzoni (Fig. 17 y 18) (Bottini y Setari, 2007, 42, fig. 19; 66, fig. 8). Las diferencias entre los dos cascos son los elementos aplicados, tres plumas en el de Paestum y un alto lophos blanco en el tarquinés. Por el contrario, particularmente próximos son los frontones sobre la frente de los cascos, terminados en un giro sobre el arranque del paragnátide anatómico, liso y articulado que puede asimilarlos a los cascos italocalcídicos de tipo B.I.

El tipo de paragnátides, más largo y articulado que los documentados sobre las producciones italo-calcídicas que encontramos en área lucana o campana, y más largo y esbelto que los representados sobre pintura vascular o funeraria en área campana y pestana ${ }^{79}$, encuentran paralelos en producciones ápulas y de la Basilicata, sobre cascos de tipo Pilos o sobre el mismo casco de Conversano.

En cualquier caso, la presencia de representaciones de cascos de tipo ático en Paestum es habitual, con mayor o menor detalle de las representaciones. En cambio, el resto de cascos son excepcionales o directamente únicos.

El detalle de las representaciones de los cascos de las lastras 2 y 3 , con indicación de una decoración sobre la frente que simula el cabello destaca por la nitidez de la realización. Más aún cuando en el momento del descubrimiento y reproducción de los dibujos de las pinturas de la tumba sólo se conocían dos realia - Bibliothèque Nationale - Paris N.2023 (Fig. 20) ${ }^{80}$ y Musei Vaticani N. 12304 (Fig. 22) ${ }^{81}$-, que difieren de los que se representaron en las pinturas de la tumba tanto por su riqueza como por su forma y detalle. Los paralelos

79. Para los paragnátides decorados con representaciones antropomorfas vid. Graells, 2011, 29-31. Los paragnátides representados sobre las pinturas campanas y pestanas corresponden a tres tipos particulares, distintos de los realizados en esta tumba:

- Paragnátides triangulares (normalmente relacionados con cascos de tipo calcídico o italo-calcídico): C.1, C.19, C. 29 , C. 31, N.8; Andriuolo 11, 12, 84, 86, 90, tumba de 1937, 24/1971; Sequestro Finanza 1; Vannullo 4; Laghetto X.

- Paragnátides anatómicos (relacionado con un casco de tipo Montefortino): N4.

- Paragnátide redondo (relacionado con cascos áticos, italo-calcídicos y calcídicos): Gaudo 2/1957, 7/1972; Laghetto III, X; Andriuolo 28 y 53.

80. Descubierto, posiblemente en Herculano y adquirido por el Rey de las dos Sicilias y, posteriormente, por el Conde de Caylus (Adam, 1982, 8, nota 1).

81. Sin procedencia, pero ya publicado en el catálogo del $\mathrm{Mu}-$ seo Gregoriano de 1842 (Adam, 1982, 11, nota 9). 
físicos proceden de hallazgos posteriores: Casco de Pacciano (descubierto en 1880) (Fig. 19), Casco de Catanzaro (publicado en 1881) (Fig. 21), Casco de la Bibliothèque Nationale - Paris N. 2022 (Publicado en 1895) (Fig. 25), Casco del Museo Poldi Pezzoli N. 2426 (publicado en 1912), casco del Louvre N. Inv. 7240 (publicado en 1896) (Fig. 24) (Lipperheide, 1896, 148, N. 358; Dintsis, 1986, 218, Taf. 19.4) y Casco de Conversano (descubierto en 1957) (Fig. 23), además de los cascos de la colección Ceccanti y el Getty Museum N. Inv. 80.AC.12. Así se ratifica la veracidad y fiabilidad de las representaciones que se muestran.

Resulta extraordinaria la representación de los cascos Pacciano-Catanzaro, como claros transmisores de unos contactos hacia el área ápula y la Basilicata, además de aportar datos precisos acerca de una cronología a finales del s. IV a.C.

A pesar de esto, el análisis anticuario considera el encaje de los cascos pintados en la tradición local pestana particularmente clara, como elementos adoptados e integrados en un imaginario lucano. Especialmente evidente por lo que a la decoración de plumas y a su disposición transversal se refiere ${ }^{82}$. El resto de la decoración la integran cánulas, en el casco de la lastra 2, para las que no disponemos de paralelos; y, en la lastra 3, con el acabado del casco con dos aletas metálicas que hallazgos posteriores al descubrimiento de la tumba, como el casco de Conversano o en le la Bibliothèque Nationale N. Inv. 2022, han confirmado como elementos frecuentes en este tipo de cascos.

En las tres pinturas del guerrero, la decoración común de los cascos son tres plumas blancas dispuestas de manera transversal y sobre la frente, a modo de tiara o de pterinos stephanos (Fig. 16). Un reciente estudio ha identificado este sistema como la aplicación de estructuras de tridente, en bronce o en hierro, para el que se propone una finalidad para sostener elementos aplicados perecederos como plumas u otros (Graells y Mazzoli, 2013). En contextos suritálicos, pestanos y campanos, se trata de unas estructuras en tridente y de combinaciones de tres cánulas ${ }^{83}$ y diademas con cánu-

82. Los cascos representados en tumbas pestanas se organizan aquí en función de su decoración:

Sin decoración: Andriuolo 114; Laghetto LXIV, X, III; Contrada Vecchia di Agropoli T.11/1967; Gaudo 2/1957; Sequestro Finanza 1.Con aletas laterales: Vannullo 2 (2).

Con cresta: Andriuolo 90 (2), 104 (3); 58 (2), 4/1971 (2);

Arcioni 271/1976; Porta Aurea tumba de 1805; Gaudo 1/1972 (3); Vannullo 1, 3, 4; Sequestro Finanza 2; Lastra indeterminada.

Con dos plumas: Andriuolo 53, de 1937; Laghetto LXIV; Gaudo 2/1957.

Con dos plumas y cresta: Andriuolo 12, 28 (2), 53, 58, 48 (2), 84, 86, 114 (3), 24/1971, de 1937; Laghetto LXIV; Contrada Vecchia di Agropoli T.11/1967; Gaudo 7/1972 (2), 2/1972 (2); Sequestro Finanza 1.

83. Ejemplar de la tumba 164 de la necrópolis Paestum-Gaudo, con dos cánulas aplicadas sobre el lado derecho y en posición central a la frente, faltando la cánula izquierda, de la

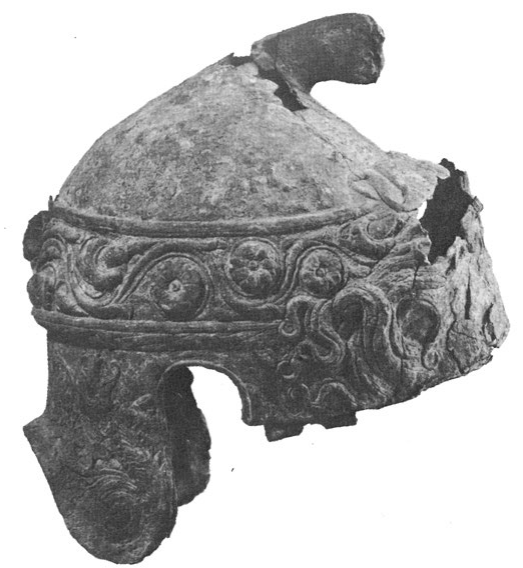

Figura 19: Casco de Pacciano. A partir de Adam, 1982, pl. III.a

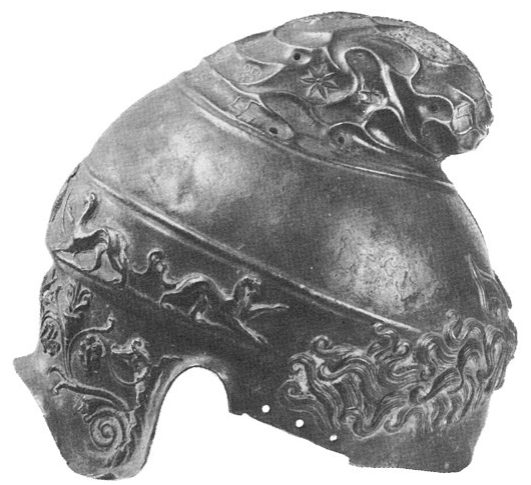

Figura 20: Casco de la Bibliothèque Nationale - Paris 2023. A partir de Adam, 1982, pl. I.a.

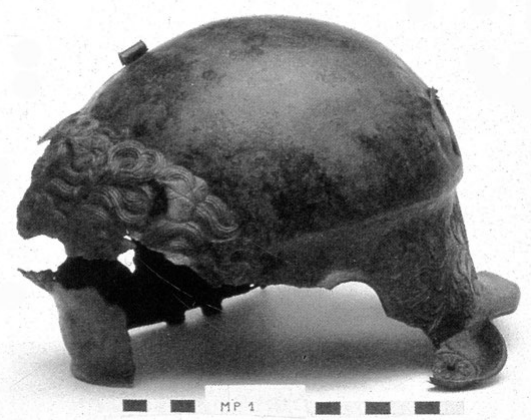

Figura 21: Casco de Catanzaro. A partir de Guzzo, 1990, fig. 8.

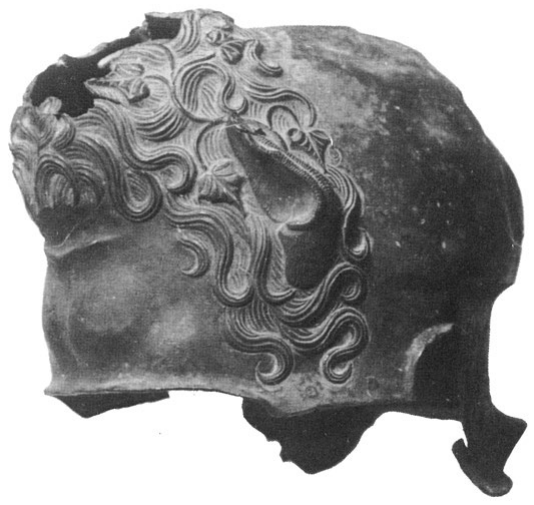

Figura 22: Casco de los Musei Vaticani. A partir de Adam, 1982, pl. VI.a. 


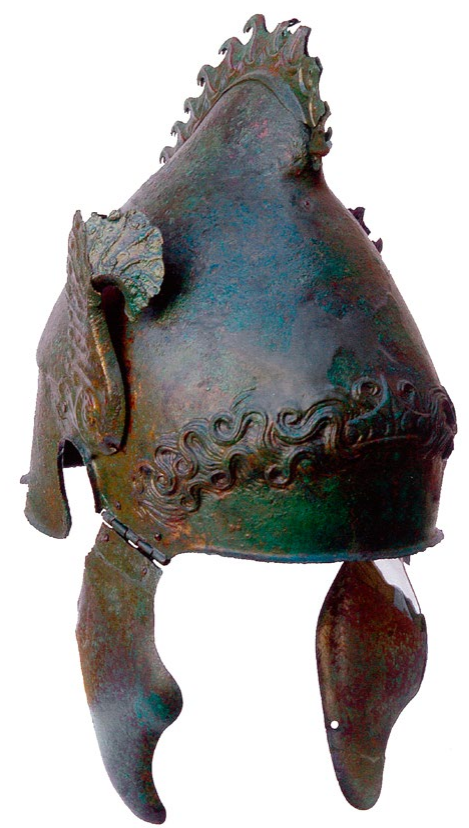

Figura 23: Casco de Conversano. A partir de Mostra Trento, 2011.

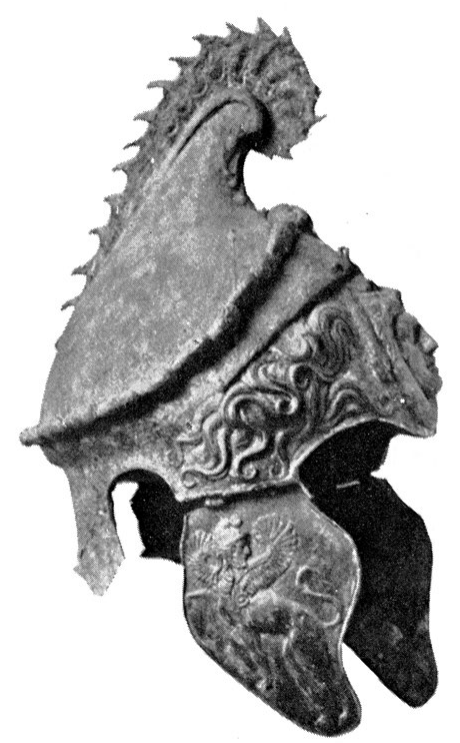

Figura 24: Casco del Louvre 7042. A partir de Dintsis, 1986, Taf 19.4.

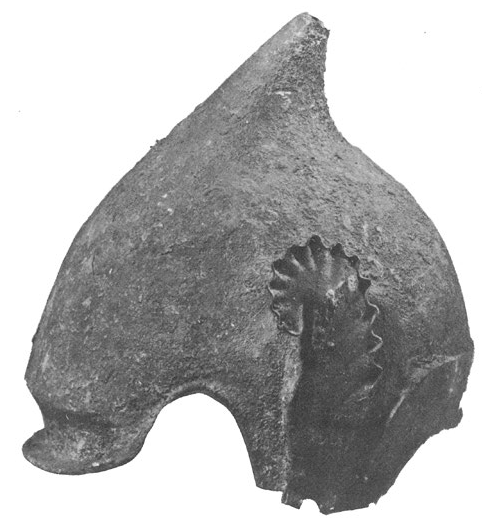

Figura 25: Casco la Bibliothèque Nationale - Paris 2022. A partir de Adam, 1982, pl. II.b.

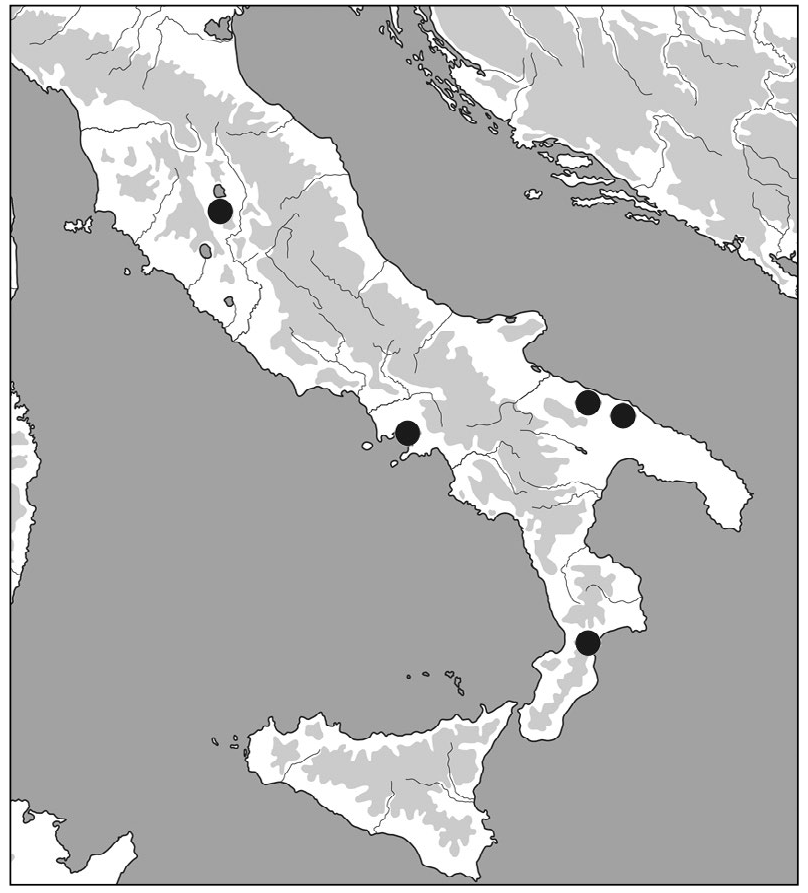

Figura 26: Mapa de distribución de los cascos de tipo PaccianoCatanzaro. (C) Dibujo R. G.

$\operatorname{las}^{84}$ de bronce que se documentan en área campana y lucana. Esta decoración encuentra correspondencia en la cabecita de terracota de la Stipe de Presenzano que representa a un guerrero con casco y cinco agujeros para fijar plumas, dispuestos de manera transversal sobre la frente del casco (Johanowski, 1990, Tav. X.2) ${ }^{85}$. La mayor concentración de dichos elementos, y de sus representaciones, como también de otros tipos de decoraciones sobre cascos, se documenta de manera notoria en el sur de la Península Italiana. Si por un lado pueden recordarse los guerreros pintados sobre algunas de las tumbas de la necrópolis de Paestum

que sólo quedan trazas de soldadura. El caso corresponde a un tipo italo-calcídico BI de Bottini y el conjunto se ha fechado entre 380-370 a.C.; sobre los ejemplares de la antigua colección Guttmann AG 521/H 174 (Hermann Historica 7-Oct.-2009, Lote 173), AG 173/H29 (Hermann Historica 11-Abr.-2008, lote 322) y (Christie's 28-abril-2004, lote 101).

84. Sobre el ejemplar de la tumba 37 de la necrópolis de Santa Croce en Eboli (Longo y Viscione, 1996, 80-81), que corresponde a un casco italo-calcídico de tipo BII de Bottini fechado entre el 340-330 a.C., se dispone una diadema con tres cánulas remachada de manera transversal; similar a este ejemplar podría considerarse el ejemplar del British $\mathrm{Mu}$ seum adquirido como procedente de Vulci (1842,0728.711), que también corresponde a un casco de tipo italo-calcídico con una diadema de la que se conserva sólo la cánula lateral izquierda; sobre tres ejemplares de la antigua colección Guttmann (Hermann Historica 19-Oct.-2005, lote 156 y lote 158, Christie's 28-abril-2004, lote 97).

85. Por otro lado, A. Bottini (1991) recopilaba un numeroso elenco de cascos de tipo suritálico-calcídicos con elementos para soportar las plumas. 

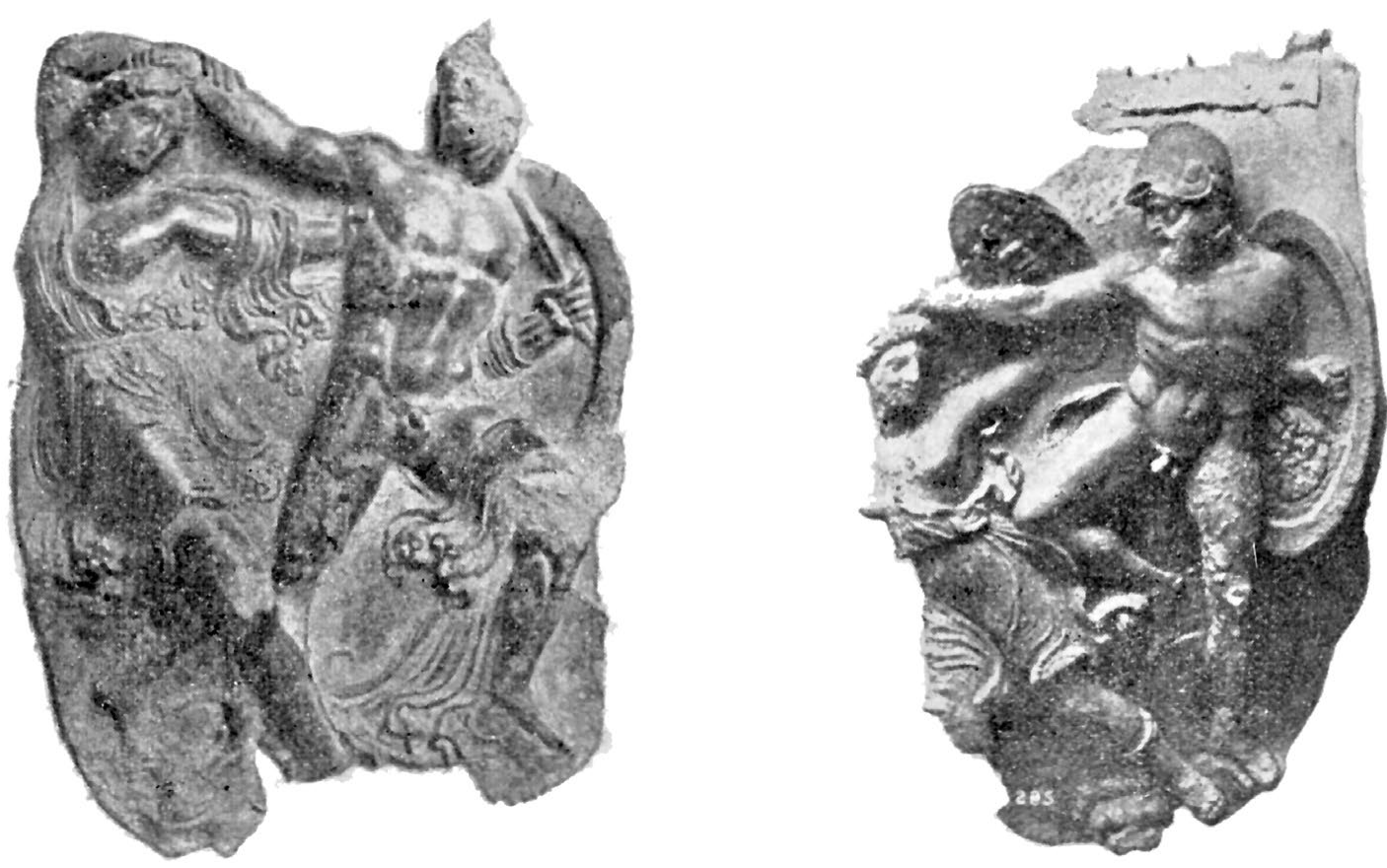

Figura 27: Bronces del Siris. A partir de Hagemann, 1919, Abb. 74 y 75.

y Capua y en numerosísimos vasos suritálicos, con una cronología de siglo IV a.C. en adelante, debemos volver un poco hacia atrás y referirnos a la presencia, ocasional, de 'cánulas' sobre los cascos de tipo ápulocorintio (desde finales del s. VI a.C. hasta mediados del s. IV a.C.). Destaca especialmente la progresiva adopción (desde el segundo cuarto del siglo IV a.C.) de estos elementos sobre los cascos ítalo-calcídicos ${ }^{86}$ del área campana próxima a la Campania etrusca (Sannibale, 2008, 225). En cronología poco posterior (se-

86. Los ejemplares de soportes laterales recopilados por Bottini (1991, 97-98), denominados por el investigador italiano como tubicini reggi-piume, son: ejemplar de Ruvo en Karlsruhe (N.A.1); Paestum Spinazzo-Parco del Fuscillo (Sestieri, 1957, 178) (N. A.2); de Cumas en el British Museum, N. Inv. 1915, 7-13.8 (N. B.14); Paestum-Gaudo t.II (Pontrandolfo y Rouveret, 1992, 380-385; Sestieri, 1958) (N. B.18); Paestum-Gaudo t.X (N. B.19); Tumba 174 de la necrópolis Gaudo de Paestum (Viscione, 1996, 149-153, Nr. 58.10); Tumba 164 de la necrópolis Gaudo de Paestum (Viscione, 1996, 155-157, Nr. 61.6); Tumba 37 de la necrópolis Santa Croce de Eboli (Longo y Viscione, 1996, 78-81, Nr. 36.35); Hermitage, San Petersburgo (N. B.20); Louvre, Nr. 1129De Ridder (1913-1915, Tav. 66-N. B.25); Musei Vaticani N. Inv. 34838-34839 (Sannibale, 2008, 222-226, Nr. 136); a los que podría añadirse el casco del British-Museum ex colección Burgon de confirmarse su procedencia de las cercanías de Nápoles (Bottini, 1991, 97-98; Kemble, 1863, 170, Tav. XII.4, citado en Sannibale 2008, p. 225) y no en Vulci, como propuso Walters $(1899,342)$. Con una funcionalidad similar, quizás puedan entenderse las espirales aplicadas sobre algunos cascos italocalcídicos, normalmente en número de 2, y sobre un casco de tipo Montefortino con tres espirales en la misma posición transversal que las cánulas (MAN-Saint Germain en Laye N. Inv. 4760). gunda mitad del s. IV a.C.) se documenta el casco de la tumba Scocchera A de Canosa que coincide con la cronología y el área del probable hallazgo de una serie de cascos con decoraciones similares en distintas colecciones particulares ${ }^{87}$.

Este tipo de decoración se ha observado, en Italia, con una mayor antigüedad para cascos del área suritálica y campana (Graells y Mazzoli, 2013), sin duda en relación con lo observado por D. Castrizio a partir de la iconografía numismática griega, donde este tipo de elementos se desarrollarían a partir del s. V a.C. (Castrizio, 2007). Su posición, sistemáticamente transversal sobre la frente, con soportes en bronce, encuentra en la pintura vascular y funeraria la evidencia de la inserción de materiales orgánicos (principalmente plumas).

Relacionado con esta decoración cabe indicar la presencia, en la lastra 3, de alas aplicadas a los laterales del casco. Este elemento, que encuentra sus primeras evidencias iconográficas sobre algunas emisiones anatólicas (Castrizio, 2007, 82-84), cuando se asocian a elementos áticos o de la órbita greco-occidental deben considerarse como un elemento de mando militar de origen itálico (Castrizio, 2007, 85-86). La distribución de los realia, confirman esta idea al concentrarse, mayoritariamente, en área lucana.

Un último detalle decorativo, relevante, es la representación de paragnátides decorados en el casco del héroe de la lastra 2 . Se trata de la indicación de una decoración de tipo figurativo que se aproxima a

87. Dos ejemplos de ellos en Cahn, 1989 (W.23a y W24a), otro en el Metropolitan Museum NY (Richter, 1915, 418, Nr. 1552) y de la colección Guttmann (distintas subastas en Christie's y Hermann Historica). 


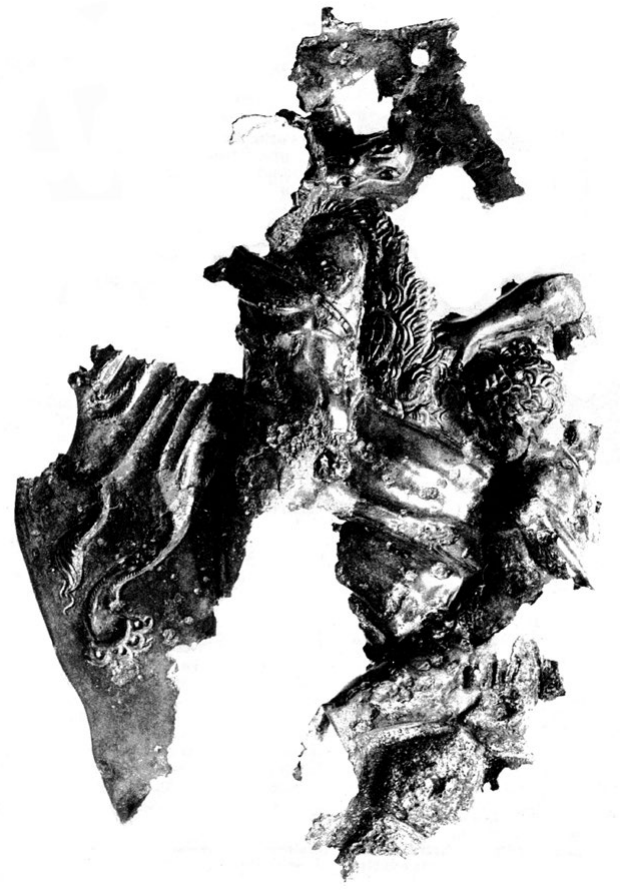

Figura 28: Paragnátide figurada con escena heraklea procedente de Pietrabbondante. A partir de D’Agostino, 1980.

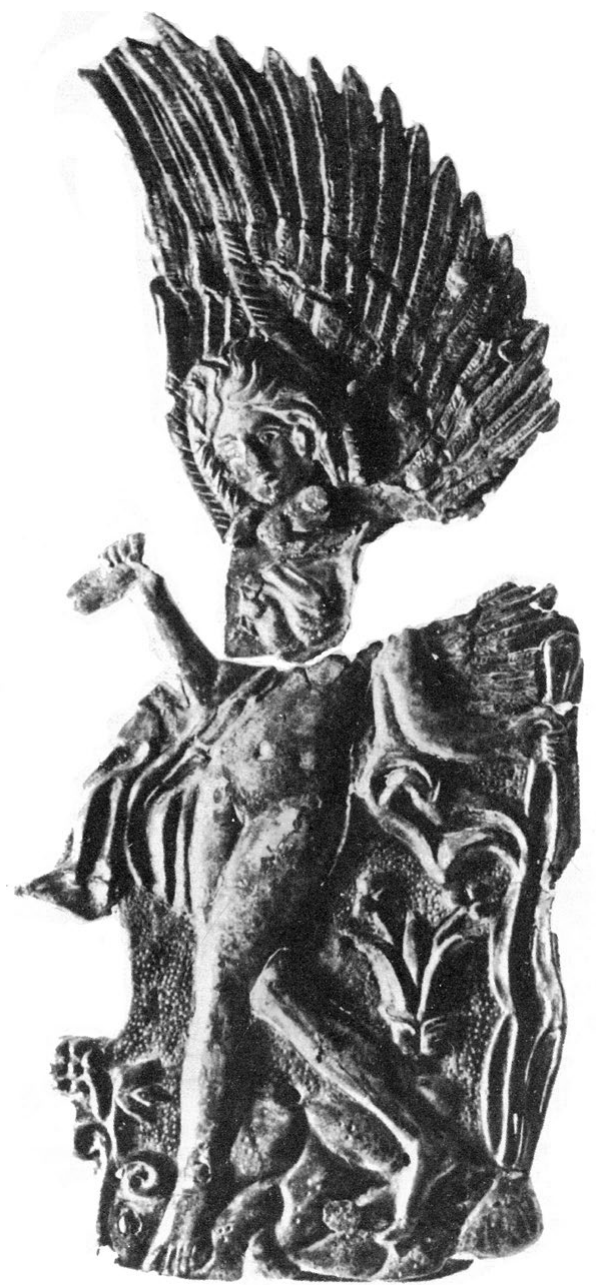

Figura 29: Aleta figurada con Niké alada procedente de Pietrabbondante. A partir de D'Agostino, 1980.

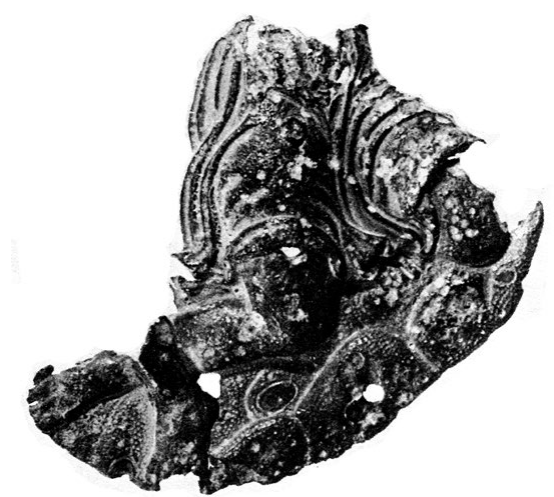

Figura 30: Parte inferior posterior de una paragnátide figurada procedente de Pietrabbondante. A partir de D'Agostino, 1980.

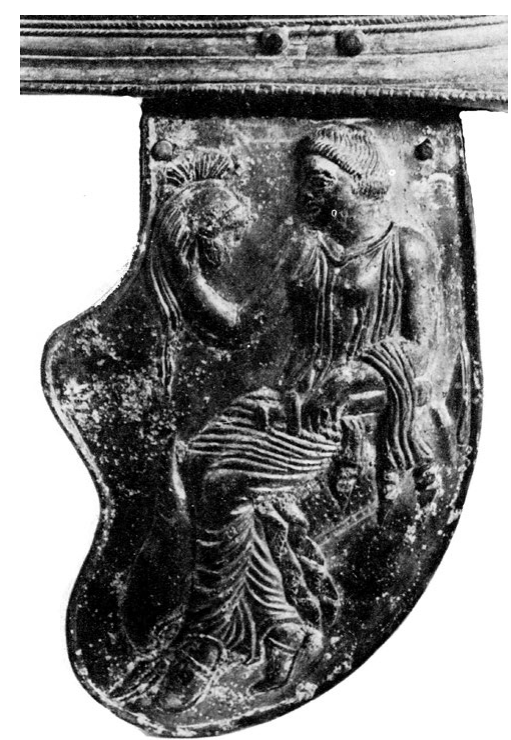

Figura 31: Paragnátide izquierda, figurada con Nereida con casco y espada, como parte del armamento de Aquiles, procedente de Pietrabbondante. A partir de D'Agostino, 1980.

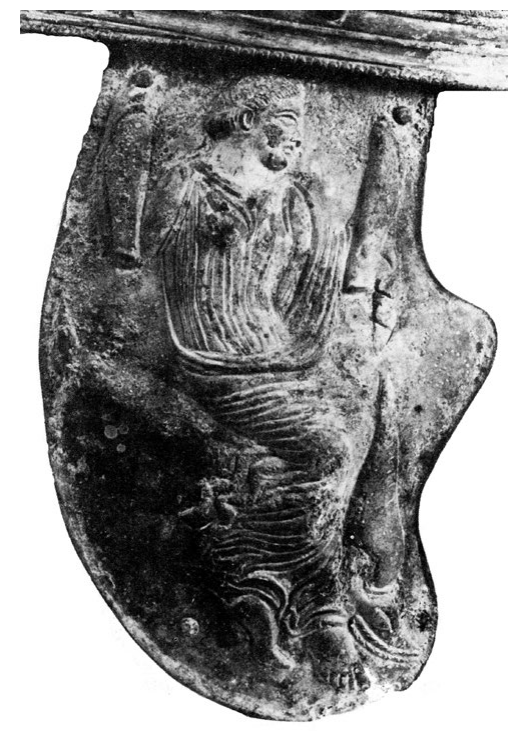

Figura 32: Paragnátide derecha, figurada con Nereida con pareja de cnémides, como parte del armamento de Aquiles, procedente de Pietrabbondante. A partir de D’Agostino, 1980. 


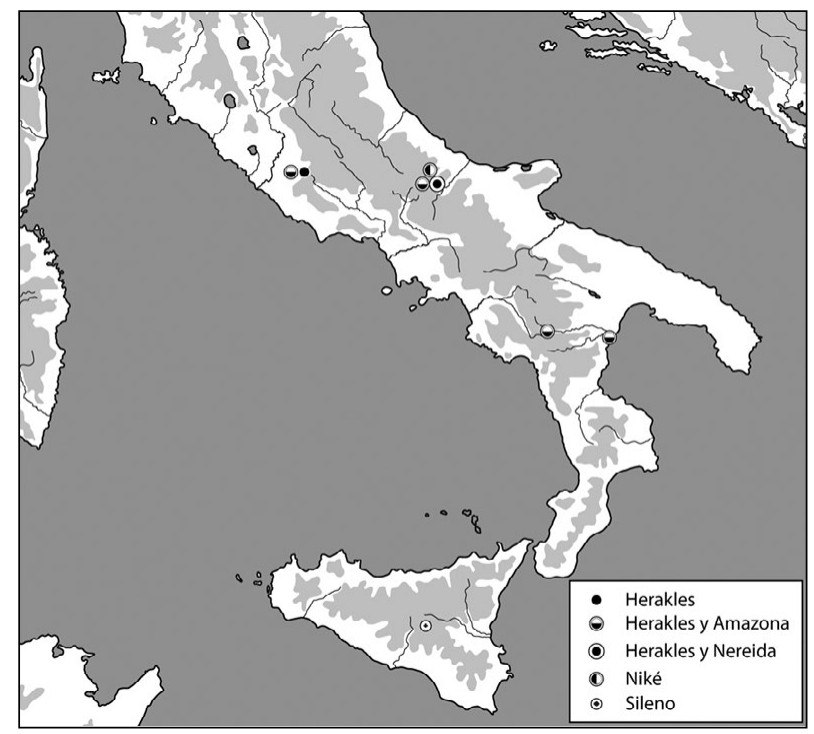

Figura 33: Mapa de distribución de las paragnátides decoradas con figura. (C) Dibujo R. G.

lo observado en las hombreras de las corazas (Guzzo, 1993, 167-168; Vermeule et alii, 1988, 94 n. 119; Tagliamonte, 2002-2003, 102, nota 42), con numerosos paralelos reales (Figs. 27, 28, 29, 30, 31 y 32), pero que contrasta con los paragnátides del resto de cascos representados en la tumba ${ }^{88}$. De esta manera, los dos cascos de tipo Pacciano/Catanzaro documentados en la tumba, que a nivel de influencias se han relacionado con los influjos tarentinos de finales de s. IV a.C. (Adam, 1982, 25-26) (Fig. 26), permiten con este detalle una última consideración: Si recordamos los paragnátides decorados y analizamos su distribución y producción vemos una compleja distribución que afecta áreas alejadas de la zona de Paestum (Graells, 2011) (Fig. 33):

\section{Corazas}

La representación pintada de corazas anatómicas es un motivo especialmente escaso en contextos funerarios $^{89}$, documentándose únicamente en la tumba François ( 2 casos), la tumba Giglioli ( 2 casos), en el sarcófago delle Amazzoni (Guerrero n.3) (Fig. 38), la tumba de Nola Via Seminario N.4, las tumbas 28 (Fig. 35) y 61 (Fig. 36) de Paestum-Andriuolo y otra más de Paestum, sin contexto preciso (Fig. 37). Normalmente las corazas aparecen pintadas en lo que se llama friso de armas, es decir, como un elemento expuesto y exhibido bien apoyado o colgado. Únicamente las corazas de la tumba François, del sarcófago de las amazonas y de la tumba de Nola, visten a guerreros.

88. Para una síntesis vid. Graells, 2011, 29-31.

89. Sobre pintura vascular, aunque no siendo habitual puede considerarse frecuente en producciones ápulas.

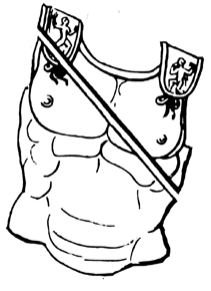

Lastra 1

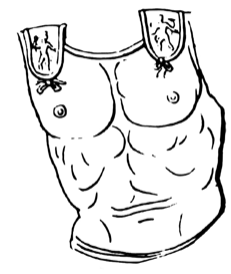

Lastra 2

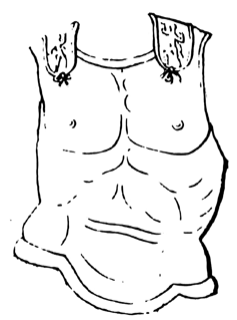

Lastra 3
Figura 34: Particular de las corazas anatómicas pintadas en la tumba. A partir de Minervini, 1856, Tav. IV-VI.

Cuatro casos a los que se suman ahora los tres de esta tumba (Fig. 34).

Las corazas anatómicas se representan con decoración complementaria en el sarcófago de las Amazonas (Bottini, 2007, 16, fig. 12-13) y en las tres corazas de la tumba pestana aquí en análisis: todas con hombreras decoradas con figura humana ${ }^{90}$, en lo que claramente corresponde a representaciones de un único personaje de pie, posiblemente una representación de Heracles (Bottini y Setari, 2007, 76, fig. 5). Este elemento, la hombrera o spallaccio, encuentra raros ejemplos metálicos, normalmente tardíos (como en Dodona, donde aparecen sin decoración figurada). Entre ellas destacan, especialmente las piezas de bronce con representación de amazonomaquia recuperados en el Siris (Fig. 27), hoy en el British Museum (BM.2 85) y que A. Russo ha demostrado como procedente de la zona de Armento (Russo, 1995, 14 y notas 65 y 66, con discusión).

En cualquier caso, la presencia de hombreras es desconocida sobre corazas anatómicas de bronce itálicas (Fig. 39), que su distribución concentra en el área central de la Italia meridional (Fig. 41). Por otro lado, aunque sin ser numerosa, su presencia se documenta en territorio epirota, macedonio (Guzzo, 1993, 167168; Tagliamonte, 2002-2003, 102, nota 42) o tracio, áreas de donde sería originario considerando la presencia de estos elementos sobre otras corazas como la coraza de tipo a corsetto de hierro de Vergina o la coraza anatómica, también de hierro, de Prodomi (Fig. 40). Si por un lado la cronología de las corazas anatómicas largas con adaptación ergonómica para montar a caballo no puede fecharse arqueológicamente en un momento anterior al 330 a.C., la presencia de hombreras rebaja ligeramente la cronología pues corresponde a un elemento tardío en la evolución de las corazas.

Si recordamos la excepcionalidad de las corazas anatómicas en la pintura funeraria, la representación de la

90. Añadiendo también el fragmento de pintura de la tumba 12 de Egnatia (Cat. Napoli, 1996, 165-166, Nr. 12.13), con representación de coraza a corsetto con dos spallacci decorados con Nikai. 


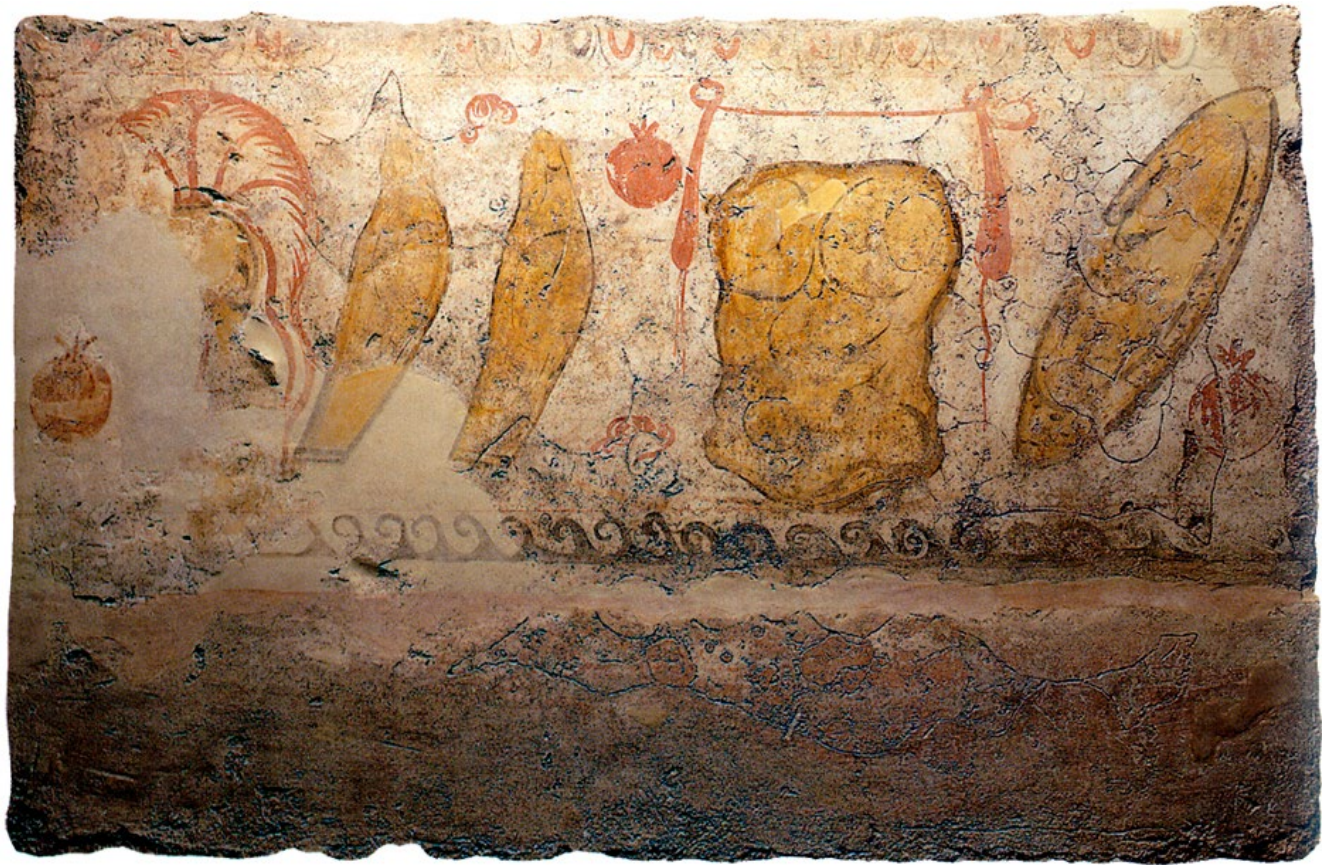

Figura 35: Lastra con friso de armas de la Tumba 28 Paestum-Andriuolo. A partir de Pontrandolfo y Rouveret, 1992 , p. 156.

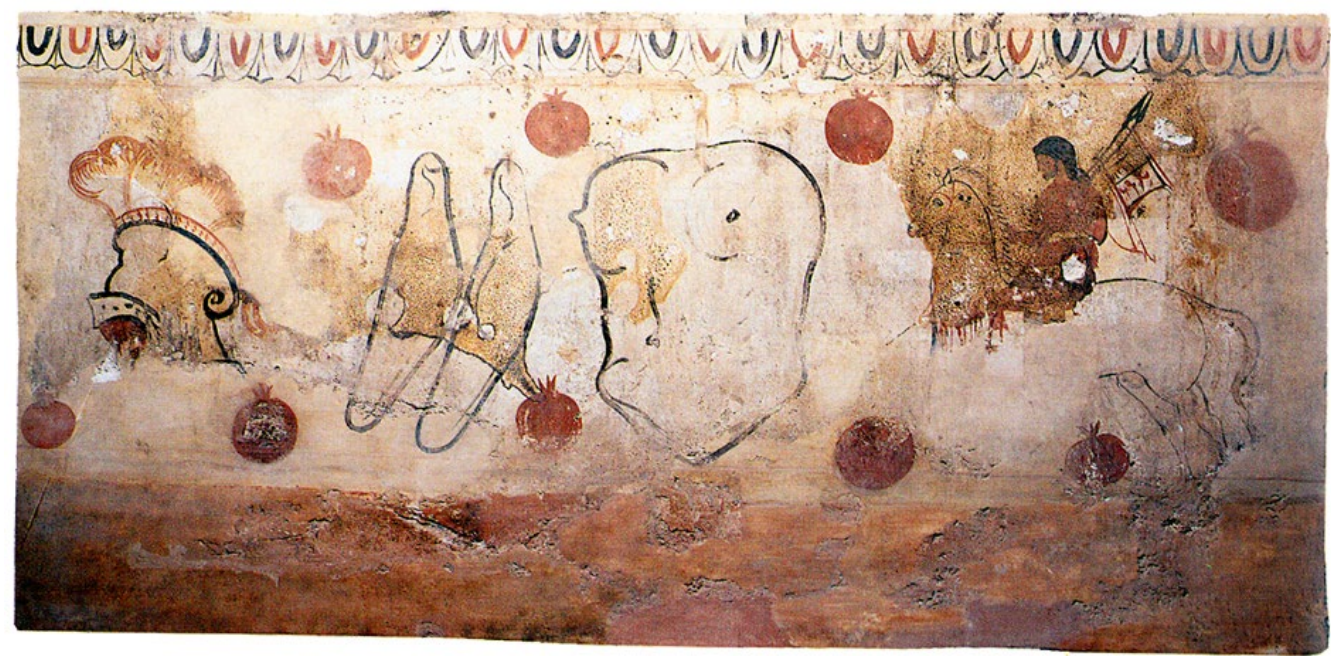

Figura 36: Lastra con friso de armas de la Tumba 61 Paestum-Andriuolo. A partir de Pontrandolfo y Rouveret, 1992 , p. 118.

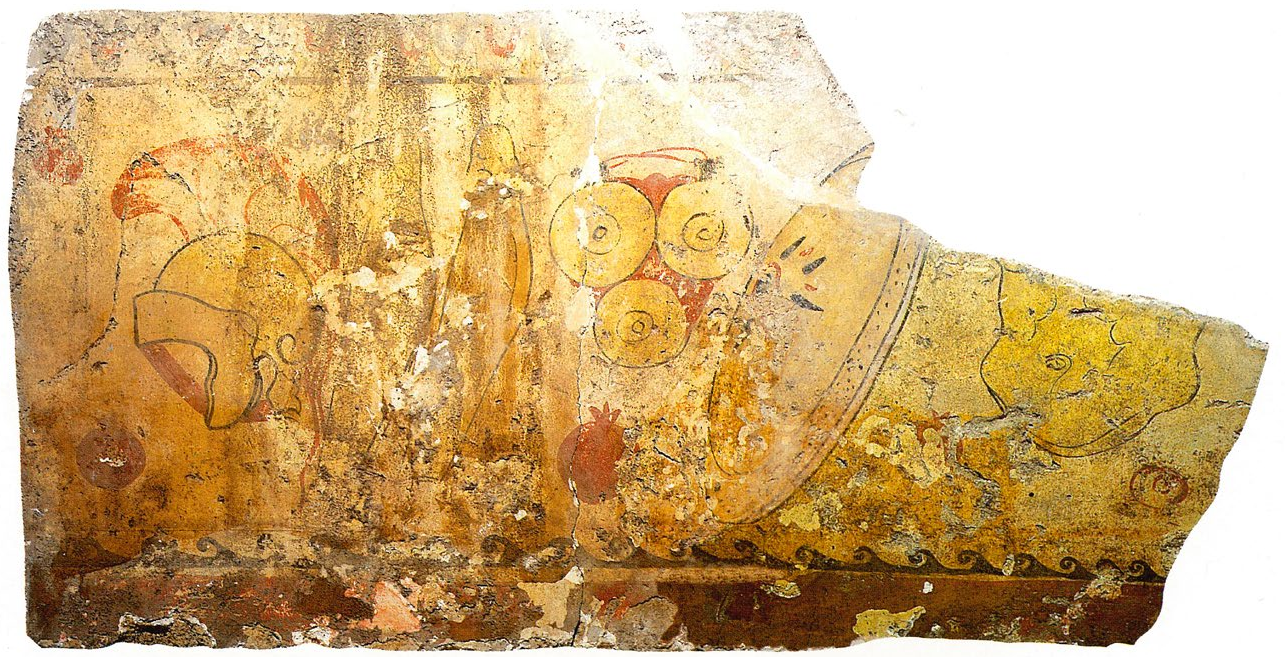

Figura 37: Lastra con friso de armas de una tumba sin Contexto de Paestum. A partir de Pontrandolfo y Rouveret, 1992, p. 302. 


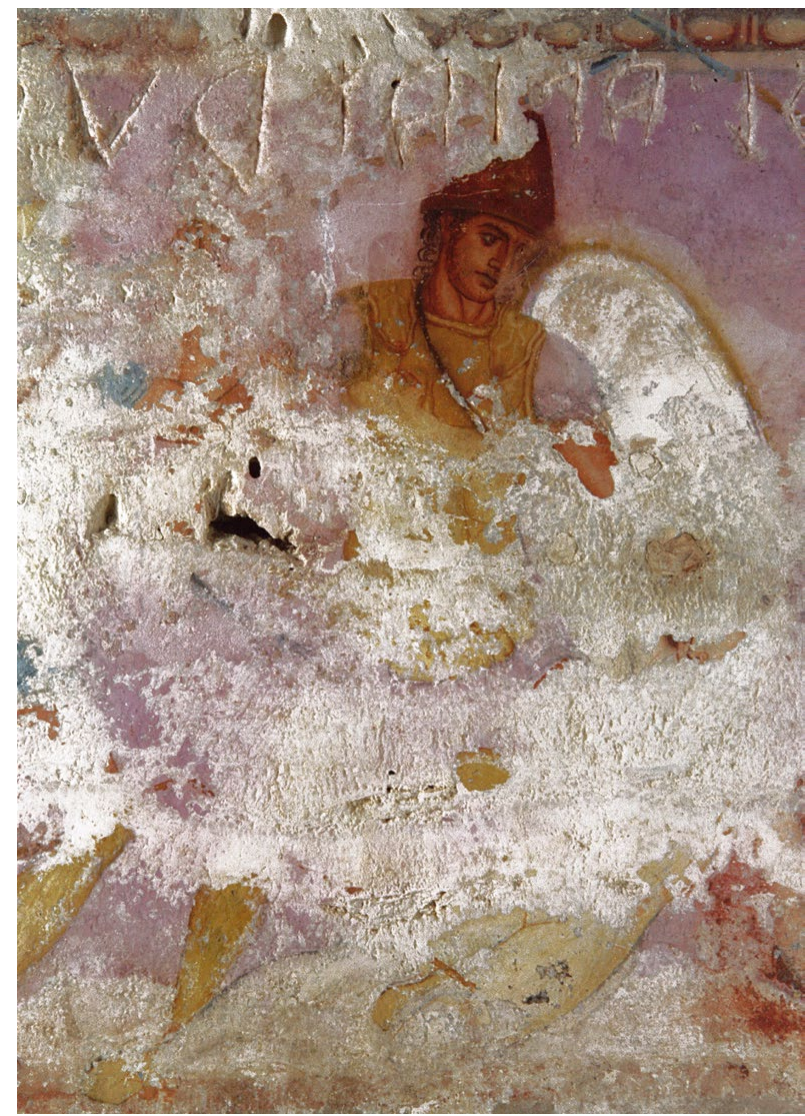

Figura 38: Guerrero Griego 3 del sarcófago Delle Amazzoni. A partir de Bottini y Settari, 2007, 36, fig. 12.

Tumba Giglioli91 ${ }^{91}$, recuperada en 1959 en la necrópolis Monterozzi, loc. Secondi Archi, representa una anomalía aún mayor pues presenta corazas y otros elementos de panoplia militar, pintados sobre las paredes laterales de la tumba. Las corazas están pintadas, una a cada lado, en las paredes izquierda y derecha en un friso que debe entenderse como la representación de las armas de la gens $\mathrm{y}$, por lo tanto, como un reclamo a una tradición gentilicia que permitiría mantener la idea de un pasado y condición aristocrática y singular en el seno de la comunidad (Cristofani, 1967, 299). Además de la tumba Giglioli se reconocen corazas anatómicas en la tumba François que confirman la excepcionalidad del uso de la coraza anatómica en la iconografía de ámbito etrusco ${ }^{92}$.

Por lo que resulta de la técnica de representación de las corazas anatómicas sobre la tumba Giglioli, $\mathrm{M}$. Cristofani señalaba algunas características adoptadas

91. A pesar del nombre, de su descubridor, la tumba pertenecía a la familia de los Pinie, familia también documentada en Vulci (Rizzo, 1989, 165).

92. Se documenta sobre algunas urnas volterranas y sobre la Cista Révil, con escena de los funerales de Patroclo similar a la del Vaso de Darío (Cristofani, 1967, 292, nota 31). Esto puede explicarse, como hizo M. Cristofani, al proponer un acercamiento artístico y cultural entre Etruria y el ambiente ápulo-tarentino durante el último trentenio del siglo IV a.C. (Cristofani, 1967, 292, nota 31).

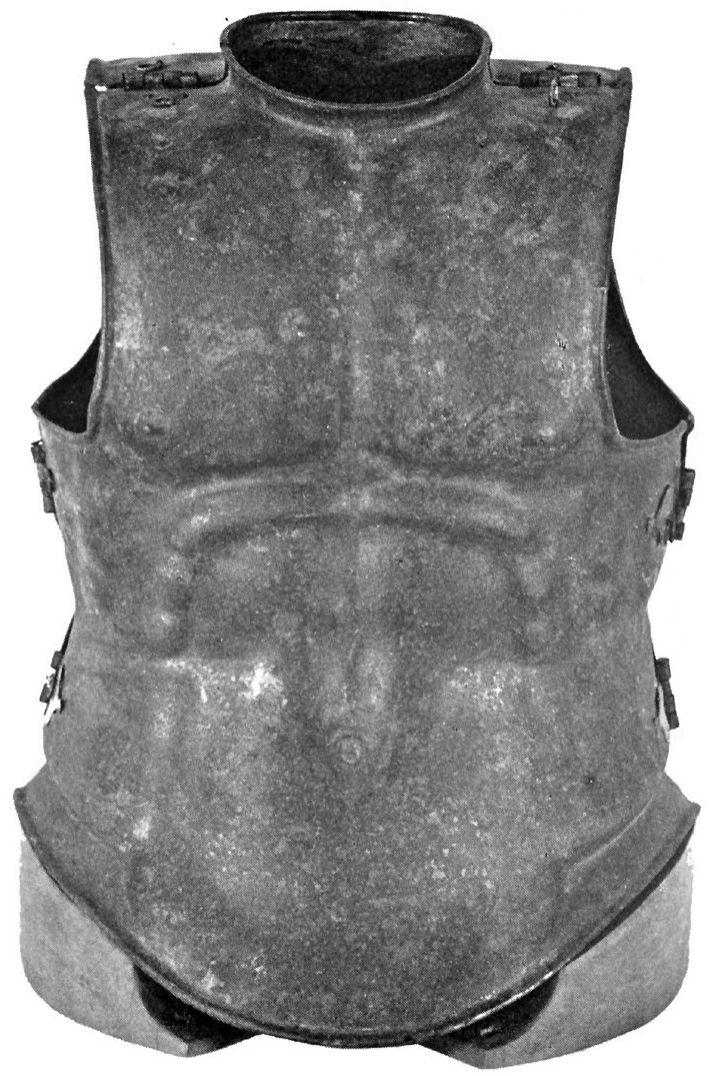

Figura 39: Coraza anatómica larga de bronce del Hipogeo Varrese-Canosa, MAN-Bari 6075. A partir de Zimmermann, 1979, pl. 6 .

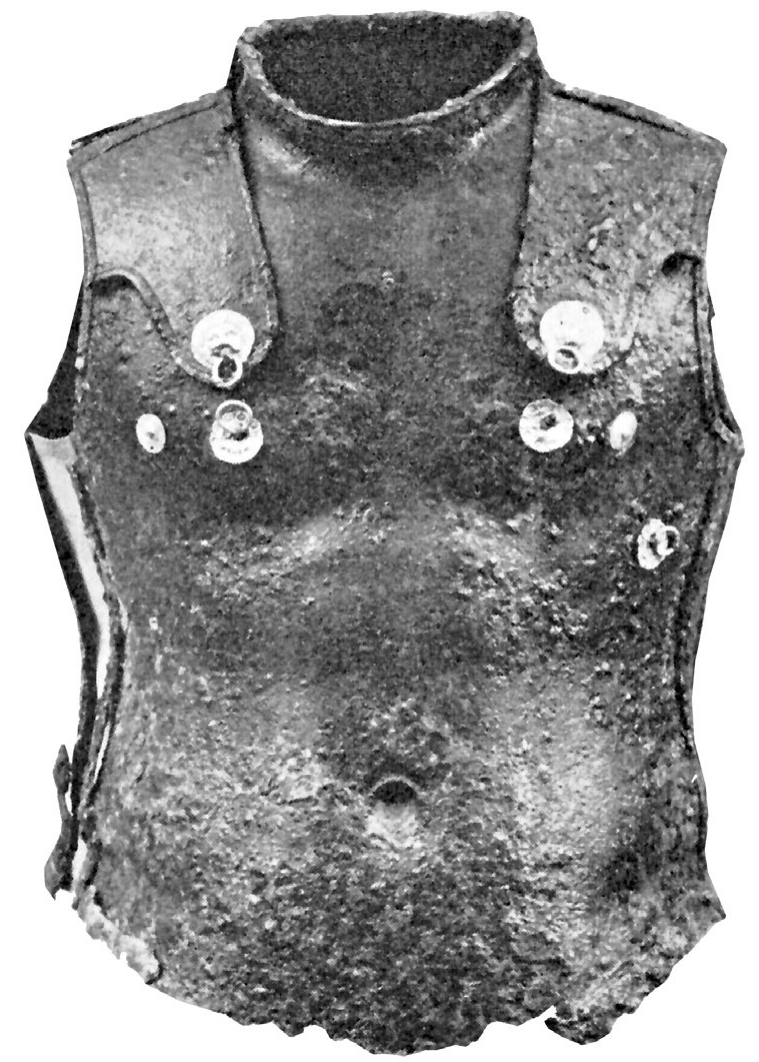

Figura 40: Coraza anatómica larga de hierro de la tumba de Prodomi. A partir de Touchais, 1982, fig. 48. 


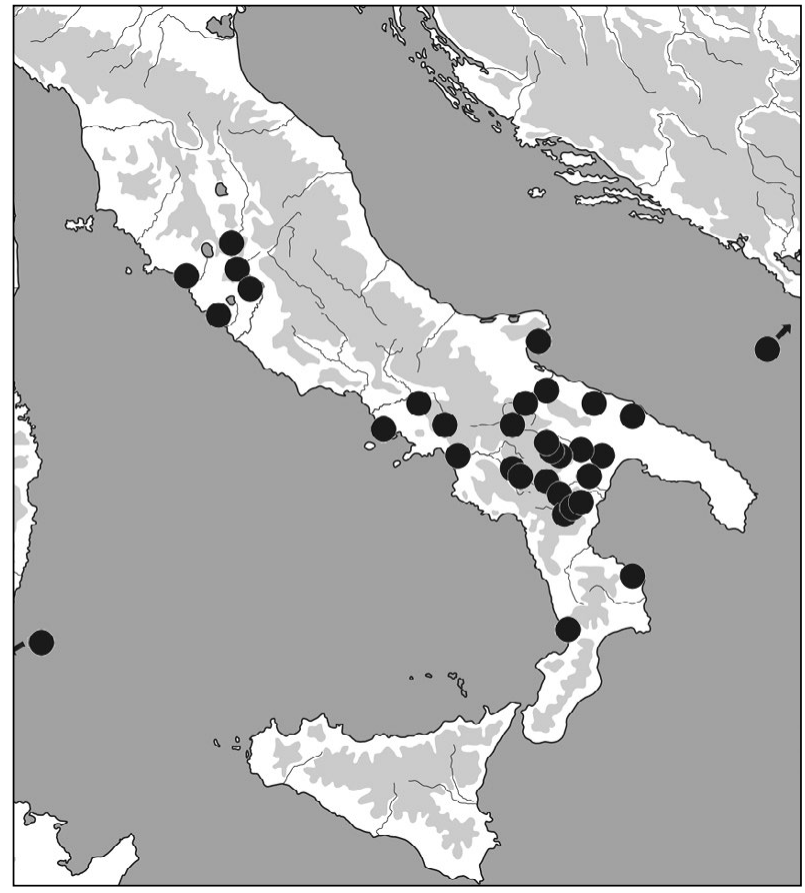

Figura 41: Mapa de distribución de las corazas anatómicas largas. (C) Dibujo R. G.

de la tradición griega, posiblemente difundidas en Italia a través de Tarento y de los intercambios artísticos que distintas ciudades etruscas mantendrían con aquella. Cristofani llegó a considerar, incluso, la formación de artesanos etruscos en talleres tarentinos. En cualquier caso la proximidad estilística no impide observar características propias en la pintura etrusca al tratar las corazas anatómicas como la desaparición de las líneas de contorno, característica de la cerámica ápula, para dejar paso a un contorno definido por juegos de intensidad de color, de claroscuros, que permite enfatizar el volumen de la musculatura (Cristofani, 1967, 294). Esto corresponde a la evolución del estilo del Pintor de Licurgo y su entorno con el estilo del Pintor de Darío y seguidores (Cristofani, 1967, 292) que permite fechar la tumba a finales del s. IV a.C. ${ }^{93}$.

En la tumba Giglioli, además de la representación de armas, particularmente algunos de los tipos representados (la coraza anatómica de manera particular, pero también el casco frigio con cresta y algunos de los episema sobre los escudos), destaca el motivo decorativo de la tumba, especialmente próximo a las influencias helenísticas de presentación de frisos de armas que rompe con el esquema local clásico de la escena de banquete (Rizzo, 1989, 165). Esta influencia podría proponerse como un contacto desde el área ápula, tarentina, o magno griega de manera más genérica (Rizzo, 1989, 165).

93. La propuesta de M. Cristofani varía entre finales del s. IV a.C. e inicios del s. III a.C. Esta propuesta es aún válida (Cristofani, 1967, 295 y 296) y demuestra que, esta tumba es posterior a la tumba François (Torelli, 1997; D’Agostino, 2003; Andreae, 2004a y 2004b; Harari, 2007; Bardelli, ep.).
En Paestum, en cambio, si excluimos la tumba objeto de estas páginas, se conocen únicamente otras tres lastras con representación de corazas anatómicas: la tumba Andriuolo 28, 61 y otra de procedencia desconocida dentro del complejo pestano. Un breve comentario sirve para contextualizar la tumba de 1854 pues se opone a una iconografía dominada por representaciones de corazas en frisos de armas pestanos:

La lastra de la sepultura indeterminada de Paestum está fragmentada en su esquina superior derecha, lo que perjudica la representación de la coraza anatómica (Adam, 2000, 128, fig. 2; Pontrandolfo y Rouveret, 1992, 302) (Fig. 37). Representa un friso de armas compuesto por un casco con lophos alto, una pareja de cnémides, una coraza trilobulada, un escudo oval y la parte abdominal de una coraza anatómica. La duplicidad de corazas en este ejemplar ha sido interpretada como una representación de la coraza utilizada por el propietario y otra como perteneciente a una spolia (Adam, 2000, 128). Aceptando esta propuesta: ¿Cuál es la del propietario y cuál el botín de guerra? Algunas tumbas de Paestum presentan también representaciones de corazas anatómicas en sus frisos de $\operatorname{armas}^{94} \mathrm{y}$ otras presentan guerreros vistiendo las corazas trilobuladas ${ }^{95} \mathrm{o}$ anatómicas (como en la tumba en estudio). Si, además, consideramos las representaciones pintadas sobre lastras de tumbas hasta el área campana, vemos como allí se representan jinetes equipados con la coraza anatómica ${ }^{96} \mathrm{y}$ guerreros con corazas cortas con detalle anatómico esquemático (Vid. Graells, 2012). Si consideramos la existencia en Paestum de tumbas con corazas anatómicas ${ }^{97}$, el debate no puede resolverse aunque las evidencias arqueológicas hagan decantar las 'sensaciones' hacia la coraza trilobulada como la local y la anatómica como la de nueva adquisición. Pero no podemos descartar que ambas representaran al mismo propietario, en un marco complejo como el que define la interpretación que se desarrolla del estudio de la tumba pintada recuperada en 1854 .

Respecto a la lastra de la tumba 61 de la necrópolis Andriuolo de Paestum (Fig. 36), Burns observó que la representación de la coraza no estaba pintada en amarillo o dorado, como el resto de casos, de manera que propuso que el artista no quisiera representar una coraza de bronce sino una coraza anatómica de hierro (Burns, 2005, 92) para la que no existe paralelo ni documentación en Italia meridional conociéndose únicamente el ejemplar de Prodomi ${ }^{98}$. Además, la presen-

94. Tumbas Andriuolo T. 28 y 61.

95. Andriuolo t.12, tomba del 1937; Laghetto T. LXIV; Tumba de 1805; Gaudo T. 7/1972; Vannullo T. 4; Sequestro Guardia di Finanza 1 (Pontrandolfo y Rouveret, 1992, 298).

96. Nola N. 4 (Benassai, 2001, fig. 210).

97. Entre las que sólo es segura su presencia en una de las tumbas recuperadas en la necrópolis de Porta Aurea en 1805.

98. Esta identificación con ejemplares reales encuentra correspondencia con lo que sucede en las representaciones escultóricas. Las corazas pintadas encuentran en la estela ática de Aristonautes un paralelo preciso sobre un monumento 
cia de la hombrera en la coraza de Prodomi coincide tipológicamente con los de la tumba de 1854 , donde el pteryges es inexistente ${ }^{99}$.

De esta manera, los paralelos iconográficos escultóricos y reales de las corazas pintadas en la tumba de 1854 evidencian una adopción de modelos iconográficos griegos, en el que la presencia de hombreras sería frecuente, pero simultáneamente los adapta a un modelo de uso suritálico según el que se utilizaría la coraza anatómica sin pteryges.

Sea como fuere, las representaciones escultóricas y todas las representaciones de corazas anatómicas metálicas pintadas en tumbas se fechan sistemáticamente a finales del s. IV o inicios del s. III a.C. como evidencia de la eclosión de este elemento de la panoplia en este momento.

\section{Cinturones}

Entre el abultado número de representaciones de cinturones en la tumba (seis ejemplares) sólo uno permite consideraciones de tipo estilístico y cronológico. Eso no impide que el resto de casos necesite de un análisis detallado sobre sus respectivos significados.

El cinturón que lleva el magistrado o Pater $\mathrm{Fa}$ milias presenta claramente dos ganchos en forma de palmeta. Este tipo ha sido clasificado por Suano como tipo $2 \mathrm{a}^{100}$. La cronología propuesta para estos casos se sitúa en un momento central del s. IV a.C. (Naso, 2011, 42-43).

La cronología se distancia de lo que hemos observado en el resto de elementos de la tumba y además, la distribución de los paralelos parece distanciarse de lo dibujado por los elementos de la panoplia defensiva. $Y$, pese a la presencia de otros cinturones en representaciones pestanas, su representación sobre un civil es sorprendente ${ }^{101}$, pues normalmente se ha observado en personajes armados.

Este detalle reabre la discusión acerca del significado del cinturón en el seno de las comunidades lucanas

escultórico próximo cronológicamente (Moreno, 1994, 85-90, fig. 104). El resto de elementos de la panoplia y, especialmente, la posición del cuerpo distancian ambos monumentos.

99. La combinación entre la coraza anatómica y un faldellín sin pteryges encuentra en una métopa de Via Calabria de Tarento una precisa correspondencia (Moreno, 1994, fig. 114).

100. Una carta de distribución ha sido recientemente considerada por A. Naso $(2011,42)$. Esta concentra dos ejemplares en la necrópolis de Campo Consolino en Alfedena, uno de procedencia imprecisa atribuida a l'Aquila, cuatro de $\mathrm{Ca}$ pua, uno en Sorrento, Pontecagnano, Eboli, Roccagloriosa y Canosa y Olimpia.

101. Encuentra representaciones sobre cuerpos de togados en las tumbas pestanas de Vannullo 2 y de la necrópolis Spinazzo (tumba recuperada por la Guardia di Finanza en Tarento y en la tumba del Magistrato). En cambio, las representaciones de cinturones sobre guerreros es mucho más frecuente (vid. Infra) así como sobre caballeros y suritálicas ${ }^{102}$, superando el discurso exclusivamente militar y en cambio, considerando de nuevo su valor como indicador de pertenencia a un grupo, en calidad de indicador de acceso a la ciudadanía, opinión que ya dispone de un abultado número de defensores (Salmon, 1967 [1995], 113-114; Johanowsky, 1990, 272274; Suano, 1991, 135-139; Benassai, 2001, 177) ${ }^{103}$.

(Paestum-Vannullo 3, Paestum-Andriuolo t. 58, 61, 86, Capua C.13, C.14, C. 15 , C. 17 y C.30 y Nola N.4 y N.8) o aurigas (Paestum-Vannullo t. 4).

102. Este debate surge del análisis de la acumulación de diversos cinturones en un mismo contexto funerario, que ha permitido interpretaciones que han considerado su presencia como:

- ofrendas hacia el difunto;

- herencias familiares, Com'è spesso dato osservare nel caso di molte classi di bronzi, i due cinturoni dovevano comunque rappresentare per $i$ rispettivi proprietari dei beni preziosi: quando essi se ne separarono definitivamente, deponendoli nelle due tombe in cui sono stati rinvenuti, dovevano essere stati indossati numerose volte e forse numerose volte passati di mano, quali segni di relazioni sociali conservati e passati di mano in mano (Bottini, 1983, 52-53);

- como elementos indicadores de estatus. En área samnítica, la presencia de un segundo cinturón se ha interpretado, tradicionalmente como parte de botín de guerra, subrayando el valor simbólico por encima del numérico, pero ulteriores análisis han demostrado como este criterio varía hacia area del Abbruzzo, donde prevalece el factor numérico, como demuestran algunos casos de las necrópolis de Cariatidi, Tiriolo o Laos, con tres cinturones o en la tumba 600 de Lavello (con 5 cinturones). Este tipo de acumulaciones ha permitido la formulación de una hipótesis de transmisión de dichos elementos en el seno de la familia, extendida, como parece proponer el decalage cronológico de los tipos presentes en la tumba 600 de Lavello (Romito, 1995, 9);

- resultado del botín de guerra, que se refuerza con la iconografía de las representaciones pintadas tanto en la pintura funeraria como en la cerámica italiota, con las conocidas escenas de regreso de héroes que a menudo presentan uno o varios cinturones congando de las lanzas y que, consecuentemente, se han relacionado como trofeos de guerra (Rebuffat, 1962, 353);

- o como elementos distintivos del personaje.

103. En referencia a la propuesta de W. Johanowski, a partir del s.V a.C. los cinturones perderían su valor como símbolos de distinción social individual y pasarían a convertirse en insignias de pertenencia a la ciudadanía, hecho que viene ratificado por la presencia de este elemento en tumbas infantiles en calidad de testimonianza evidente di una articolazione sociale legata al ruolo della classe militare e da esso espressa, pero que la presencia de cinturones en tumbas femeninas vuelve a poner en entredicho siendo más claro su uso como indicador de un derecho a la ciudadanía. En palabras de M. Romito: In conclusione, le tombe contenenti più di un cinturone - sopratutto più di due - sono per lo più contrassegnate da una particolare ricchezza nel corredo di armi e oggetti mettallici, come se l'interazione di questo oggetto così carico di valenze volesse sottolineare ulteriormente la ricchezza e il prestigio del defunto 
Así, si los cinturones acumulados en tumbas no se interpretan más como símbolos militares y sí, en cambio, como elementos de ciudadanía o de estatus, su representación en pinturas funerarias debe tener idéntica interpretación.

Pero lejos de verlo como una anomalía, este detalle muestra un elemento relacionado con la indumentaria local que refuerza la interpretación de la iconografía como una combinación entre elementos locales, fundamentales, con elementos foráneos, asimilados en una coyuntura compleja que caracterizó el marco histórico de la Italia meridional. De esta manera el detalle del cinturón evidencia las raíces locales del grupo, ahora involucrado en una órbita más compleja y lejana, como el ambiente tarentino.

En otra línea cabe considerar el resto de cinturones pintados en la tumba. La representación del cinturón femenino, la Zone, representa el ideal de fertilidad y de fidelidad (Bennet, 1997, 182). Más compleja es la presencia del Zoster, cinturón de carácter masculino y normalmente con una superficie metálica, que aparece en la Ilíada y la Odisea asociado normalmente a guerreros y en algunas ocasiones se convierte en una pieza clave de la armadura defensiva. En opinión de Bennet sería un instrumento ideológico más, símbolo heroico y de rango, hasta el punto que en la obra homérica debería interpretarse como el heroic's warrior belt (Bennet, 1997, 91).

El cinturón masculino en las representaciones pintadas de la tumba (Pater Familias y guardianes de la puerta ${ }^{104}$ ) evidencia una pluralidad de usos: como indicadores de ciudadanía; como complementos de la panoplia militar ${ }^{105}$; e incluso, como elementos indicadores de edad ${ }^{106}$.

e il suo ruolo guerriero...Il cinturone è legato alla sfera militare, ma non in modo esclusivo, e si prefigura piuttosto come elemento distintivo di status (Romito, 1995, 9 y 12).

104. La ausencia del protagonista de las tres lastras de la caja, armado con coraza pero sin cinturón, debe relacionarse como una alegoría a su condición de propietario de la tumba, heroizado después de su muerte (en el tímpano), como Aquiles. De esta manera toma fuerza la propuesta según la que At the same time, these belted heroes demonstrate that high birth, seniority, wealth and personal connections are actually honored above war strength in the eroic world of the poems (Bennet, 1997, 88). A tal efecto, la figura de Aquiles no se representaría con cinturón ya que aún estaría enmarcada en la esfera de los mortales y, en cambio, que Agamenón llevara el único cinturón de plata y el cetro de oro lo relacionaría con Ares y Zeus, respectivamente, combinando de esta manera los paradigmas reales con los del héroe-guerrero (Bennet, 1997, 88).

105. Recordemos a tal efecto la frecuente representación pintada cinturones colgando de lanzas a modo de panoplias o de trofeos militares.

106. Esta propuesta encuentra correspondencia en lo observado por Bennet acerca de la obra homérica: The largest share of honor accrues to the belted hero based on seniority and ruler status. This explains the fact that Agamemnon,

\subsection{EQUiPO DEL CABALlO}

El equipo del caballo es extremadamente complejo y rico de detalles, especialmente si se compara con el resto de pinturas pestanas (Fig. 42). Ello permite profundizar en los elementos de atalaje y gobierno equino en entorno pestano y suritálico en el cambio entre el s. IV y III a.C., especialmente en torno a dos de sus elementos más singulares: el prometopidion y el prosternidion, protector de la cabeza y del pecho respectivamente.

Estos elementos, que se consideran como producciones magno-griegas, posiblemente tarentinas (Bottini, 1989, 710), permitieron el desarrollo de sus decoraciones llegando a una enorme complejidad técnica que, a partir de siglo IV a.C., se combinó con bozales de bronce de tipo calado (Garcés y Graells, 2011; Faklaris, 2010). Especialmente elocuente en este sentido es el conjunto procedente de Ruvo di Puglia, hoy en la colección White and Levy del Metropolitan Museum de Nueva York (Von Bothmer, 1990, 114-122).

Las indicaciones sobre los colores con que se representaron los elementos para el gobierno del caballo (rojo y azul), evidencian una estructura compleja con materiales orgánicos y metálicos que no hace más que ratificar una información intuída, al mismo tiempo que su detalle distingue estos equipos de los representados en otros contextos. Por un lado, la ausencia de aplicaciones circulares doradas los distingue de otros casos pintados en tumbas pestanas y campanas ${ }^{107}$. Pero un segundo detalle es igualmente importante, se trata del nudo e inflexión de la rienda lateral del equipo. Este elemento permite confirmar hasta qué punto el dibujo refleja exactamente una pintura realista, sin invenciones, pues encuentra correspondencia en otras tumbas pestanas $^{108}$.

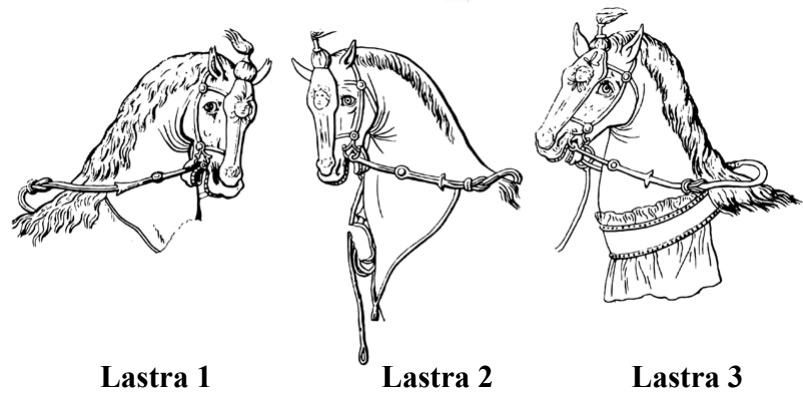

Figura 42: Particular de los prótomos de caballo pintados en la tumba. A partir de Minervini, 1856, Tav. IV-VI.

Menelaos and Nestor own distinctive zorestes, while Achilles, surely the best Achean warrior, apparently does not. (Bennet, 1997, 87).

107. Paestum Andriuolo 18 y 58; Paestum - Spinazzo tumba del Magistrato; C.1.

108. Paestum Andriuolo 2/1971 y Spinazzo - tumba recuperada por la Guardia di Finanza. 

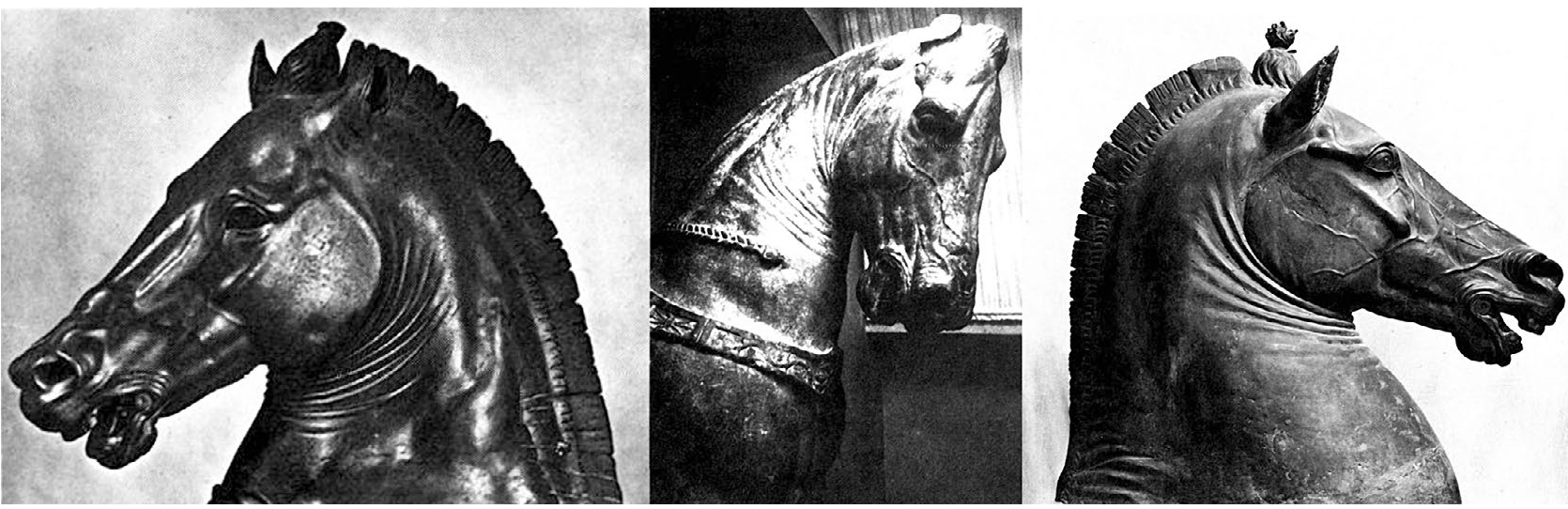

Figura 43: Caballos, de izquierda a derecha: MAN-Firenze, Colección Weiller y MAN-Napoli. A partir de Coarelli, 1981, figs. 44, 50 y 46.

Los elementos de atalaje son indicativos de orígenes y tradiciones particulares. La posición del caballo, particularmente de su cabeza, que aparece vista de tres cuartos, ligeramente recogida ${ }^{109}$, y el tocado de su crin encima de la cabeza, en forma de penacho ${ }^{110}$, son elementos que demuestran el peso de la tradición local e iconográficamente permiten una correspondencia con paralelos escultóricos. Por ejemplo, la cronología del grupo escultórico recuperado en Lanuvio, Santuario de Juno Sospita, corresponde al tardo-helenismo (Coarelli, 1981, 233). Este modelo corresponde al tardo-clasicismo (finales del s. IV a.C.) (Coarelli, 1981, 244) del que el bronce de Herculano con representación de Alejandro Magno es el exponente más revelador, pero el grupo ecuestre de Lanuvio, fechado en un momento más avanzado, permite definir una evolución en el que los caballos representados en la tumba de 1854 y sus paralelos escultóricos (caballo del MAN-Firenze y MAN-Napoli) (Fig. 43) encajan perfectamente en un momento que debemos situar en el cambio entre el s. IV y el s. III a.C.

Por otro lado, la posición de la cabeza y cuello del caballo, ligeramente recogida y girada hacia el espectador, con profundas líneas de los pliegues del cuello y detallada musculatura, encuentra numerosos paralelos en los que la expresión de dolor e incomodidad por

109. Esculturas con prótomos de caballo en idéntica posición han sido recopilados por F. Coarelli procedentes de Lanuvio (Coarelli, 1981, fig. 23-24), de una métopa de Tarento (Coarelli, 1981, fig. 32), de la Colección Weiller de Paris (Coarelli, 1981, fig. 50), de Melos (Coarelli, 1981, fig. 49) y de Roma - Via Appia (Coarelli, 1981, fig. 53).

110. El penacho sobre la frente del caballo se representa en las tumbas: N.4; Andriuolo 48, 58, 86, 2/1971 y 4/1971; Sequestro Finanza 1 y 2; Spinazzo Sequestro Finanza y tumba del Magistrato. El mismo penacho se representa sobre las esculturas recopiladas por F. Coarelli procedentes de Ercolano (Coarelli, 1981, fig. 40), Firenze (Coarelli, 1981, fig. 44-45) y Napoli (Coarelli, 1981, fig. 46). Además de la lastra del caballero a galope de la Via Calabria de Tarento (Moreno, 1994, fig. 114) y algunos de los caballos de la batalla del sarcófago de Abdalonimo de Sidón. parte del caballo, normalmente a causa de un esfuerzo violento o de una severa sujeción con los elementos de gobierno. Esto también encuentra paralelos en numerosos testimonios escultóricos ${ }^{111}, \mathrm{y}$, a partir de las fuentes antiguas podríamos citar las pinturas de Atenión y de Nealce (circa 250 a.C.) (Moreno, 1994, 84). Esta forma toma como modelo el sarcófago de Abdolimo de Sidón (datado entre el 315-312 a.C.) (Moreno, 1994, 82), evolucionando progresivamente hasta la representación, más exagerada, del caballo de la métopa de Via Calabria de Tarento, con representación de Pirro (Moreno, 1994, fig. 88).

En cualquier caso, la iconografía que nos interesa es la de la estela de Colono que presenta una matriz ática que en opinión de P. Moreno encontraría correspondencia en área occidental casi en el mismo momento cronológico. Pero además de la identificación iconográfica, destaca la circulación de la idea referida con esta representación de agresividad que corresponde a una representación de fiereza del caballo, únicamente gobernable por el héroe. De esta manera, este topos permite comprender también las representaciones más complejas en las que el caballo aparece en actitud agitada con un escudero, pues entra dentro del mismo discurso ideológico.

El cuello y la cabeza de los caballos evidencian una iconografía de segunda mitad del s. IV a.C. (Coarelli, 1981, 246) que los pintores lucanos adoptaron de manera excepcional en una composición anómala dentro de su repertorio. La composición, dominada por el movimiento y agitación de las escenas laterales, transmite una paradoja en los caballos, con el cuerpo en reposo y la gestualidad helenística de tensión. Parece una adaptación de un modelo exógeno, netamente griego y con ejemplos en Tarento, que no llega a consolidarse en área pestana, o no llega a eclosionarse de manera plena.

111. Entre los que destaca la estela de Colono (NM-Athens) (Moreno, 1994, fig. 86) o una de las métopas de Via Calabria de Tarento con representación de caballero al galope (Moreno, 1994, fig. 114). 


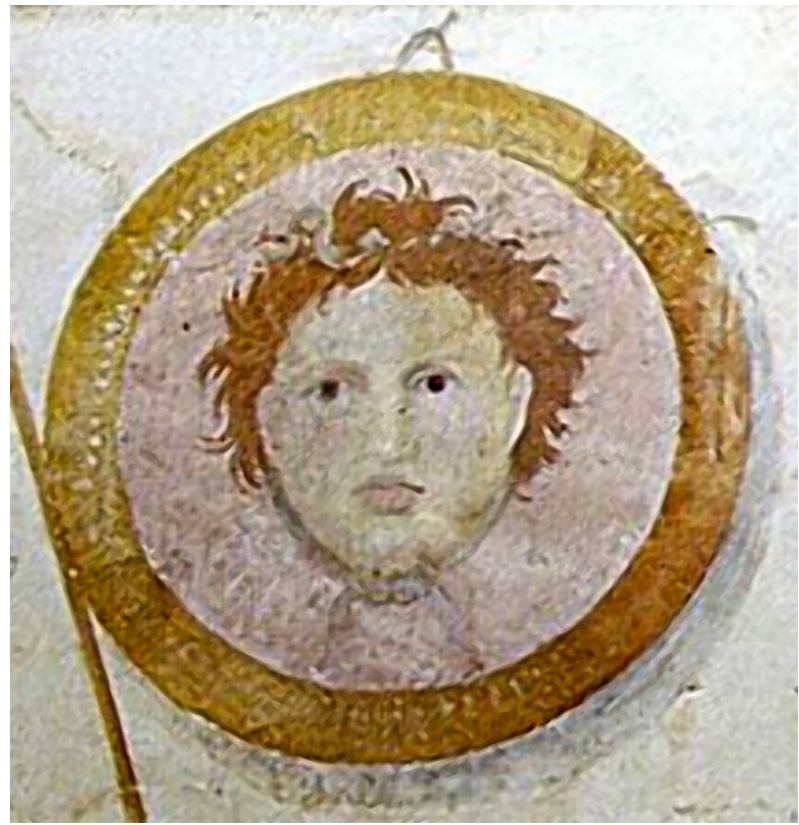

Figura 44: Pintura del escudo decorado con cabeza de Medusa de la tumba III de Ágios Athanásios. A partir de TsimpídouAyloníti, 2005, pl. 27 b.

\section{Prometopidia (testeras)}

Los tres prometopidia reproducen la forma clásica y aparecen decorados con cabeza de Medusa en su parte superior, lo que permite una última confirmación de esta influencia ápula, pues el catálogo de paralelos no encuentra fuera de aquella área (Apulia, Pencetia y Basilicata) otros ejemplos. La presencia de testeras no es frecuente en área campana ni pestana, donde sólo se conocen pintadas ${ }^{112}$. Aún así, el detalle de las testeras pintadas de la tumba de 1854 obliga a considerar, claramente, sus paralelos en área ápula y, quizás, de la Basilicata.

Sobre las testeras de segunda mitad del s. IV a.C. pueden distinguirse dos tipos, los de decoración simple, en repujado, de la parte superior, normalmente en forma de corona y con el protector del muso liso, y un segundo tipo con decoración compleja de la parte superior mediante una composición de elementos vegetales y palmetas entrelazadas que se extiende en parte del protector del morro y se completa con una ligera decoración en el extremo inferior mediante un detalle vegetal, derivado y simplificado de la composición superior. Esta repetición de motivos, permite suponer que serían producciones distintas.

Este detalle dista de lo observado en las testeras de período arcaico y clásico, en los que si bien se puede aceptar una producción estandarizada para los

112. Capua C.14, C.15, C.17; Nola Via Seminario N.4. En la necrópolis de Paestum, únicamente en dos tumbas de la necrópolis Spinazzo se documentan estos elementos en la tumba recuperada por la Guardia di Finanza y en la llamada del Magistrato.

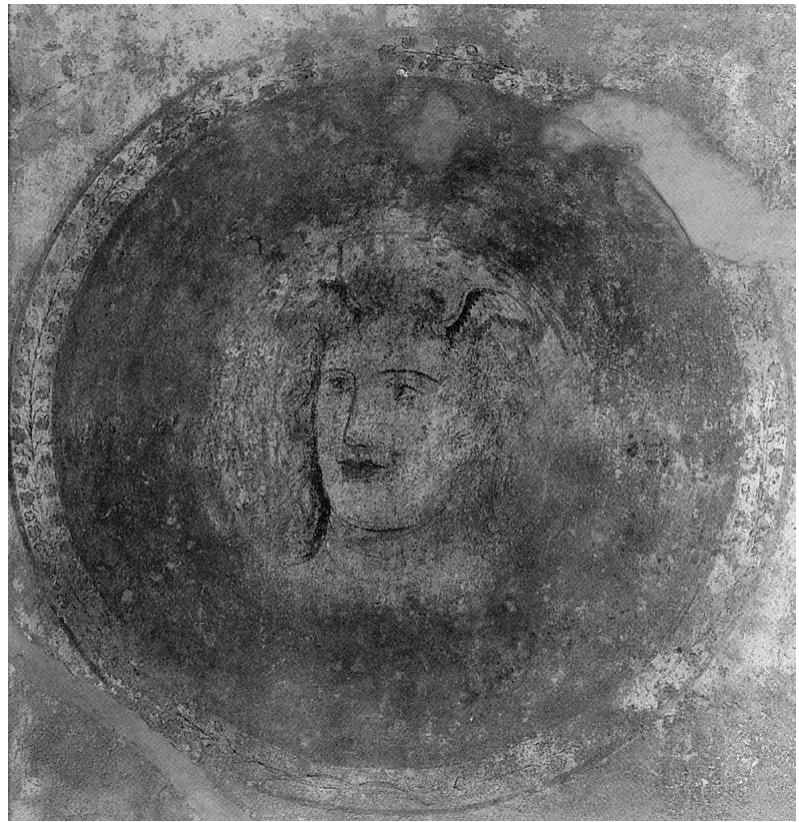

Figura 45: Pintura del escudo del hipogeo descubierto en 1846/1847 en Gnathia. A partir de Cassano, 1996, 166

ejemplares con representación de cabeza de guerrero con casco calcídico, el resto de representaciones presentan una producción individual y exclusiva tanto por lo que a las dimensiones como a la decoración se refiere.

Las características decorativas de estas testeras y sus paralelos en otros elementos de la panoplia de s. IV a.C. suritálico permitió a A. Bottini proponer una producción en ámbito tarentino (Bottini, 1989, 710). Esta propuesta podría aceptarse también para las testeras representadas en la tumba pestana, pues la aplicación de cabezas de Medusas sobre armas defensivas (principalmente escudos) encuentra paralelos en Egnatia (Fig. 45) y Macedonia (Fig. 44) (Cassano, 1996, 166; Tsimpídou-Ayloníti, 2005, Pl. 27 b) a finales del s. IV a.C. e inicios del s. III a.C., y no será hasta avanzado s. III a.C. cuando se difunde en área itálica-mediterránea.

El tipo aparece ya en el s. VI a.C., pero es a partir del s. V a.C. cuando surgirán y se estandarizarán una serie de elementos de ornamentación, y quizás de protección, del caballo en el sur de Italia (Peucetia, Apulia y Lucania), desarrollándose particularmente entre la Basilicata y la Apúlia durante el s. IV a.C. (Fig. 51). Consistían en elementos ornamentales evolucionados de los antiguos protectores que cubrían las cabezas (testeras o prometopidia) y pectorales (petrales o prosternidia). Estos elementos se asocian con amplias panoplias militares de prestigio en lo que podrían llamarse tumbas emergentes (LoPorto, 1996) e incluso, principescas, donde la coraza anatómica larga es uno de los elementos fundamentales que explican y connotan al propietario como équites.

El caso mejor documentado corresponde a la tumba de Sangiorgio di Ginosa (LoPorto, 1996, 24-33), con 


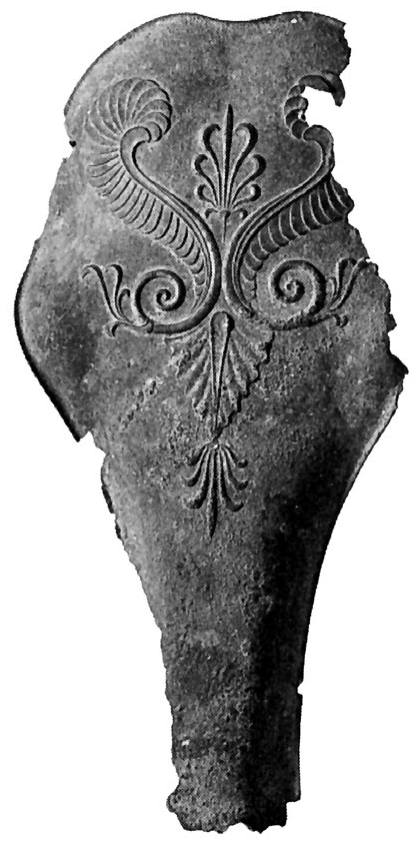

Figura 46: Prometopidion del Hipogeo Monterisi Rossignoli - Canosa. A partir de Mazzei, 1992a, fig. 11

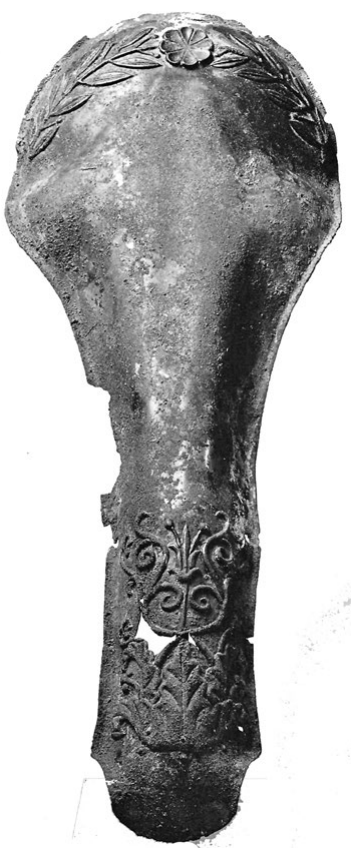

Figura 47: Prometopidion de la colección White \& Levy. A partir de Von Bothmer, 1991,116, N.95d.

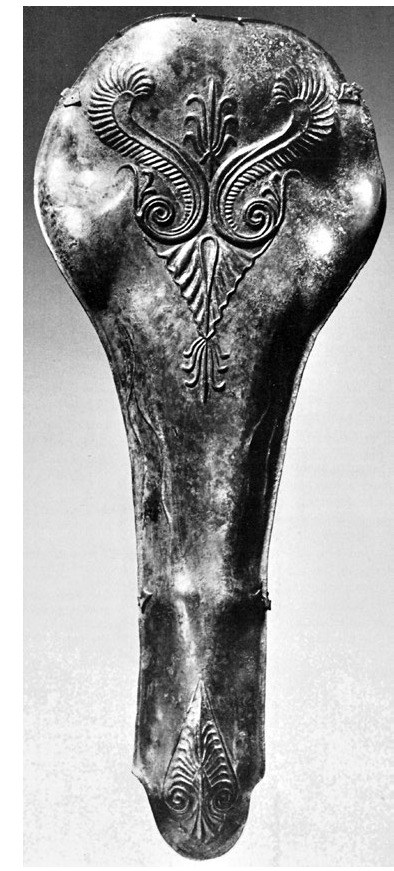

Figura 50: Prometopidion de colección particular suiza. A partir de Cahn, 1989, W24i.

una pareja de testeras (Lippolis, 1995, Tav. LXXXII, 2; LoPorto, 1996, figs. 25, 1-2, 26, 2) de bronce asociados a una pareja de petrales (Lippolis, 1995, Tav. LXXXII, 2; LoPorto, 1996, fig. 25, 3-4); una pareja con decoración del extremo inferior en motivo de palmeta y la parte superior con composición vegetal compleja, de procedencia ápula, se conserva repartida

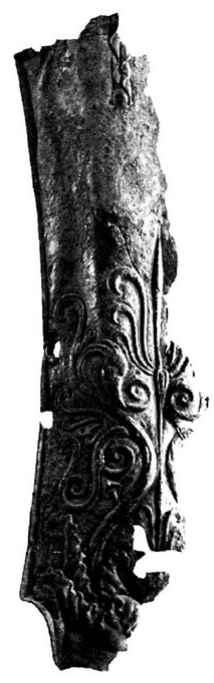

Figura 48: Prometopidion de San Giorgio Lucano. A partir de Bottini, 1989, fig. 5a.

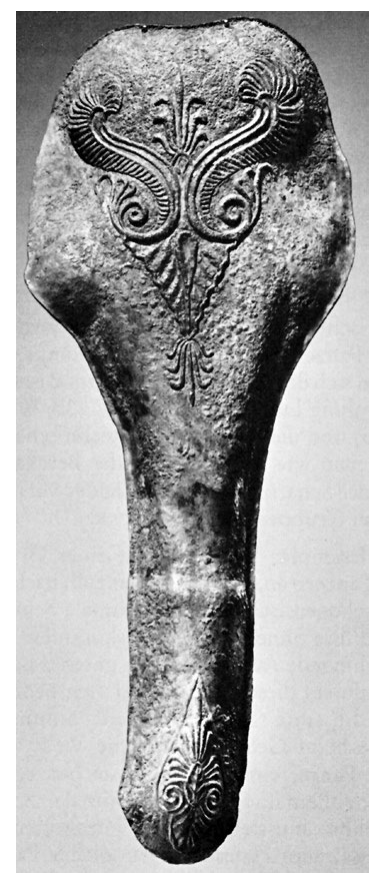

Figura 49: Prometopidion de colección particular suiza. A partir de Cahn, 1989, W23d

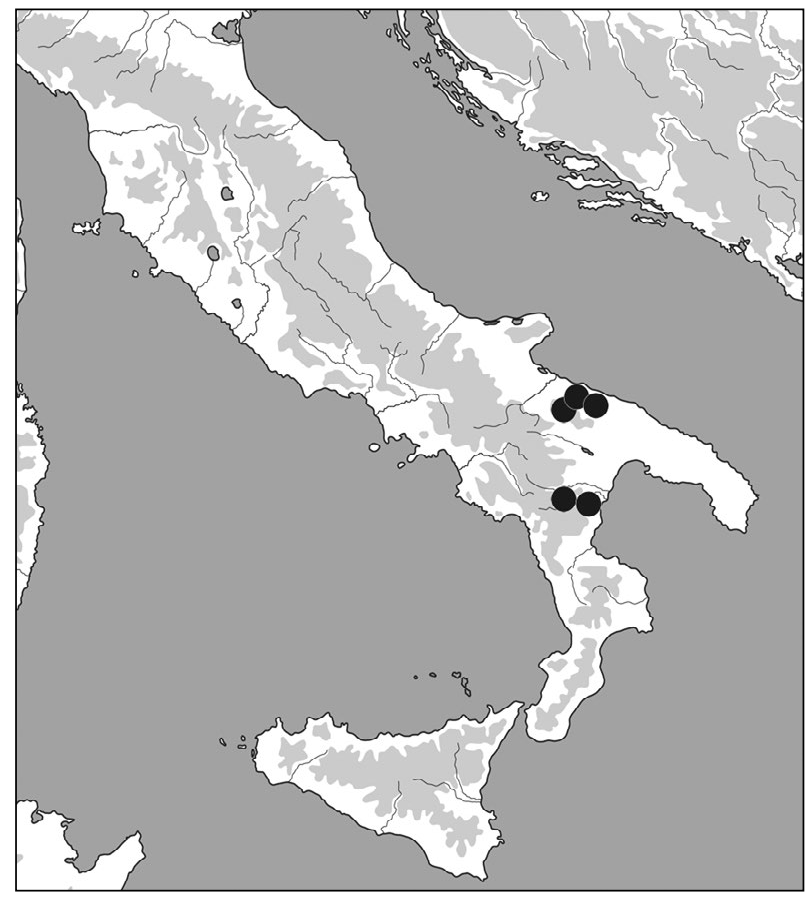

Figura 51: Mapa de distribución de los prometopidia (testeras) de bronce de s. IV a.C. (C) Dibujo R. G.

entre el Badisches Landesmuseum Karlsruhe y el MAN-Napoli (LoPorto, 1996, 30); dos más en el Antikenmuseum Basel und Sammlung Ludwig (Figs. 49 y 50) (Bottini, 1989, 706); otro idéntico en el Museo de Mougins (Burns, 2011, 206, fig. 73, MMoCA.561); en el mismo museo otro ejemplar con decoración de pseudo-corona de mirto en la parte superior (Burns, 2011, 
191, fig. 24, MMoCA.597F); otro más en la tumba de Sangiorgio di Lucania, hoy en el Museo Provinciale di Potenza (Fig. 48) (Bottini, 1989, 706); otro en la tumba 669 de Lavello (Bottini, 1991); tres ejemplares en el hipogeo Monterisi-Rossignoli de Canosa (Fig. 46) (Botini, 1989, 706) y uno en la supuesta tumba de Ruvo di Puglia de la colección White and Levy (Fig. 47) (Von Bothmer, 1990); otra testera se documentó en el área de Campo Scavo de Armento, tipológicamente afín al de la colección White \& Levy, Canosa y Basilea a pesar de su estado de conservación, que ofrece únicamente la parte superior, más ancha y sin decoración, y parte del lateral derecho (Russo, 1995, 26, fig. 31).

Además, tres ejemplares de la Tomba principesca rinvenuta su Corso Cotugno (già Via dei Cappuccini) de Ruvo di Puglia (Montanaro, 2007, 440-488, n. 103), se conocen otros ejemplares de pectorales en lámina de bronce idénticos procedentes de Ruvo y depositados en el MAN-Napoli (LoPorto, 1996, 30). Finalmente hay dos tumbas de Ruvo di Puglia localizadas en Corso Cotugno (già Via dei Cappuccini): números 114-115 de Montanaro (Montanaro, 2007, 537-546), con un prosternidion y una pareja de prosternidia respectivamente, que se fechan en siglo V a.C. Por último, citaremos el ejemplar de prometopidion de Olimpia (MA Olimpia, N. Inv. B.4800).

Sobre los Prosternidia decir únicamente que se trata de un elemento raramente representado en pinturas pestanas $^{113}$ y que también encuentra escasa representación en escultura ${ }^{114}$, siendo sumamente raro en el registro arqueológico.

\section{CONCLUSIONES}

Las características excepcionales de la tumba y su decoración obligan a considerarla como uno de los monumentos más espectaculares que ha proporcionado la Poseidonia lucana.

Arquitectónicamente corresponde a una tumba distinguida, aunque el ajuar descrito no permite abundar en los detalles. La pintura, en cambió, incide en una condición privilegiada y evidencia un imaginario helénico único entre las representaciones pestanas ${ }^{115}$ donde se mezclan elementos locales con esquemas clásicos del mito griego: la amazonomaquia y la lucha contra el bárbaro. Pero si las influencias foráneas son claras, muchos detalles evidencian una mano y propiedad

113. Sobre pinturas pestanas, las representaciones de petrales se documentan en las tumbas Andriuolo 28 y 104, y en la tumba recuperada por la Guardia di Finanza, procedente de la necrópolis Spinazzo.

114. Entre estas esculturas, destacan los ejemplares de Lanuvio, hoy en el British Museum (Coarelli, 1981, 23) y el de la Colección Weiller de Paris (Coarelli, 1981, fig. 50).

115. Para un resumen de los modelos utilizados en ámbito pestano vid. Pontrandolfo y Rouveret, 1992; Lévêque, 1993. local, influenciada y particularmente preocupada por evidenciar su filo-helenismo.

A tal efecto cabe destacar el peso del área ápula en la difusión del mito y la iconografía de las amazonas y de la guerra contra el persa, pues como demostraron A. Pontrandolfo y A. Rouveret, la difusión de la iconografía de la amazonomaquia sobre vasos áticos se concentró en área etrusca, siendo rara su presencia en área magno-griega (Pontrandolfo y Rouveret, 1983a, 1053-1054). Posteriormente, a partir de la mitad del s. IV a.C., mito e iconografía, viven un auge significativo en área ápula, donde sus ceramistas lo utilizan de manera recurrente para reflejar la inestabilidad del momento. Si en Atenas la inestabilidad con las poblaciones extranjeras había creado estos mitos, una situación similar en Tarento podría explicar la reaparición del mito, especialmente si recordamos las empresas militares contra poblaciones itálicas y, posteriormente, contra Roma. Esta misma lógica podría explicar su adopción en área pestana, inmersa en similares enfrentamientos y participando en los conflictos tarentinos.

La influencia ápula es aún más clara cuando se observa el modo en el que está representado el personaje principal, como caballero con coraza anatómica, que contrasta con el esquema lucano/pestano de representación del caballero con el trofeo o de su panoplia local (coraza trilobulada). La representación del propietario en el mundo italiota como héroe equipado al estilo ápulo en un momento tardío (datación a partir de los detalles del armamento) en el que sistemáticamente el héroe se representa con el equipo local es una anomalía (Pontrandolfo y Rouveret, 1983a, 1065-1066) o quizás ¿una última evidencia de un filo-helenismo (filo-tarentinismo) por parte de una comunidad pestana de final del s. IV a.C. contra Roma ${ }^{116}$ ?

La representación global de esta tumba quiso entenderse, en el s. XIX, como una exaltación de las gestas militares del propietario (Minervini, 1856, 177) en el marco de las guerras entre lucanos y posedonienses (Minervini, 1856, 180) ${ }^{117}$. Ese planteamiento, válido en otros $\operatorname{casos}^{118}$, aquí parece corresponder a la representación de unos modelos iconográficos que reprodu-

116. La romanización de Paestum es aún objeto de un debate en el que participan discursos históricos, fuentes clásicas y, en menor medida, argumentos arqueológicos. El principal problema es la cronología sobre la descripción que aparece en la obra atribuida a Aristosseno, Symmikta Sympotikà (Para una síntesis y bibliografía vid. Zevi, 2004, 802-811). Las principales posiciones proponen, en base a la biografía de Aristosseno, que se trate de una obra de segunda mitad del s. IV a.C. (Zevi, 2004, 805-806, nota 39), mientras que otra opción la considera un apócrifo neopitagórico, seguramente pestano, posterior a la fundación de la colonia romana (Torelli, 1988).

117. A estos episodios bélicos podemos relacionar numerosas evidencias de integración de guerreros lucano-samnitas en Ruvo (Montanaro, 2010).

118. Por ejemplo la tumba Weege XXX (Nola N.8). Para discusión y bibliografía vid. Graells, 2012. 
cen un imaginario heroico enmarcado históricamente en otro contexto. Como ha propuesto A. Bottini (2007, 15) $[. .$.$] i greci dipendono da un numero limitato di$ modelli, opportunamente adeguati e modificati. Así, aquí nos encontramos con uno de los más importantes topoi de los grandes enfrentamientos de la mitografía griega (la amazonomaquia - Minervini, 1856, Tav. VI) y local (pacto de Fides con el Pater Familias representado como magistrado y anciano - Minervini, 1856, Tav. IV, en la lastra de fondo, y recepción y apoteosis en el tímpano). Ambos elementos combinados muestran un momento histórico concreto de claro desenlace victorioso por parte de la gens representada, lejos del momento indeterminado representado en el sarcófago delle Amazzoni.

El tipo de depósito funerario recuperado en la tumba, por otro lado, muestra una constante local en la que el guerrero aparece únicamente equipado por la coraza y la lanza, lejos de los enormes ajuares de las tumbas coetáneas, con coraza anatómica, de la Basilicata y la Apulia.

Pero la espectacularidad de la tumba de 1854 reside en su ruptura con la norma de la necrópolis Spinazzo al sustituir el cortejo funerario por dos escenas mitológicas de exaltación del héroe que sustituye el protagonismo del togado por el del guerrero armado con panoplia completa y compleja. De esta manera, se interrumpe la repetición y gradación de los personajes representados en la tumba (Pontrandolfo, 1996a, 290) a favor de la exaltación de un único héroe, visto en tres momentos gloriosos, no necesariamente diacrónicos.

Los detalles pictóricos del armamento y panoplia equina, permiten encontrar sus paralelos en área ápula y de la Basilicata de finales del s. IV a.C., la representación de topoi iconográficos griegos acentúa esta impresión y la pone en relación con la iconografía vascular ápula y, finalmente, la presencia de dos porteros en los vanos laterales de la puerta indica una ascendencia macedonia, a caballo entre el s. IV y III a.C.

¿Pero son estos elementos suficientes para proponer una adopción de las corazas anatómicas largas en área lucana en el cambio entre el s. IV y III a.C.? O en cambio, ¿son éstas evidencias de un último uso de estas corazas, en sus tipos más evolucionados y decorados? En relación a la primera cuestión, parece difícil argumentar esta recepción en un momento tan tardío, más aún cuando el ejemplar real recuperado en la tumba de 1805 de Porta Aurea se fecha en un momento anterior (c. 325 a.C.), pero lo inusual de las corazas anatómicas largas en área lucana pueden evidenciar su presencia y, quizás, una fascinación lucana hacia esas corazas en el marco de acontecimientos históricos particulares, como las campañas de los condottieri epirotas (Alejandro el Molosso y Pirro). En respuesta a la segunda pregunta, las representaciones de corazas anatómicas con hombreras decoradas permiten prolongar más allá de finales del s. IV a.C. la vida de estas corazas que, a partir del registro arqueológico, cayeron en desuso durante la primera mitad del s. III a.C., dando paso a otros tipos más ligeros y, quizás, económicos.

En cualquier caso, el armamento representado evidencia una panoplia extraña en contexto pestano que se contrapone a lo observado hasta inicios de s. III a.C. A. Pontrandolfo proponía que a partir de finales de $\mathrm{s}$. V a.C. las armaduras itálicas y las pinturas eran una expresión macroscópica de la voluntad de hacer prevalecer la identidad itálica de las poblaciones pestanas respecto a la ciudad griega (Pontrandolfo, 2004) ${ }^{119}$. Con los mismos argumentos, la representación de un equipo extraño hace prevalecer una voluntad de asimilación a un grupo de ámbito itálico meridional, sin duda lucano pero dentro de la órbita de Tarento.

Si A. Pontrandolfo y A. Rouveret vieron como las representaciones pintadas en las tumbas de PaestumSpinazzo se podrían referir a un discurso próximo al de las élites campanas de inicios de s.III a.C. y, consecuentemente, con una proximidad al imaginario y comportamiento romano (Pontrandolfo, 1988, 260 y ss.; 1996a, 292; Pontrandolfo y Rouveret, 1983b; Rouveret, 1988), el documento que aquí hemos visto parece indicar una situación distinta, contraria incluso a esa tendencia que encontraría correspondencia en el contexto de la guerra tarentina, con una participación lucano-pestana al lado de Pirro (Bettalli, 2004, 121122) y los tarentinos contra Roma (Mele, 1996, 19). Quizás estas pinturas representan una fotografía del momento, acertadamente propuesto por Minervini, de la ocupación lucana de Poseidonia (Zevi, 2004, 815, nota 64) en un momento inmediatamente posterior a la empresa del Molosso (Torelli, 1992, XVI-XVIII). Una representación alejada del imaginario 'romano' o campano y, en cambio, como hemos visto, próximo a un imaginario que utiliza los recursos de exaltación militar y afirmación aristocrática del ambiente lucanoápulo-tarentino y, en menor medida, epirota. Quizás debamos entender esta tumba como la expresión de una última gens de guerreros lucanos que se opusieron, sin suerte, a la derrota, conquista y fundación de la colonia latina de Paestum del 273 a.C.

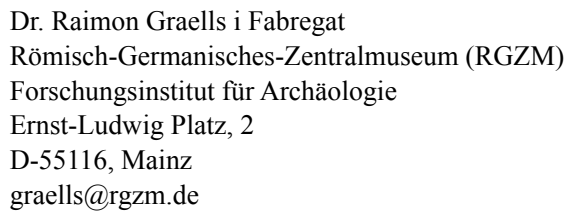

\section{BIBLIOGRAFIA}

ADAM, A. M., 1982: «Remarques sur une série de casques de bronze ou Tarente et les Barbares dans la deuxième moitié du IVe s. Av. J.-C. », MEFRA, 94.1, 7-32.

119. El argumento encuentra un debate prolífico en Asheri, 1999 y Zevi, 2004, 799 y ss. 
ADAM, A. M., 2000: «Le bûcher de Patrocle et l'ostentation des armes dans les sociétés indigènes d'Italie méridionale», Ktéma, 25, 123-132.

AITKEN, B. T., 1982: «A new cheekpiece», AntK, 25, 58-61.

ANDREAE, B., 2004a: «La Tomba François», en Forma Urbis. Itinerari nascosti di Roma antica IX.1, 8-57. [traducción ital. reducida de $I d$., en B. ANDREAE, A. HOFFMANN y C. WEBER-LEHMANN (Ed.), Die Etrusker. Luxus für das Jenseits. Bilder vom Diesseits. Bilder vom Tod (Catalogo Mostra Amburgo 2004), 176207, München].

ANDREAE, B., 2004b: «La Tomba François ricostruita», en A.M. MORETTI SGUBINI (Ed.), Eroi etruschi e miti greci. Gli affreschi della Tomba François tornano a Vulci (Catalogo Mostra Vulci), 41-57, Firenze.

ANDRONIKOS, M., 1984: Vergina, The Royal Tombs, Athens.

ASHERI, D., 1999: "Processi di "decolonizzazione" in Magna Grecia: il caso di Poseidonia Lucana», en La colonisation grecque en Méditerranée occidentale, Hommage à $G$. Vallet, CEFR, 251, 361-370, Roma.

BARDELLI, G., ep.: «Lumi vulcenti. Riflessioni sullo stile pittorico della Tomba Francois», en Segni e colore. Dialoghi sulla pittura tardoclassica ed ellenistica, (9-10 Marzo 2012), Pavia

BENASSAI, R., 2001: La pittura dei campani e dei sanniti, Atlante tematico di topografía antica, IX supplemento, Roma.

BENNET, M. J., 1997: Belted Heroes and Bound Women: The Myth of the Homeric Warrior-King, Lanham-Boulder-New York-Oxford.

BETTALLI, M., 2004: «I "condottieri” di Taranto e la guerra nel mondo greco», en Alessandro il Molosso e $i$ «Condottieri» in Magna Grecia, Atti del quarantatreesimo convego di Studi sulla Magna Grecia, Taranto-Cosenza (26-30 settembre 2003), 112-134, Taranto.

BORN, H., 1993: Restaurierung antiker Bronzewaffen, Sammlung Axel Guttmann, Bd. 2, Mainz.

VON BOTHMER, D., 1990: Glories of the Past, Ancient Art from the Shelby White and Leon Levy Collection, New York.

BOTTINI, A., 1983: «Cinturoni a placche dall'area melfese», Annali del Seminario di Studi del Mondo Classico, 5, 33-63.

BOTTINI, A., 1989: «La panoplia lucana del Museo provinciale di Potenza», MEFRA, 101.2, 699-715.

BOTTINI, A., 1991: «Armi e strumenti», en A. BOTTINI y M.P. FRESA (a cura di), Forentum II. L'acropoli in età classica, Leukania 4, Monografie di Archeologia della Basilicata, 97-112.

BOTTINI, A., 1992: «Metallotecnica», en L. TODISCO, G. VOLPE, A. BOTTINI, P.G. GUZZO, F. FERRANDINI y M. CHELOTTI (a cura di), Introduzione all'artigianato della Puglia antica. Dall'età coloniale all'età romana, 139-160, Bari.

BOTTINI, A., 2007: «Il Sarcofago tarquinese delle Amazzoni», Ostraka, 16.1, 11-22.
BOTTINI, A. y SETARI, E., 2007: Il Sarcofago delle Amazzoni, Napoli.

BRAUN, E., 1854: «Pittura parietaria d'una tomba pestana», Pubblicazioni dell'Istituto di Corrispondenza Archeologica, 79-80.

BURNS, M., 2005: The cultural and Military Significance of the South Italic military equipment: Warrior's Panoply from the 5th to the 3rd Centuries BC, London.

BURNS, M., 2011: «Graeco-Italic Militaria», en M. MERRONY (Ed.), Mougins Museum of Classical Art, 183234, Mougins.

CAHN, D., 1989: Waffen und Zaumzeug: Antikenmuseum Basel und Sammlung Ludwig, Basel.

CASSANO, R., 1996: "Ipogeo scoperto nel 1846 o nel 1847», en S. DECARO y M. BORRIELO (Coords.), I greci in Occidente, La Magna Grecia nelle collezioni del Museo Archeologico di Napoli, 165-168, Napoli.

CASTRIZIO, D., 2007: L'elmo quale insegna del potere. La documentazione numismatica, Semata e Signa 3, Reggio Calabria.

COARELLI, F., 1981: «Alessandro, i Licinii e Lanuvio», en L'art décoratif à Rome à la fin de la République et au debut du principat, Table ronde de Rome (10-11 mai 1979), Publ. EFR, 55, 229-284, Roma.

COLONNA, G., 2007: «De la fouille au pastiche: les casques en bronze à couronnes en or étrusques», en F. GAULTIER y C. METZGER (Eds.), Les bijoux de la collection Campana, de l'antique au pastiche, Rencontres de l'École du Louvre 2005, 61-77, Paris.

CRISTOFANI, M., 1967: «Il fregio d'armi della Tomba Giglioli di Tarquinia», DialArch, I.3, 288-303.

D'AGOSTINO, B., 1980: «Le paragnatidi dal nuovo scavo», En: Sannio, Pentri e Frentani dal VI al I sec. A.C., Catalogo della mostra Isernia, Museo Nazionale (Ottobre-Dicembre 1980), 140-150, Roma.

D'AGOSTINO, B., 2003: Appunti in margine alla Tomba François di Vulci, en A. MINETTI (Ed.), Pittura etrusca: problemi e prospettive, Atti Convegno SarteanoChiusi, 2001, 100-110, Siena.

DE'SPAGNOLIS, M., 2005: «Una tomba pestana con il "ritorno del cavaliere". Sequestro della Guardia di Finanza», en F. GILOTTA (a cura di), Pittura parietale, pittura vascolare. Ricerche in corso tra Etruria e Campania, Atti della Giornata di studio, Santa Maria Capua Vetere, 28 maggio 2003, 133-141, Napoli.

DEONA, W., 1953: «Mars Tropaeophore», ZSchwA, XIV, 65-67.

DINTSISI, P., 1986: Hellenistische Helme, Archaeologica 43, Roma.

DOHAN-MORROW, K., 1985: Greek Footwear and the Dating of Sculpture, Madison.

FAKLARIS, P. V., 2010: «Knuós (Horse-Muzzle)», en D. TRIANTAPHYLLOS y D. TERZOPOULOU (Eds.), Horses and Wagons in the Ancient World, Orestiada 30/09/2006, 199-229, Orestiada.

FORCHHAMMER, G., 1854: «Scavi di Pesto e Capua», Pubblicazioni dell'Istituto di Corrispondenza Archeologica, 63. 
GARCES, I. y GRAELLS, R., 2011: «Ancient Bronze Horse Muzzles of the Iberian Peninsula», Gladius, XXXI, 7-42.

GOLDMAN, N., 1994: «Roman Footwear», en: J. L. SBESTA y L. BONFANTE (Eds.), The World of Roman Costume, 101-129, Madison.

GRAELLS, R., 2011: «Tres cascos Italo-Calcídicos de la antigua colección Marqués de Salamanca en el Museo Arqueológico Nacional de Madrid», Oebalus, 6, 7-49.

GRAELLS, R., 2012: «Corazas cortas Campanas con detalle anatómico esquemático», MEFRA, 124/2, 475-549.

GRAELLS, R. y MAZZOLI, M., ep.: «¿Cascos con tridentes? El problema de la aplicación de estructuras metálicas sobre cascos prerromanos», Études Celtiques.

GRECO, E., 1979: «Ricerche sulla chora poseidoniate: il "paesaggio agrario" dalla fondazione della città alla fine del sec. IV aC», DialArch, 2 n.s., 7-26.

GUZZO, P. G., 1990: «L'elmo da Pacciano. Ipotesi sulla circolazione delle armi decorate ellenistiche», Boll.Arch, 2 , $1-11$.

GUZZO, P. G., 1993: «L'armamento in Lucania fra IV e III secolo», en A. BOTTINI (a cura di.): Armi. Gli strumenti della guerra in Lucania, catalogo della mostra, 159-171, Bari.

HAGEMANN, A., 1919: Griechische Panzerung. Eine entwicklungsgeschichtilche Studie zur antiken Bewaffnung, Leipzig - Berlin.

HARARI, M., 2007: «Lo scudo "spezzato" di Vel Saties», Ostraka, 16.1, 45-54.

JOHANOWSKI, W., 1990: «Il Sannio», en Italici in Magna Grecia. Lingua, insediamenti, strutture, Atti del Convegno di Acquasparta (1986), 13-21, Venosa.

LEPORE, L., 1996: «Elmo di tipo frigio», en, G. PUGLIESE-CARRATELLI (a cura di), I greci in occidente, catalogo della mostra, Palazzo Grassi (marzo-dicembre 1996), 652-653, Venezia.

LÉVÊQUE, P., 1993: «L'imaginaire des tombes de Paestum», DHA, 19.2, 179-186.

LIPPERHEIDE, F., v. 1896: Antike Helme, Berlin.

LIPPOLIS, E., 1995: «Mostra Atleti e guerrieri. Tradizioni aristocratiche a Taranto e nel mondo iapigio tra VI e V sec.a.C. (11 marzo 1994)», Taras, 15, 175-177.

LIPPOLIS, E., 2011: «Taranto nel IV secolo a.C.», en R. NEUDECKER (Hrsg.), Krise und Wandel. Süditalien im 4. und 3. Jahrhundert v. Chr., Internationaler Kongress anlässlich des 65, Geburtstages von Dieter Mertens, Roma 26-28 Juni 2006, Palilia, 23, 121-145.

LONGO, F. y VISCIONE, M., 1996: «Eboli, Santa Croce, tomba 37», en, M. CIPRIANI y F. LONGO (a cura di), I greci in Occidente, Poseidonia e i Lucani, 78-81, Paestum.

LOPORTO, F. G., 1996: «Tombe arcaiche di peuceti emergente», StAnt, 9, 7-36.

MAZZEI, M., 1995: Arpi. L'ipogeo della Medusa e la necropoli, Bibliotheca Archaeologica 3, Bari.

MELE, A., 1996: «Storia di Poseidonia tra VI e V secolo a.C.», en M. CIPRIANI y F. LONGO (a cura di), I Greci in Occidente: Poseidonia e i Lucani, 17-20, Paestum.
MINERVINI, G., 1856: «Brevi osservazioni intorno una tomba di Pesto», Bullettino Archeologico Napolitano, 97 (Giugno), 177-181.

MONTANARO, A. C., 2007: Ruvo di Puglia e il suo territorio, le necropoli. I corredi funerari tra la documentazione del XIX secolo e gli scavi moderni, Studia Archeologica 160, Roma.

MONTANARO, A. C., 2010: «Intervento», en L. TODISCO (A cura di), La Puglia centrale dall'età del bronzo all'alto Medioevo. Archeologia e Storia. Atti del Convegno di Studi (Bari 15-16 giugno 2009), Archaeologica 157, 185-193.

MORENO, P., 1994: Scultura ellenistica, II vol., Roma.

MORENO, P., 1998: «Elementi di pittura ellenistica», en L'Italie méridionale et les premières expériences de la peinture Hellénistique, Actes de la table ronde de Rome (18 février 1994), Coll. EFR 244, 7-94, Roma.

MORENO, P., 2010: «Pittura in Grecia dalla maniera alla restaurazione romana (323-31 a.C.)», en Linguaggi e tradizioni della pittura ellenistica in Italia e in Sicilia, XVII International Congress of Classical Archaeology, Roma 22-26 Sept. 2008, Bollettino d'Archeologia Online, http://151.12.58.75/archeologia/index.php?option $=$ com content $\&$ view $=$ article $\&$ id $=49 \&$ Itemid $=49 \quad$ (consultado el 29 de marzo de 2012).

MORET, J.-M., 1975: L'Ilioupersis dans la céramique italiote. Les mythes et leur expression figurée au IV siècle, Roma-Genève.

NASO, A., 2011: «Reperti italici nei santuari greci», en R NEUDECKER (Hrsg.), Krise und Wandel. Süditalien im 4. und 3. Jahrhundert v. Chr., Internationaler Kongress anlässlich des 65, Geburtstages von Dieter Mertens, Roma 26-28 Juni 2006, Palilia, 23, 39-53.

PFLUG, H., 1988: «Chalkidische Helme», en A. BOTTINI, M. Egg, F.W. VON HASE, H. PFLUG, U. SCHAAFF, P. SCHAUER y G. WAURICK (Hrsg.), Antike Helme. Sammlung lipperheide und andere bestände des antikenmuseums Berlin, RGZM Monographien, 14, 137-150, Mainz.

PONTRANDOLFO, A., 1988: «Le necropoli dalla città greca alla colonia latina», en Poseidonia-Paestum, Atti del XXVII convego di Studi sulla Magna Grecia, Taranto 1987, 225-265, Napoli.

PONTRANDOLFO, A., 1996a: «Trasformazioni nella società pestana dell'inoltrato IV secolo», en M. CIPRIANI y F. LONGO (a cura di), I Greci in Occidente: Poseidonia e i Lucani, 289-292, Paestum.

PONTRANDOLFO, A., 1996b: «Paestum», en S. DECARO y M. BORRIELO (Coords.), I greci in Occidente, La Magna Grecia nelle collezioni del Museo Archeologico di Napoli, 15-21, Napoli.

PONTRANDOLFO, A., 2004: «Dibattito finale», en Alessandro il Molosso e i "Condottieri» in Magna Grecia, Atti del quarantatreesimo convego di Studi sulla Magna Grecia, Taranto-Cosenza (26-30 settembre 2003), 847 848, Taranto

PONTRANDOLFO, A. y ROUVERET, A., 1983a: «La rappresentazione del barbaro in ambiente magno-greco», 
en Modes de contacts et processus de transformation dans les sociétés anciennes, Actes du colloque de Cortone (24-30 mai 1981), Publ. EFR, 67, 1051-1066.

PONTRANDOLFO, A. y ROUVERET, A., 1983b: «Pittura funeraria in Lucania e Campania. Puntualizzazioni cronologiche e proposte di lettura», DialArch, III, s.1, 2, 91-130.

PONTRANDOLFO, A. y ROUVERET, A., 1992: Le tombe dipinte di Paestum, Modena.

PONTRANDOLFO, A., ROUVERET, A. y CIPRIANI, M., 1998: Le tombe dipinte di Paestum, Paestum.

REBUFFAT, E., 1962: «Ceinturons italiques», MEFRA, 74.2, 335-367.

RICHTER, G. M., 1915: Greek, Etruscan and Roman Bronzes, New York.

De RIDDER, A., 1913-1915: Les bronzes antiques (Paris, Musée du Louvre), 2 vols. Paris.

RIZZO, M. A., (A cura di), 1989: Pittura etrusca al Museo di Villa Giulia nelle foto di Takashi Okamura, Studia Archeologica 6, Roma.

ROBERTS, P., 1996: «Due paragnatidi in bronzo», en G. PUGLIESE (a cura di): I greci in Occidente, 720, Venezia.

ROLLEY, Cl., 1986: Greek bronzes, Freiburg.

ROMIOPOÚlOU, K., 1997: Lefkádia, Archaía Mieza, Athína.

ROMITO, M., 1995: I cinturoni Sanntici, Materiae, Napoli.

ROUVERET, A., 1973: «Contribution à l'étude des influences grecques sur les mondes périphériques. Étude de la peinture étrusque à l'époque classique», $E P H E-4 e$ Sect. Annuaire 1972-1973, 831-840.

ROUVERET, A., 1988: «Les langages figuratifs de la peinture funéraire pestane», en Poseidonia-Paestum, Atti del XXVII convego di Studi sulla Magna Grecia, Taranto 1987, 267-315, Napoli.

ROUVERET, A., 1997: «Intervento», en Mito e storia in Magna Grecia, Atti del trentaseiesimo Convegno di Studi sulla Magna Grecia (Taranto 4-7 ottobre 1996), 134-141.

RUSSO, A., 1995: Armento, Archeologia di un Centro indigeno, Bolletino di Archeologia, 35-36, Roma.

SALMON, E. T., 1967 [1995]: Il sannio e $i$ Sanniti, Cambridge.

SANNIBALE, M., 2008: La raccolta Giacinto Guglielmi, II. Bronzi e materiali vari, Roma.

SCHNEIDER-HERMANN, G., 1996: The Samnites of the fourth century B.C. as depicted on Campanian vases and other sources, Bull. Inst. Class. Studies 61, London.

SESTIERI, P. C., 1957: «Paestum.- Tomba di guerriero Lucano», NSc, 11, 171-180.

SESTIERI, P. C., 1958: «Tomba a camera d'età lucana», $B A, 43$, s.4, 46-63.
SIGANIDOU, M., 1978: «Western Macedonia», en K. NINOU (Ed.), Treasures of Ancient Macedonia, 38-47, Athens.

STEINGRÄBER, S., 1991: «Zu Entstehung, Verbreitung und architektonischem Kontext der unteritalischen Grabmalerei», JdI, 106, 1-36.

SUANO, M., 1991: Sabellian-Samnite Bronze Belts in the British Museum, British Museum Occasional Papers 57, London.

TAGLIAMONTE, G., 2002-2003: «Dediche di armi nei santuari sannitici», CUPAUAM, 28-29, 95-125.

TAGLIAMONTE, G., 2003: «Note sulla circolazione degli elmi nell'Abbruzzo e nel Molise preromani», MEFRA, 115.1, 129-175.

TORELLI, M., 1988: «Paestum romana», en PoseidoniaPaestum, Atti del XXVII convego di Studi sulla Magna Grecia, Taranto 1987, 33-115, Napoli.

TORELLI, M., 1992: «Da Leukania a Lucania», en Da Leukania a Lucania. La Lucania centro-orientale fra Pirro e i Giulio-Claudii, Venosa (8 nov. 1992 - 31 marz. 1993), XIII-XXVIII.

TORELLI, M., 1997: Il rango, il rito e l'immagine. Alle origini della rappresentazione storica romana, Milano.

TOUCHAIS, G. 1982: «Chronique des fouilles et découvertes archéologiques en Grèce en 1981», BCH, 106, 529-635.

TRENDALL, A. D. y CAMBITOUGLOU, A., 1978: The red figured vases of Apulia, I, Oxford.

TSIMPÍDOU-AYLONÍTI, M., 2005: Makedonikoi Táphoi ston Phoínika kai ston Ágio Athanásio Thessaloníkis, Athína.

VENTURO, D., 2001: «Altamura (Bari)», Taras, rivista di Archeologia, XXI.1, 70-73.

VERMEULE, C.C. ET ALII, 1988: Sculpture in Stone and Bronze in the Museum of Fine Arts, Boston. Additions to the Collections of Greek, Etruscan, and Roman Art 1971-1988, Boston.

VISCIONE, M., 1996a: «Tomba 174 (scavo 1990)», en I greci in Occidente, Poseidoni e i Lucani, 149-151, Napoli.

VISCIONE, M., 1996b: «Tomba 164 (scavo 1990)», En: I greci in Occidente, Poseidoni e $i$ Lucani, 155-158, Napoli.

WALTERS, H.B., 1899: Catalogue of the Bronzes. Greek, Roman and Etruscan in the Department of Greek, Roman Antiquities, British Museum, London.

ZEVI, F., 2004: «Alessandro il Molosso e Roma», en Alessandro il Molosso e $i$ "Condottieri» in Magna Grecia, Atti del quarantatreesimo convego di Studi sulla Magna Grecia, Taranto-Cosenza (26-30 settembre 2003), 793831, Taranto.

ZIMMERMANN, J.-L., 1979: «Une cuirasse de Grande Grèce», Museum Helveticum, 36, 177-184. 